\title{
An Assessment of Applications from Oral History Interview Methods to Journalism
}

\author{
By Ashley Wright
}

A thesis submitted to the faculty of Graduate Studies and Postdoctoral Affairs in partial fulfillment of the requirements for the degree of

Master of Journalism

School of Journalism and Communication

\author{
Carleton University \\ Ottawa, Ontario
}

(C) 2011, Ashley Wright 


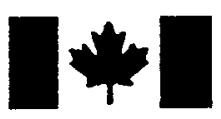

Library and Archives

Canada

Published Heritage

Branch

395 Wellington Street

Ottawa ON K1A ON4

Canada
Bibliothèque et

Archives Canada

Direction du

Patrimoine de l'édition

395 , rue Wellington

Ottawa ON K1A ON4

Canada
Your file Votre référence
ISBN: $978-0-494-81611-0$
Our file Notre référence
ISBN: $978-0-494-81611-0$

\section{NOTICE:}

The author has granted a nonexclusive license allowing Library and Archives Canada to reproduce, publish, archive, preserve, conserve, communicate to the public by telecommunication or on the Internet, loan, distribute and sell theses worldwide, for commercial or noncommercial purposes, in microform, paper, electronic and/or any other formats.

The author retains copyright ownership and moral rights in this thesis. Neither the thesis nor substantial extracts from it may be printed or otherwise reproduced without the author's permission.
AVIS:

L'auteur a accordé une licence non exclusive permettant à la Bibliothèque et Archives Canada de reproduire, publier, archiver, sauvegarder, conserver, transmettre au public par télécommunication ou par l'Internet, prêter, distribuer et vendre des thèses partout dans le monde, à des fins commerciales ou autres, sur support microforme, papier, électronique et/ou autres formats.

L'auteur conserve la propriété du droit d'auteur et des droits moraux qui protège cette thèse. $\mathrm{Ni}$ la thèse ni des extraits substantiels de celle-ci ne doivent être imprimés ou autrement reproduits sans son autorisation.
In compliance with the Canadian Privacy Act some supporting forms may have been removed from this thesis.

While these forms may be included in the document page count, their removal does not represent any loss of content from the thesis.
Conformément à la loi canadienne sur la protection de la vie privée, quelques formulaires secondaires ont été enlevés de cette thèse.

Bien que ces formulaires aient inclus dans la pagination, il n'y aura aucun contenu manquant.

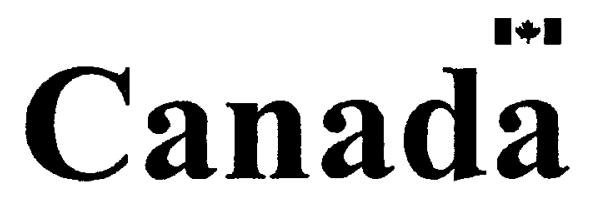




\begin{abstract}
The fields of journalism and oral history interviewing intersect at multiple points: they share a lineage that dates back to pre-literate societies; they both use personal experience as a primary source in their search to understand the world in which we live; and they struggle with concepts about truth, ethics and meaning during the interview process. This thesis examines assumptions about the journalistic interview (primarily feature and investigative genres) in light of what is known about oral history interview methodology as it is used in the humanities and social sciences. It identifies areas in which journalism could benefit from oral history interview approaches, in particular in matters of memory, reliability of evidence, interpretation, and relationships with interviewees. The thesis concludes with recommendations on how journalists could adapt some oral history interview concepts to their own work as they strive to produce relevant and meaningful stories.
\end{abstract}




\section{ACKNOWLEDGEMENTS}

There are a number of people who provided assistance in the conception and writing of this thesis. My first formal exposure to oral history came in the form of a course at Carleton University taught by history professor Marilyn Barber and Scottish oral historian Murray Watson. Their knowledge of oral history and their insight into its fundamental differences with journalism helped shape the thoughts that sparked the proposal for this thesis. Dave Tait, from Carleton's School of Journalism and Communication, helped develop the course of inquiry and offered ideas from his own vast knowledge about storytelling and its connection to journalism. When I had moments of doubt in the early stages, Professor Dwayne Winseck, also of Carleton's School of Journalism and Communication, took the time to offer valuable suggestions and muchappreciated encouragement. My thesis advisor, journalism professor Mary McGuire, through her extensive corporate memory of people, books and online sources in Canada's journalism landscape, and during multiple reviews of the chapters, pointed me in many directions that may otherwise have been overlooked. There were others who read parts of this thesis and provided feedback, including Alexandra Wright, whose insightful comments were invaluable. I am also indebted to the journalists who took time out of their busy schedules to be interviewed as part of my research. Finally, this thesis would never have come to fruition were it not for the patience and support of my husband, Jeff, and our three children, Melinda, Antonia and Ted. To all of the above, I am forever grateful. 


\section{PREFACE}

So this is one story I must tell...I'm in a housing project, and it's mixed. I can't remember if she was white or she was black (...) Three little kids running around -- five, six, seven years old. They want to hear their mama's voice; she's talked into my tape recorder. So I say to the kids: 'Now you quiet down, and I'm going to play it back.' She hears her voice for the first time in her life. She hears her voice and something she said. She puts her hand to her mouth and says, 'Oh, my God!' And I said, 'What is it?' She said, 'I never knew I felt that way before,' hearing herself. And to me, that's 'Bingo!' Bingo for her! Suddenly she realizes she thinks certain things she never thought of. And for me, of course, as a fellow-journey man with her, it's pretty exciting. That's the kind of stuff that I find very rewarding. ${ }^{1}$

These words, spoken by the late Studs Terkel, aptly describe the feelings of many of us who work in the interview business. The idea that during an interview, someone can not only reveal information to the interviewer, but can also expose their own previously unknown thoughts and feelings, is all at once thrilling, rewarding and thought-provoking. When Terkel died in 2008 at the age of 96 , he left a long legacy of interviewing nuggets amidst his many books (mostly oral histories) and his 45 -year career as a radio show host. He was a Pulitzer-prize winning author and the recipient of the Peabody Award for excellence in journalism. Many consider Terkel to be the best creator of "oral history as journalism" that ever lived. His apparently seamless fusion of oral history and journalism is one of the reasons I wanted to write this thesis. The other reason dates back to a time when I had never heard of Studs Terkel or oral history. Back in 1990 I was working as a

\footnotetext{
${ }^{1}$ From: "Conversations with History," Institute of International Studies, UC Berkeley, Harry Kreisler, October $29^{\text {th }}, 2003$. http://globetrotter.berkeley.edu/people3/Terkel/terkel-con0.html
} 
journalist for CBC Radio (Canadian Broadcasting Corporation) in the northern Ontario city of Thunder Bay. The Ontario Native Women's Association released a report concluding that the rate of family violence in aboriginal communities was eight times higher than the non-aboriginal population in Canada. I believed the topic deserved more than the usual 90 -second news story or six-minute current affairs interview. Initially, there was some hesitation about pursuing the story: First, because of the concern that women would be reluctant to talk about their own suffering (and indeed, this was addressed in the report); also, due to the costly additional resources required to travel to a fly-in northern community. However, I was given the go-ahead by the $\mathrm{CBC}$, and one day I set out to interview an aboriginal woman who had agreed to talk about her experiences. It was one of the longest and least-focused interviews I ever did, but it resulted in some incredible stories about her life and the violence she had endured, and provided background to the wider context of the elevated levels of violence in aboriginal communities. That woman led me to another woman, and then to another, and soon I had invaluable first-person accounts about the cycle of violence plaguing some aboriginal communities. The raw material needed to be turned into a journalistic piece.

At that point one of CBC's top documentary producers Steve Wadhams came on board to help the Thunder Bay staff produce a 40-minute documentary we called "Forbidden Voices." It aired on CBC's national program Morningside. The piece won a couple of journalism awards, but far more importantly, it helped to place the subject of family violence in aboriginal communities on the national agenda. It also brought the perspectives of people who weren't usually part of the collective conversation to the attention of other Canadians. In the process of doing this story I learned some valuable 
lessons: First, that daily deadlines and office budgets can be impediments to some good stories. Second, I learned that despite our assumptions to the contrary, the women (and in this case, one man) who participated in the documentary very much wanted to speak about what was happening in their lives and their communities. I also learned that allowing them to tell their stories in their own voices was critical to the authenticity of the process. Finally, it was clear to me that their experiences were of interest to people living all across Canada, whether in Victoria, Toronto, Winnipeg, or a small village in Newfoundland.

Fast forward about 10 years, to when I was working at CBC Radio in Ottawa. One day I picked up a second-hand book called an oral history-it was about life on the prairies during the depression, as told by the people who lived it. It was fascinating. That set me out in search of other oral histories-Studs Terkel, more Barry Broadfoot, among others-some were really good and others were pretty simple with little or no background to provide context. What appealed to me was how they offered such frank, open and in-depth revelations that clearly resulted from, among other things, time allowed during interviews for people to share their experiences.

I realized then that what I had done back in 1990 - and periodically as a daily journalist since then-was a kind of oral history interviewing but with a journalistic purpose. The obvious similarities between journalism and oral history prompted me to explore more about oral history. I discovered that, in the popular realm, the concept of oral history is as expansive and wide-ranging as journalism. In the academic world, however, oral history is very clearly defined and has been painstakingly studied across many disciplines that use it in research. The primary focus of oral history studies involves 
the interview process. So naturally the question arose: If journalists were privy to the knowledge that academics who use oral history interviews (in various fields) have gained about the interview process, would it make a difference to how we do interviews? So my starting point was an exploration of how if at all, academic knowledge from the oral history interview process could help journalists do better interviews. Defining the parameters of the study was a huge challenge, but once the focus was narrowed down to the interview process alone, it started to become apparent that some elements of the oral history interview methodology could add value to the journalistic interview.

It's clear to me, for example, that awareness about matters of memory, and specifically, how people remember trauma, could have helped in "Forbidden Voices." A deeper understanding of the nature of the relationship between me, the journalist, and the women I interviewed (in oral history terms "the narrator") could have had an impact on the process as well. How these things would have changed the outcome of the documentary is indefinite, but I am certain that the knowledge of these issues would have enhanced the quality of the interviews on several levels.

Many journalists share with me a deep sense of gratitude to the men and women who entrust us with their stories and experiences on a daily basis. As we strive to do reports that are informative and interesting, we search for information that will help us become better at informing listeners/viewers/readers about the world in which we live. My hope is that this thesis will contribute to some of the knowledge out there about how the interview process works and will help us all produce more informative and meaningful stories. 


\section{TABLE OF CONTENTS}

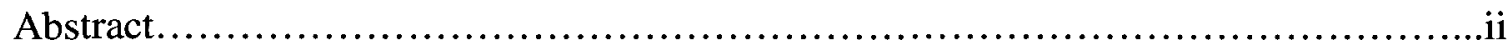

Acknowledgements..............................................................

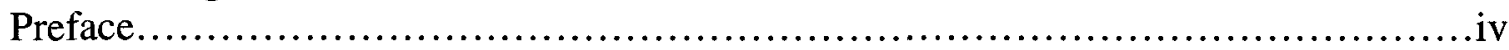

Table of Contents...................................................................

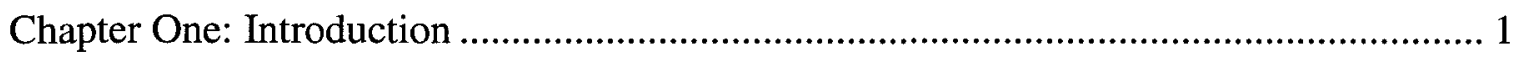

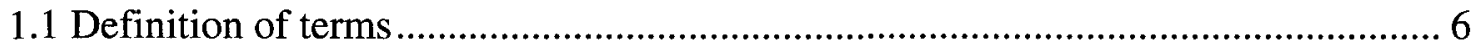

1.2 Journalism, interview, oral history and lived experience ................................ 8

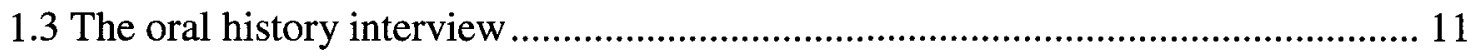

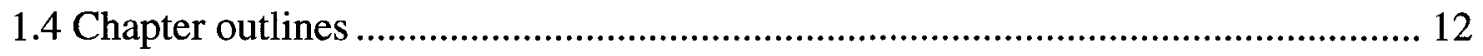

Chapter Two: The Journalistic Interview ........................................................... 17

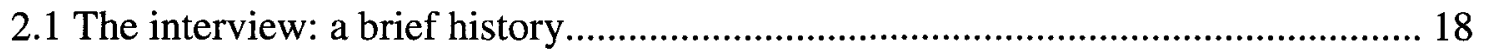

2.2 The interview: a theoretical perspective .................................................. 20

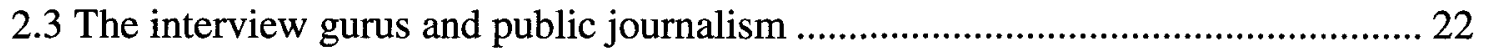

2.4 Storytelling and the use of narrative in feature and investigative journalism........ 27

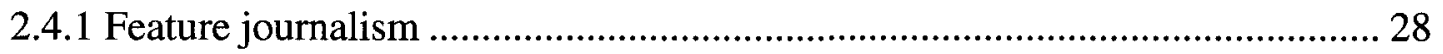

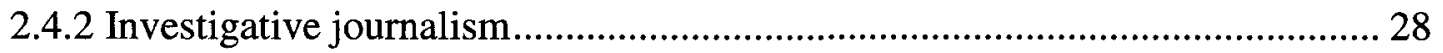

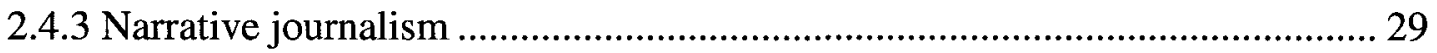

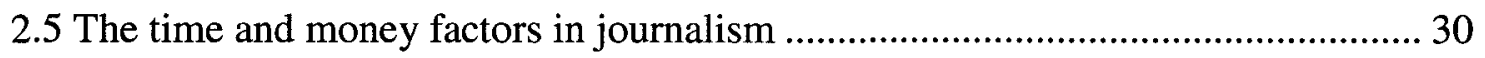

2.6 Assumptions about the journalistic interview (or, how to do an interview) ........... 32

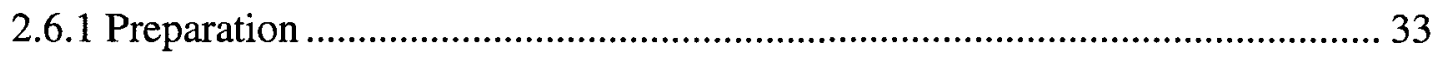

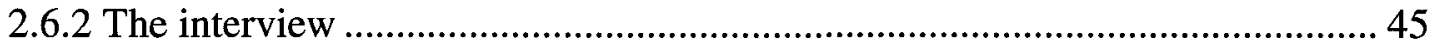

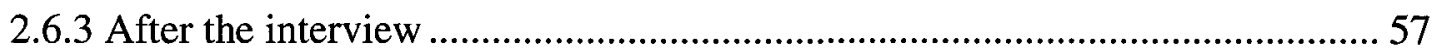


3.1 Definitions: Oral tradition, oral history and the life experience interview 72

3.2 Qualitative research and the reliability of oral testimony 76

3.3 The development of oral history: social purpose, tape recorder, interviewing....... 81

3.3.1 Social purpose 81

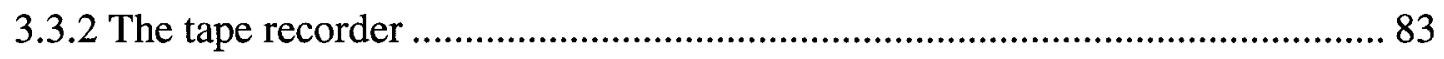

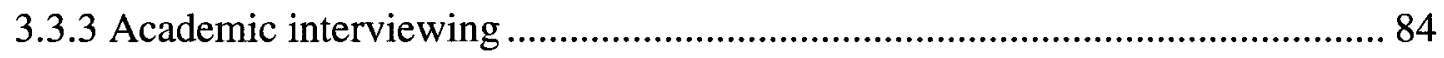

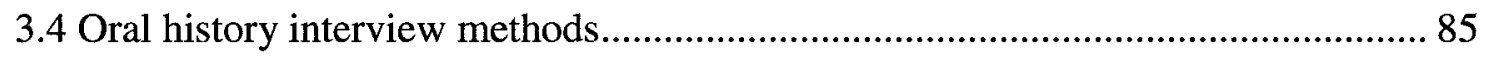

3.4.1 Preparation and central themes in oral history interviewing ........................... 85

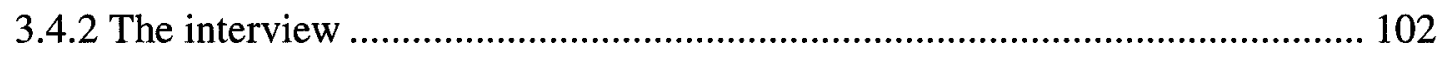

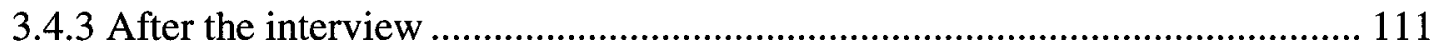

Chapter Four: The Intersection of Journalistic and Oral History Interviewing .............. 122

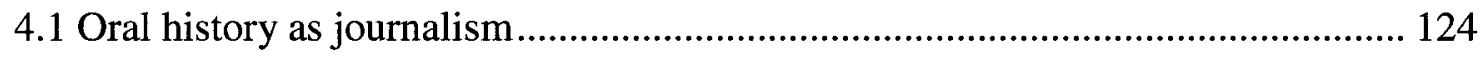

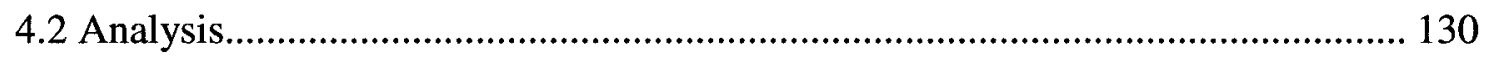

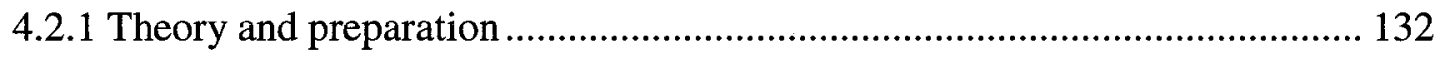

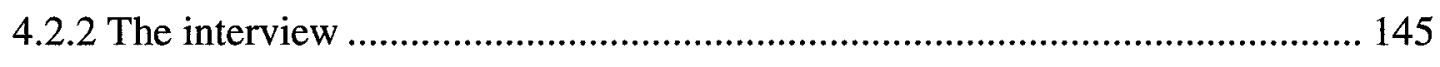

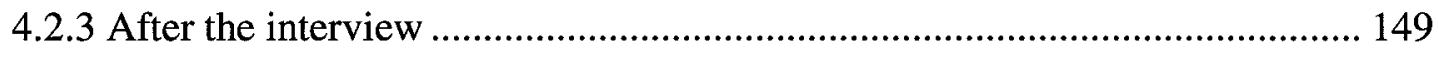

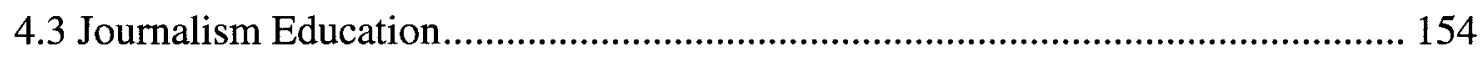

Chapter Five: Conclusion ........................................................................................ 160

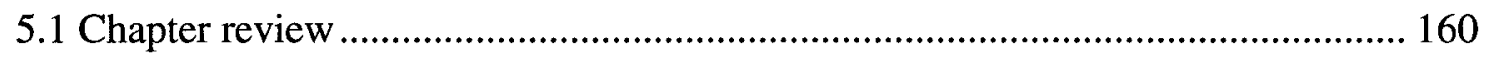

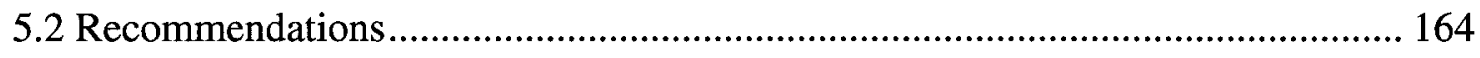

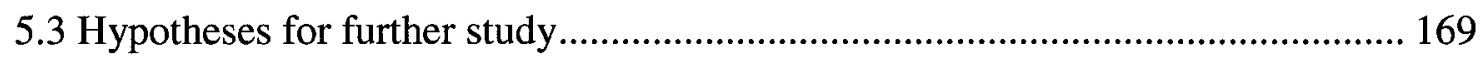

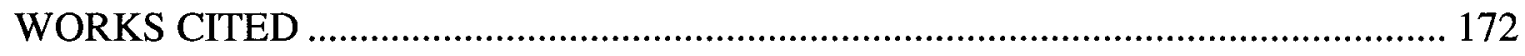




\section{Chapter One: Introduction}

Journalism, in its most fundamental form, is an exercise involving the collection and dissemination of information. The interview is intrinsic to that process, notwithstanding the manifold forms a journalistic work can take, nor the often competing and diverse goals of journalists or journalistic organizations. The interview method has a long history: beginning with the verbal transmission of stories from village to village in ancient times, through to the oral journalism of the Greek periods, to the transcribed postings of the Roman era, to the dawn of modern journalism when travellers told and wrote about their adventures in pubs. The purpose of these activities was to collect and share information about the world in which they lived. This allowed people to make informed decisions about how to survive, a founding and enduring concept of the origins and function of journalism. ${ }^{2}$ The recent advent of technological advances such as the tape recorder, video camera and the Internet have sparked increased access to personal narratives and created new ways of presenting information, largely based on eye witness accounts, or interviews, cementing the interview as a cornerstone of most journalism. Accordingly, journalists have looked for ways to do better interviews, through various forms of in-house training, external professional advice, and to a limited degree, journalism academia. The resulting field of literature demonstrates emphatically that while journalists do their work based on a set of traditions and conventions, there is no distinct or sole prescription for the journalistic interview. Research reveals a strong link to core standards and a common code of conduct: however, there is no single condoned

\footnotetext{
${ }^{2}$ For more on the history of journalism, as well as Mitchell Stephens "Awareness Instinct" theory, see Kovachs and Rosenstiel (20-25).
} 
approach, no proven formula and no set of rules that defines the interview. This finding is regarded by some to be a reflection of the field of journalism itself. For example, in his call for better journalism, long-time journalist Davis "Buzz" Merritt posits that the production of news is done...

...without universal, formal rules, without legal prescriptions or proscriptions...guided only by the sometimes contradictory conventions of a peculiar culture. (3)

This thesis examines some of those contradictory conventions and how they guide journalists in their approach to the interview process. In The Canadian Reporter, authors Catherine McKercher, Allan Thompson and Carman Cumming write:

Mastery of some journalistic tools can be acquired routinely, but interviewing depends crucially on a reporter's level of knowledge and interpersonal skills...everyone can improve with training and with a better understanding of the process involved. (99)

While the authors acknowledge the importance of general knowledge as well as the possible effect of a person's personality on the interview, neither they nor the vast majority of journalistic interview experts draw on evidence from outside the field of journalism for information about the interview process. Canada's best-known interview trainer, John Sawatsky, states: "No significant component of journalism has been more widely neglected" by scholars of journalism, resulting in a lack of knowledge for journalism educators:

They do not understand the subject, cannot identify its essential ingredients, and lack even a sense of where to start. The entire subject is a mystery they cannot unravel, and therefore they do not try. (15)

This thesis proposes that journalists, innately curious, should be aware of the extensive literature on interview methodology in the academic world, and in particular in the field of oral history interviewing, a subject that shares an historical pedigree with 
journalism. The thesis seeks ways to enhance the existing assumptions about the interview process, first through a critical look at the journalistic interview, and then through an examination of the oral history life experience interview. It presents major themes emerging from the methodology of oral history interviewing, assessing its relevance to all forms of journalism, although chiefly to feature and investigative journalism (Feldstein; Iorio; Coleman).

Noting the role journalists have in the process of recording history, Sawatsky suggests that journalists "have the not inconsiderable advantage of drafting the first" version of history.

When significant events occur journalists break the news to the world, and instantly interpret their meaning and significance. (2)

Sawatsky proposes that journalists help shape public opinion and policies of the day, as well as contribute to the "final recording of history." However, he warns that being first on the scene has its drawbacks.

...journalism's vantage is both best and worst; best because journalists are closer to the scene than most of the other interpreters of history-they see the event while it still breathes, or still is warm; and worst because this same immediacy distorts their vision, often obliterating the bigger view, and leading them to see the superficial drama of the moment rather than the underlying significance at the roots of the events. (2)

Sawatsky and others, such as Kovach and Rosenstiel, identify journalism as an exercise firmly planted in the present, with implied contrast to those Sawatsky refers to as "other interpreters of history," who are more concerned with events of the past. This thesis acknowledges the difference in perspective. However, by showing how both fields share the goal of seeking truth and meaning about our society, this thesis argues that journalists 
can benefit from knowledge about the oral history interview process as it is used by academics in the humanities and social sciences.

Just as journalists attempt to provide a better understanding of the world to citizens, social scientists such as historians, sociologists, ethnographers, psychologists, and anthropologists also seek knowledge and illumination about issues, people and societies. In ever-increasing numbers, they find answers to their research questions by interviewing people about their personal experiences; by employing the interview as a reliable research method. During the past half-century academia has seen an enormous shift in attitude within its ranks: from those who traditionally supported pure empiricism and favoured a quantitative approach to research, to those who see the interview as a valid and respected alternative (or complement) to quantitative data (Thompson 4; Yow 4; Iorio 7). The evolution of the interview as a desirable qualitative research method has prompted much academic debate about the pros and cons of personal narrative as evidence. The outcome of this polemic discourse is an exhaustive, eloquent and thorough body of work legitimizing the interview as a research tool, encompassing a number of approaches, including the use of oral history interviewing (Perks and Thomson). Oral history theory and methods refer to a range of concepts and applications including the meaning of memory and the reliability of evidence to the analysis and interpretation of oral testimony (Yow). Specific issues of oral history interview methods debate questions regarding the use of technology and question style. Although dissension on some points still exists, oral historians across the disciplines have converged sufficiently to recognize the oral history technique as an efficient and reliable tool for research (Iorio; Yow; Perks and Thomson). Journalism stands to benefit from these debates, by integrating social 
science methods of inquiry into journalistic work. Indeed, some journalistic scholars, such as public journalism advocate, Jay Rosen, have taken note of the vast dialogue:

Two professionals alive to the same question (What's really going on out there?) can obviously instruct each other. Thus, social science if it's any good, must have smart things to teach journalism about how better to understand people and the larger public world. (Rosen in Iorio xi)

This thesis seeks to examine how the social sciences approach the oral history interview and to ask the explicit question: What can a critical examination of the assumptions about journalistic interviewing tell us in light of what has been established in the theory and practice of oral history interviewing in the humanities and social sciences? In other words, can journalists improve their craft by gleaning knowledge from the academic discourse surrounding oral history interviewing? The thesis aims to fill a gap in the literature on this subject, by suggesting that journalists can indeed draw from the lessons learned about oral history in academia. The thesis also identifies how the application of oral history techniques could hinder the production of journalism (Feldstein; Iorio; Coleman).

In his study on the commonality between oral history and journalism, journalist, historian, and scholar Mark Feldstein, asks the questions: "What is the difference between oral history and journalism? Where does one end and the other begin? And what might each learn from the other" (1)? Feldstein observes:

The objective of both journalism and oral history is to record truth. But this lofty philosophical purpose is often as much a goal as a destination. In reality, both journalists and historians have more practical and proximate objectives. For the historian, writing history may mean not so much recording truth as much as trying to interpret what is left of the preserved part of the recorded part of the remembered part of what happened, to paraphrase the historian Louis Gottschalk. Journalists are similarly constrained somewhere between their immediate goal of meeting the next deadline and their larger ambition to educate the citizenry. (par. 8) 
Despite the limitations, both journalists and oral historians share a key methodology in that they try to record the truth by gathering people's stories through the interview. Their approach to those interviews, however, varies for many reasons. In his study, Feldstein concludes there are lessons to be shared between the two fields (he calls them "kissing cousins") in how they collect and handle oral evidence. This thesis builds on this concept, specifically by examining ways in which journalistic assumptions about the interview can be informed by oral history interviewing methodology.

\subsection{Definition of terms}

Journalists and academics differ in many ways, but in a western democracy, constituents of both fields generally agree on some common goals, one being the quest for a deeper understanding of how society works (Thompson 12; Kovach and Rosenstiel 21). Bill Kovach and Tom Rosenstiel are the authors of The Elements of Journalism: What Newspeople should know and the Public Should Expect, a significant text written for journalists about the relationship between journalism and democracy. They say journalism's primary purpose is to provide citizens with the information they need to be "free and self-governing" (17). This is the basis of a free press and the foundation of a democratic society. The authors highlight ten key elements of journalism, beginning with: "Journalism's first obligation is to the truth" (12-13). The pursuit of truth is at times vague and confusing (Feldstein; Kovach and Rosenstiel; Daniel Kerr 486-487), but it remains the primary objective for both camps. To get at the truth, both fields produce evidence from a variety of sources, including personal narratives. ${ }^{3}$ While there are many

\footnotetext{
${ }^{3}$ For more on the meaning of narrative in general, see the website "Digital Humanities." http://www.units.muohio.edu/technologyandhumanities/nardef.htm
} 
ways of defining the term narrative, this thesis is interested in the concept as it relates to personal experience. A personal narrative can be defined as "a storied piece which relates the parts and core of the piece to a personal experience, observation or idea." ${ }^{4}$ Personal narrative is used in both journalism and oral history frequently during the interview process. On the academic side for example, books such as Julie Cruikshank's Life Lived Like a Story: Life Stories of Three Yukon Elders in which oral history interviews are used to examine and illuminate some of the lifelong social challenges faced by three First Nations women, provide context to very current political issues. In the journalism realm broadcast documentaries, print features and web material use personal narratives as primary sources to help the audience understand current affairs and daily news topics. ${ }^{5}$ Although the difference between the two fields is sometimes very stark in terms of approach, goal, content and style, the result of this kind of work is hard to categorize. The most famous oral historian of them all, Studs Terkel, was neither strictly a journalist nor an academic by vocation, despite the fact that he hosted a radio show for almost five decades and wrote 18 books, most of which are based on oral history interviews about various pockets of American society. His books are commonly found in the history or biography sections of book stores, although some academics refer to his work as "oral history as journalism" (Coleman 95). Similar books, also called "oral histories," are found in the journalism shelves of stores and provide extensive insight into current news topics. These books may be authored or edited by journalists, such as the recent book Reporting Iraq: An Oral History of the War by the Journalists Who Covered it, published

\footnotetext{
${ }^{4}$ This definition is from the "Faculty Leadership for Writing Initiative" at the University of NebraskaLincoln. http://flwi.unl.edu/resources/glossary.html

${ }^{5}$ For example, the Canadian Broadcasting Corporation's recently-cancelled Outfront and National Public Radio's This American Life, and Radio Diaries. See also the works of author and broadcaster Studs Terkel.
} 
by the staff at the Columbia Journalism Review (Hoyt and Palattela). They can also be presented by non-journalists, such as Outside the Wire: The War in Afghanistan in the Words of its Participants, a Canadian collection of personal reflections by doctors, soldiers and aid workers (Patterson and Warren). This wide-ranging use of extensive personal narrative (and often naming it "oral history") is indicative of how people's personal experiences can help to better understand events and issues in the world. However, while both journalism and oral history share a common thread in their use of people's lived experiences, their approaches and goals differ enormously. Unfortunately, there is limited material that aims to share academic knowledge on this topic with practicing journalists. This thesis hopes to contribute to a gap in the literature on this front, by examining how the journalistic approach to interviewing could be informed by the academic approach to the oral history interview.

\subsection{Journalism, interview, oral history and lived experience}

In order to define some parameters for this study, this thesis draws from the teachings of journalism authors such as Davis Merritt and Jay Rosen. Merritt and Rosen are leaders of "public" or "civic" journalism, a movement that calls for more context in stories, more civic engagement, and more leadership from those who work in the media. ${ }^{6}$ In this vision, Merritt defines the journalist as much more than the traditional news reporter. For him, the journalist is...

....any person who sets out to inform the public about current affairs. It includes newspaper people, broadcasters, article writers of all sorts, and their editors. (xiii)

\footnotetext{
${ }^{6}$ For more on public and civic journalism see the works of David K. Perry, Jay Rosen and Davis "Buzz" Merritt
} 
This study employs Merritt's definition of journalist as it encompasses the broad range of men and women who, through their work as journalists, disseminate information aimed at helping to understand the world in which we live. The interview is one of the tools journalists use to do their job. The following is a definition of the interview as presented by the authors of the book Interviewing: Art and Skill:

An interview is a communication interaction between two (or more) parties, at least one of whom has a goal, that uses questions and answers to exchange information and influence one another. (Barone and Switzer 8)

Accepting this definition, and, as will be demonstrated later in this thesis, the interview can be used for myriad purposes. In journalism, it is frequently employed to share stories of individuals that represent the experiences of a larger population. For example, the CBC Radio Style Guide points out that one way of comprehending broader societal issues is to draw from personal lived experience:

We rarely talk about issues, problems or ideas in the abstract, without specific examples of how they affect us or other people. Most of us share an abiding interest in other people: their smiles, tears, hopes, fears, victories and defeats...we are all touched in some way when we hear of the shoemaker who wins the lottery, the politician who's caught naked in the corridor, the veteran football player who never makes it to the Grey Cup. (39)

This connection with the personal experience, and how it can be used to illuminate what's going on at a more public level, is something historians who use the oral history interview method also understand. Valerie Yow, who wrote a book about doing oral history interviews for scholars in the humanities and social sciences, suggests that human beings' fundamental yearning for stories and narrative nurtures the oral history interviewing process. 
Oral history reveals daily life at home and at work-the very stuff that rarely gets into any kind of public record....It is through oral history that the dimensions of life within the community are illuminated. (12)

Both Yow and another venerable scholar of oral history, Paul Thompson, author of The Voice of the Past, point out that while historical documents have dominated the official record for hundreds of years, the acceptance of personal experience as a valid contribution to history, through the interview process specifically, uncovers evidence that alters our understanding of the world.

Valerie Yow defines oral history as "the recording of personal testimony delivered in oral form" (3). Expanding, she observes some of the confusion in the field:

... what is the oral history? Is it the taped memoir? Is it the type-written transcript? Is it the research method that involves in-depth interviewing? The term refers to all three. (3)

This thesis supports Yow's definition, principally because all three components have potential applications to journalism.

Oral history is a vast and complicated realm. The term "oral history" is often mired in confusion as it is commonly used to refer to anything denoting the recording of personal experience. However, in its modern academic form, the use of oral history must include the desire to not only record the language and information of an individual, but also to seek meaning from the person's words. Valerie Yow says "to reveal the meanings of lived experience is the great task of qualitative research and specifically oral history interviews" (23). The Oral History Association (OHA) defines oral history as consisting of two main components: method and product:

Oral history refers both to a method of recording and preserving oral testimony and to the product of that process. It begins with an audio or video recording of a first person account made by an interviewer with an interviewee (also referred to as narrator), both of whom have the 
conscious intention of creating a permanent record to contribute to an understanding of the past. A verbal document, the oral history, results from this process and is preserved and made available in different forms to other users, researchers, and the public. (oralhistory.org)

This thesis examines the method component of oral history as described by the OHA, in particular the practice of oral history interviewing, and specifically the life experience interview. The latter is a narrative device used as a well-respected qualitative research tool in a myriad of disciplines including history, anthropology, ethnography, political science, psychology and sociology, to name a few. While the thesis notes various possibilities for content outcomes in both journalism and oral history, it is only where they relate directly to the method that they are mentioned.

\subsection{The oral history interview}

Oral historian Paul Thompson writes extensively on how to do an interview. He remarks that it is not a simple exercise, and that to be academically sound, the practice necessitates study and scrutiny:

...to be a successful interviewer a new set of skills is needed, including an understanding of human relationships. Some people can find these skills almost immediately, others need to learn them. (9)

Since Thompson wrote those words in 1978 , the discourse surrounding oral history interviewing has flourished and its use in disciplines other than history has proliferated. This thesis will draw from the dialogue on oral history interviewing, and specifically the style known as the "life story" interview, in order to examine how journalists might benefit from the kind of skills to which Thompson alludes. It will highlight key concepts from oral history including: the study of memory, the inclusion of diverse voices, the reliability of evidence, the meaning of personal experience within a social context, the relationships between interviewer and interviewee (also known as informant or narrator), 
and of course, the idea of truth. This thesis proposes that the literature on oral history interview theory, which is vast and profound, has the potential to inform the practice of journalistic interviewing and to challenge some assumptions about the journalistic interview. It explores both the theory and the practice-the methodology—of oral history. Frequently the terms research method and research methodology are used interchangeably. Clarification is required for the purposes of this study. If oral history interviewing has been established as a research method, or, a way of collecting evidence, what is a methodology? According to qualitative research experts Hesse-Biber and Leavy, it is "the bridge that brings theory and method, perspective and tool, together." In other words, it is the entire research design "from question formulation through analysis and representation" (21).

This thesis examines the research and debate that has shaped the way oral history concepts are used in the interview process, regardless of the academic discipline. It describes and compares the differences between journalistic interviewing and oral history style interviewing and how each employs personal experience. It seeks knowledge or techniques that could be applied to the fourth estate, and concludes with recommendations regarding the potential application of oral history methodology to journalism.

\subsection{Chapter outlines}

Chapter one states the research question, provides a definition of the concepts, terms and parameters, and briefly outlines future chapters. In order to examine and evaluate the relevance of oral history interviewing techniques to journalism, a thorough review of journalistic practices is necessary. Chapter two deconstructs the conventions 
and practices employed by journalists within the context of extended journalistic interviews. This inquiry notes that certain applications may be made to news, feature and investigative stories, although in-depth interviews are used more frequently in the two latter genres. Particular attention is paid to radio interviews, as the voice recording is especially relevant to this study. Chapter two also includes a critical examination of assumptions that define the journalistic interview, through a broad range of primary and secondary documents. The chapter studies the interview in an historical context and defines specific terms. The uses and applications of interviews are infinite, making the task of defining limits for this thesis extremely challenging. Therefore, this study does not purport to be in any way a definitive guide to the interview. It does, rather, provide a solid overview of the guiding principles and conventions of the journalistic interview. Vast portions of academic study on interviewing in general are not included in this study, and should not be anticipated.

Once journalistic interview practices have been reviewed and established, the third chapter shifts to a broad look at the methodology of oral history interviewing. An examination of oral history interviews as a qualitative research method within the humanities and social sciences provides the foundation upon which the relevance of oral history techniques to journalism can be compared. Chapter three includes an overview of how academics in such disciplines as history, anthropology, education, ethnography, sociology, and psychology use oral history interview techniques in their research, with a focus on the life history genre. The overview encompasses research surrounding methodological issues such as the nature of memory, reliability of evidence, validity of oral testimony, and interviewer-interviewee relationships. The discussion in this chapter 
is informed by an understanding of qualitative research, however, it does not provide a deep methodological study of the topic; rather it uses the qualitative base to illustrate the oral history interview's applicability to journalism. To that end, the thesis refers to other types of interviews used in the humanities and social science research, such as in-depth interviewing, focused interviewing, participant observation and case study interviewing, but these do not form its core. In addition, the study of oral history is expansive and reflects varying degrees of academic sophistication. This thesis draws from a broad range of oral history critique, favouring literature with content and language that is relevant to the field of journalism, and therefore is by no means a complete survey of oral history writings, nor is it a review of only peer-reviewed works.

Chapter four synthesizes the journalistic and oral history literature reviews, comparing and contrasting similarities and differences. As the research question examines the relevance of oral history interviewing to the journalistic interview process, chapter four is informed by the views of journalists and academics in the book Qualitative Research in Journalism, in particular the social history perspective of Renita Coleman. She speaks of "giving voice to the voiceless," an underlying concept of oral history, which is echoed in many journalistic endeavors (Coleman; Kovach and Rosenstiel; Merritt). It also draws on the works of historian and journalist Mark Feldstein who has identified a number of areas in which journalism and oral history can enhance one another. This study builds on possible applications of concepts from oral history to journalism. The majority of the research points to evidence that the process of the journalistic interview could be improved if journalists were informed by some of what oral historians have determined are the most effective approaches to interviewing. They 
also concede that the application of some elements from the academic world would be a hindrance to the fourth estate.

As mentioned above, the evidence in this thesis draws from both primary and secondary sources. While there is a vast array of literature on the subject of journalism and interviewing, there is no single definitive text. This thesis refers to prominent books, guides and websites that all advance their own version (and they do differ) on how to conduct the best interview. Where oral history discourse is concerned, this study will be interdisciplinary, as the oral history interview style is used in multiple academic contexts. There are a number of highly regarded texts as well as a number of journal articles, web sites and original works of oral history that figure prominently in this study. Also, in order to identify potential applications of oral history techniques to journalism interviewing, three journalists with extensive experience doing long-form radio journalism were interviewed about their perspectives on the value of adapting oral history knowledge to their journalism work. The findings reveal ways in which they believe a deeper awareness of the research method could enhance their vocation. On that note, chapter four identifies examples of ways in which journalists have already incorporated concepts from oral history methods into their story gathering process, whether by design or by accident. The purpose is not to assess the projects' successes or failures, but rather to acknowledge the synthesis that already exists between oral history and journalism.

The conclusion, chapter five, summarizes the main points raised in the thesis, and the findings based on the research. The results support the existing literature suggesting that while it would be unrealistic to expect journalists to adapt all the techniques used by 
academics in the production of oral history projects, some applications are in order. Renita Coleman:

... for longer journalistic projects the oral history method can be adapted to suit journalists' work and can enhance the credibility of their reports with the more rigorous attention to issues of validity and reliability, and greater focus on interpretation and analysis that is the hallmark of social scientific research.

This chapter concludes with recommendations on how some of the concepts from oral history interview methodology could be applied to the journalistic interview. Chapter five also identifies possible hindrances to journalism from the methodology, as well as hypotheses for further study, based on ideas raised during the course of the research. From the findings of this thesis, a discussion should emerge about how journalists could benefit from a more thorough knowledge of academic discourse surrounding oral history interview methods and theories. It is in this way that this thesis contributes to the field of journalistic study and practice. 


\section{Chapter Two: The Journalistic Interview}

The interview is the heart and soul of journalism. "Reporting is incomplete without interviews" writes journalism author Wynford Hicks, in the book Interviewing for Journalists (1). Despite its importance, research shows there is no single set of rules or clearly defined formula for a successful interview. Indeed, journalists conduct interviews for so many purposes and in such diverse media that to expect a single prescription for the perfect interview would be naïve. The different approaches are stark from the outset: Canadian journalist and author Paul McLaughlin calls the interview "an art form: an intricate discipline that combines preparation and spontaneity in a potent and sometimes dangerous mix" (xiii). Interview trainer John Sawatsky says: "Interviewing is not an art or a science. It is a social science" (qtd. in Eddy). The authors of The Canadian Reporter, a textbook that includes a chapter on interviewing, state: "...despite the importance of interviewing (...) the teaching and learning of interviewing techniques are frustratingly difficult" (99). Despite these diverse views and clear challenges surrounding the journalistic interview, countless journalists and others have attempted to come up with guidelines for the interview that will result in better journalism. Their advice is in textbooks, guides, articles and on websites. This chapter examines some of the fundamental themes that emerge from prominent interviewing guides. As most guides are directed towards a one-size-fits-all journalistic interview, the following review addresses both news and feature interviews. However, where possible it highlights texts that speak to longer-form interviews, more likely to employ personal narrative in feature and investigative journalism. The question will be asked: "What do journalists know about 
the interview?" This should help us understand the assumptions journalists make about the interview process as they engage in story gathering and as they prepare to disseminate information. Interview texts and models were selected for this study based primarily on their prominence in the field. Two points must be noted: First, that there appears to be a lack of interview instruction even in journalism schools, according to many, including media scholar and interview expert David Altheide:

Many journalism schools do not even require students to take courses in interviewing, often combining these with more general courses on information-gathering techniques. (419)

Second, there appears to be a dearth of comprehensive contemporary textbooks, papers and guides on journalistic interviewing. While there are numerous books on journalism history and theory, new material about the interview turned up most often on websites, and was generally more practical (concerned with technology, working batteries, etc) and less theoretical than existing texts. Therefore, the following examination of the journalistic interview does not derive from any single prominent text, rather it stems from a review of a combination of books, chapters in textbooks, articles, guides and websites, mostly from the past two decades.

\subsection{The interview: a brief history}

A study of the journalistic interview needs to begin with an understanding of the goals of the journalist. According to the seminal textbook The Elements of Journalism: What Newspeople Should Know and the Public Should Expect, "the primary purpose of journalism is to provide citizens with the information they need to be free and selfgoverning" (Kovach and Rosenstiel 17). This definition underscores the importance of journalists, first and foremost, as obtainers and disseminators of information and is 
supported by Mitchell Stephens, a professor of Journalism and Mass Communication at New York University, and author of the book A History of News, in which he traces the origins of journalism from preliterate societies to the age of the Internet. Stephens tells us that humans began spreading news by word of mouth around 40,000 B.C. (xi). The Chinese conducted early forms of oral history 3,000 years ago, as did the Greeks, beginning in about 490 B.C. The Romans, too, were broadcasting knowledge about history and philosophy in open-air forums around 145 B.C. By the time the printing press was invented in the $15^{\text {th }}$ century, news accounts had been circulating in both oral and written form for centuries. The development of modern journalism as a "free and responsible press" emerged primarily during the $19^{\text {th }}$ and $20^{\text {th }}$ centuries, enhanced by the invention of the telephone, and later, the radio and the television. ${ }^{7}$ To some degree, Stephens describes all societies that have sought knowledge elsewhere as having engaged in reporting, which he defines as "embarking into the field in search of news," a technique he associates with valid research.

Indeed, the strategy for gathering information now employed by most journalists-what might be called the "journalistic method"-is a product of the same spirit that spawned the techniques of historical research and intelligence gathering, the same spirit that gave birth to the scientific method. (216-217)

The interview has long been an integral part, if only one component, of the oral tradition, both in the social science and journalistic realms. Whether it was the woman 10,000 years ago who relayed back to her village that the river had run dry, or the witness to a drive-by shooting in 2010 , personal testimony has been used as evidence since the dawn of oral communication. Most texts trace the first modern journalistic interview to a reporter

\footnotetext{
${ }^{7}$ This concept emerged from the Hutchins Commission in 1947 that suggested "the press must be more that just free; it must be responsible." From The History of News, Stephens. Also see page 69 of Osler.
} 
covering a crime scene in New York City in 1836 (Stephens 230; Schudson 202). Specific dates aside, the interview is widely recognized in journalism as the primary form of intelligence gathering (Adam 30; Adams and Hicks 1; Stephens 230). ${ }^{8}$ The advent of the tape recorder and other more affordable and accessible recording devices in the past century sparked a new interest in documenting people's experiences. For journalists, it helped cement what some call the "new journalism movement" that came from England to North America in the late $19^{\text {th }}$ century, making journalistic content more diverse and the product more widespread (Adams and Hicks 1, Schudson 15). The tape recorder also enabled journalists to gain access to more voices from the general population (in contrast to the political or social elite), bringing them to the airwaves and newspapers (Adams and Hicks 3). For oral historians, it marked the birth of the modern version of oral history studies at Columbia University by journalist and historian Allan Nevins (more on this in chapter three). The tape recorder's influence cannot be underestimated in the development of interview concepts for both oral history and journalism.

\subsection{The interview: a theoretical perspective}

In The Elements of Journalism: What Newspeople Should Know and the Public Should Expect, Kovach and Rosenstiel lay out a framework for journalists in the new millennium. They begin with the idea that to educate the citizenry, “journalism's first obligation is to the truth" (37). Scottish journalism professor and author Brian McNair states "all definitions of journalism assume some commitment to the truth" (4). The actual definition and measurement of truth is a more difficult task (Kovach and Rosenstiel use terms like "confusion" and "befuddled" when discussing the concept of

\footnotetext{
${ }^{8}$ For a more in-depth history of the news interview see Steven Clayman and John Heritage in The News Interview: Journalists and Public Figures on the Air (26-27).
} 
truth in journalism), but the pursuit of it is inherent to the practice of journalism. ${ }^{9}$ The interview is one way of searching for that truth. Here is a straightforward dictionary definition of the interview:

2 a: A meeting at which information is obtained (as by a reporter, television commentator or pollster) from a person.

b: a report or reproduction of information so obtained. ${ }^{10}$

In the book Interviews that Work, author Shirley Biagi offers this distinction between a conversation and an interview:

Like a conversation, an interview is an exchange of information, opinion or experience from one person to another. In a conversation, control of the discussion passes back and forth from one person to the other. In an interview, however, the interviewer causes the discussion to happen and determines the direction of the questioning. (6)

For a deeper understanding of the interview and its importance to the practice of journalism, one might turn to some of the leading scholars in journalism and interviewing. "The interview is at the heart of the practice of journalism," writes G. Stuart Adam in Notes Toward a Definition of Journalism: Understanding an Old Craft as an Art Form (30). Adam considers the interview to be one of three primary devices the reporter uses to do their job:

Acts of observation, the analysis of documents, and interviewing in journalism are intended to provide authoritative facts. They represent the operations of the principle of reporting. (31)

In Talk Straight, Listen Carefully: The Art of Interviewing, Susan Paterno and M.L. Stein write "people talking to each other is the essence of journalism"(3). In Interviewing for Journalists, Wynford Hicks claims "interviewing is the central activity in modern

\footnotetext{
${ }^{9}$ For a more in-depth discussion about the concept of truth in journalism, see Kovach and Rosenstiel (3649).

${ }^{10}$ This is from the Merriam-Webster Dictionary
} 
journalism. It is now the main means by which reporters and feature writers gather their material" (1).

\subsection{The interview gurus and public journalism}

John Sawatsky has spent most of the past two decades teaching journalists how to do better interviews. He is a former investigative reporter, author and adjunct professor of journalism. He is so closely linked to interview training that many people in the business use his name as a verb, as in "I've been Sawatskied," which means either trained in his method or interviewed by someone using the Sawatsky method. He is Canada's (and arguably North America's) pre-eminent interview trainer, now employed full-time as senior director of talent at ESPN (Entertainment and Sports Programming Network). In a paper Sawatsky presented at a journalism conference in 1993, he rates the interview as the single most important tool in journalism because of its ability to broaden the story:

The interview's potential to go beyond the formal agenda, and the nominal limits, to draw out additional information and new levels of explanation is almost limitless. It can reach behind the story, and delve into the elements of motive and emotion. It can cause somebody to blurt out their genuine feelings which were previously hidden, or to break down and confess, whereas observation and the study of documents binds journalists to the evidence as presented. (11)

Sawatsky, however, is clear about the limits of the interview as well as the risks involved when an interview goes wrong:

In addition to the usual sources of error-faulty assumptions, mistaken reasoning, lack of clarity in the answer, etc.-interviewing introduces the potential for verbal miscommunication, thus interjecting into the process a new set of complications. Reporters can easily injure the quality of the exchange through the nature of their questions. Conversely the people being interviewed can be vague, inarticulate, deceptive, dishonest or merely mistaken. Given the number of combinations involved, the many ways an interview can go wrong are too numerous to mention here. (12) 
Despite the importance of the interview to journalism —and the hazards involved in the process-Sawatsky says it has been "largely ignored as an area of study" by journalism scholars (13). Unfortunately he has not (yet) published a book on interviewing, so his method is not accessible to most journalists. As a result, this thesis does not delve deeply into his methodology, but rather draws from the basics of his teachings over several decades and from personal communication. In the paper quoted above, entitled: Interviewing: The Need for a Methodology, Sawatsky proposes that journalism needs more than a set of standards about interviewing:

It needs a methodology, one that is defined, and one that has been dispassionately examined, and sets out a course of behavior that makes journalism not only more effective but more ethical. (17)

As evidence that this would improve the quality of journalism, Sawatsky describes how a group of television reporters were hesitant and/or unable to critique a sample interview he showed them. However, after challenging them to write down what techniques are helpful in interviews, they came up with some concrete ideas about how interviews could be better.

Now they possess some definitional tools and can recognize shortcomings much more readily. Introducing a set of definitions helped them establish a set of standards which caused them to measure performance in more demanding and precise terms. A simple set of definitions succeeded in raising their standard of assessment. (16)

Sawatsky's teachings over the past two decades are built on the idea that journalists should approach the interview in a more methodological manner, by understanding the fundamentals of inquiry during the interview process. He breaks it down into "fundamental units....because just like in biology, that's where it all happens, at the cellular level" (Personal communication 2010). In Sawatsky's method, communication is 
divided into two parts: input and output. The interview, as one component of input, is then divided into what he calls macro and micro. Sawatsky anchors his examination of questions (which is part of the micro section) with the idea that each question has a topic and a demand. This is where the most well-known of his teachings appear, in the form of Sawatsky's seven deadly sins. The following is a brief summary of those common mistakes made during the interview process:

1. Failing to ask a question. This means there is no demand. It's very important to make a demand.

2. Asking two questions at once, or "double-barreled" questions. The interviewer should only impose one demand.

3. Overloading questions. This is when the interviewer puts too much information into the question and the demand "conks out."

4. Adding statements or comments to questions (such as, because, etc). There is no need to make remarks when asking questions of someone else.

5. Using loaded or "trigger" words in questions. Some interviewees will shut down when certain words are introduced into the questions.

6. Using hyperbole, or asking hyperbolic questions. Sawatsky says this can be good as an "output tool" but not for questions because it kills the value of the question.

7. Asking closed-ended questions. You'll get a yes or no for an answer.

Sawatsky's views about the need for better interviewing methodology in journalism are well known. In an interview with National Public Radio's (NPR) David Folkenflik, he talks about challenges in his current job, training sports journalists:

I want to change the culture of the journalistic interview. We interview no better than we did 30 years ago and in some ways we interview worse... It 
is very haphazard, you're hoping the person being interviewed is a very good talker and can do something with your inept question. (NPR.org)

Not everyone agrees with John Sawatsky's approach to interviewing. He has followers and detractors. A page on NPR's website is devoted to an article on Sawatsky's method, including a link to an eight-minute audio story by Folkenflik. The site also has print and audio recordings of famous interviewers who've been critiqued by Sawatsky, such as Larry King and Mike Wallace, responding to his assessments of them. Online journalism forums reveal disparate views his method, with some applauding it but others suggesting his ideas are too verbose and the tips are irrelevant to journalists, especially to those who conduct short interviews (NPR.org). ${ }^{11}$ Regardless of dissenting views about his interviewing advice, John Sawatsky is out front in the field of journalism educators in his attempt to bring a social science approach to the interview process.

Although not as renowned, there are many other interview trainers, including another Canadian journalist, Paul McLaughlin, author of the book How to Interview: The Art of the Media Interview. ${ }^{12}$ McLaughlin is a former CBC researcher, a part-time journalism teacher, a freelance writer and a communications consultant. He approaches the interview from a completely different perspective from Sawatsky, describing his book as a "personal interpretation of the interview process" adding "the media interview cannot be reduced to a set of rigid rules and formulas" (xiii). McLaughlin proposes that "interviewing is essentially about interpersonal relationships and how we communicate with each other" (225). He also notes the origins of the word itself:

\footnotetext{
${ }^{11}$ For more perspectives on the Sawatsky method see http://ajr.org/article.asp?id=676 and http://www.sportsjournalists.com/forum/index.php/topic,40406.0.html

${ }^{12}$ This book is also called Asking Questions: The Art of the Media Interview
} 
The word interview is derived from the French entrevue/entrevoir, meaning "to see one another," which is an important distinction not usually associated with its English counterpart. Herein lies the key to one of the most overlooked benefits of interviewing: the tremendous opportunity available to find out about yourself through discovering other people, their ideas, and your responses to them. (xiii)

This is a thought-provoking perspective on the interview process, one that augurs well for some of what lies ahead in this study, especially with respect to oral history interviews and their specific attention to the interviewee/interviewer connection. It also speaks to some degree to the desired outcome of "public" or "civic" journalism, as proposed by such journalists as Davis Merritt and Jay Rosen.

In his book Public Journalism and Public Life: Why Telling the News is Not Enough, Merritt calls for journalists to change the nature of the traditional relationship between themselves and public life in order to sustain healthier democratic societies. $\mathrm{He}$ identifies several mental shifts that would advance the cause. These include going beyond the basic news facts in stories, becoming more engaged in civic life, initiating and exploring solutions to problems, and perceiving readers/listeners/viewers as active participants in life and in stories in general as opposed to simply consumers of media (139-140). Another leading public journalism advocate is Jay Rosen, author of What are Journalists for? Rosen traces the history of the public journalism genre, exploring the ways in which it calls on journalists and citizens to be more involved in the democratic process. This thesis is informed by the call for stories that seek to understand the important topics of the day as well as to engage citizens to participate. To that end, this study is also committed to exploring the realm of interview methodology within a framework of long-form journalism, which, albeit with exceptions, generally falls into two categories: feature journalism and investigative journalism. 


\subsection{Storytelling and the use of narrative in feature and investigative journalism}

A simple understanding and acknowledgement of both the value of story-telling and personal narrative are important to any examination of possible applications from the oral history tradition to journalism. Most journalists are initially schooled in the importance of some version of the five W's and one $\mathrm{H}$. Who, what, where, when, why and how have become the staple diet of journalistic practice. The simpler, more technical guides about the journalistic interview contain little or no mention of storytelling and narrative. Delve into more substantial and narrative-specific texts, though, and one finds no shortage of journalists and academics who study the topic. ${ }^{13}$ For example, in the first chapter of Telling True Stories; A Non-fiction Writer's Guide, journalist Jacqui Banaszynski describes covering a story about famine in a part of war-ravaged Africa. She tells how the displaced people lived in unspeakable conditions, but that they still engaged in nightly singing, which, she discovered, was their way of telling stories. "It was their version of school. It was how they carried their history and culture and law with them" she writes, underscoring the importance of story-telling to the human condition (4). Banaszynski is one of 90 journalists in the book to share her views on the fundamental importance of story-telling and by extension, narrative writing, to the practice of journalism (whether adapted to print or broadcast media).

\footnotetext{
${ }^{13}$ For example, see the Neiman Foundation for Journalism program in Narrative Journalism. http://www.nieman.harvard.edu/NiemanFoundation/ProgramsAndPublications/NarrativeJournalism.aspx
} 


\subsubsection{Feature journalism}

Feature journalism is a category of journalism most often referring to stories that take an in-depth look and analysis of a particular subject (McNair 9). The term is used in contrast to news journalism, which is primarily concerned with today's events. McNair says news "aims simply to inform us about what is happening" while feature articles provide "a more in-depth reportage and analysis of a particular subject" (9). The feature story may be presented in a variety of media, including a print article, online or in a newspaper or magazine, a radio or television documentary, or in a long-form current affairs interview.

\subsubsection{Investigative journalism}

Investigative journalism is a type of journalism in which some kind of problem is uncovered, whether it be moral wrongdoing, criminal activity or otherwise. It requires varying degrees and types of investigative work in order to reveal what's really going on. According to the authors of Digging Deeper: A Canadian Reporter's Research Guide, investigative journalism often delves into stories that people want to keep secret or that involve corruption: journalism that can result in very real improvements to society.

At their best, investigative stories reveal injustice and misery, expose wrongdoing, force accountability, uncover wasteful spending, and point out the failures of public officials or public systems. Ideally, the stories move people in authority to fix the problems. (3)

Pulitzer Prize winning reporter Tim Weiner compares a good investigative journalist to "a scientist, historian, a cop, or anybody else who is trying to dig beneath the surface of things (6). Cribb et al. consider investigative journalism to be a key element of the fourth estate in the sustainability of democracies. 
Investigative journalists play a critical role in our democratic society, acting as a counterweight to the many forces that seek to control the flow of information and obscure the truth. (3)

Investigative stories are frequently published in longer format presentations and can involve more in-depth and skilled interview techniques than daily journalism.

\subsubsection{Narrative journalism}

Both investigative and feature journalism frequently use the technique known as personal narrative in their reports. Narrative journalism refers to the style of journalism in which the journalist's interpretation of the story is significant and creative, in contrast to stories that simply reveal the facts of a situation. The narrative is not just the story itself but rather the telling of the story-which is why it is so often used in phrases such as "written narrative" or "oral narrative." While a story can refer simply to a sequence of events, a narrative recounts those events in more detail, sometimes omitting key points, other times highlighting aspects that may not seem relevant to the story, but illuminate the perspective of the storyteller. ${ }^{14}$ Walt Harrington, a former staff writer for the Washington Post, now author and journalism professor, underscores the importance of individual experiences in his book Intimate Journalism: The Art and Craft of Reporting Everyday Life:

The stories of everyday life-about the behaviour, motives, feelings, faiths, attitudes, grievances, hopes, fears and accomplishments of people as they seek meaning and purpose in their lives, stories that are windows on our universal human struggle-should be at the soul of every good newspaper. (xiv)

\footnotetext{
${ }^{14}$ For more on Narratives see website "Digital Humanities" http://www.units.muohio.edu/technologyandhumanities/nardef.htm) and the Neiman Foundation for Journalism program in Narrative Journalism. http://www.nieman.harvard.edu/NiemanFoundation/ProgramsAndPublications/NarrativeJournalism.aspx
} 
Harrington points out that people have a variety of names for this kind of journalism"literary journalism, creative journalism, creative nonfiction, documentary narrative" and that they often imply a more trivial kind of journalism in contrast to daily news stories (xv). Harrington argues these are absolutely not "human interest stories" (xvii). He claims journalists who include intimate reporting methods in their stories produce a higher level of journalism:

Giving the same depth of attention to people as they live their everyday lives, seeking out the extraordinary in the ordinary, is rare. Yet everyday life is the only real laboratory we have for understanding ourselves and our society, our values and our behaviour. (xv)

This study is framed by the above parameters: It looks at the ways in which journalists tell stories through interviews that use personal narrative in their reports as they explore the world beyond the headlines. It is likely to apply primarily to feature and investigative pieces that fall into the longer form journalism category, but it does not exclude news reporting. Whether presented in book form, online, a newspaper piece, a magazine article, a radio interview or documentary, or on national television news, this kind of journalism can bring enhanced meaning and context to the daily news, and can encourage a sense of engagement from citizens. It is also the most relevant kind of journalism to benefit from potential applications from oral history.

\subsection{The time and money factors in journalism}

Before proceeding with an examination of the journalistic interview, it is important to note two major factors that affect the collection and production of information in the field of journalism. If one accepts Kovach's and Rosenstiel's definition of the purpose of journalism-the journalist's responsibility to the citizen/public/audience—one must also acknowledge that most journalism operates as a 
business, meaning it operates under complex fiscal pressures. Mark Feldstein says journalism is "ultimately a commercial vehicle for selling advertisements" (6). While this is not the case for all media outlets (CBC Radio being one such example), financial restraints and constant deadlines are all but universal factors in the practice of journalism. Issues such as ownership, competition, and telecommunications policy have a steady and omnipresent influence over news organizations. Technological advances, principally the advent of the Internet, have fundamentally altered both the practice and the corporate structure of journalism. Computers and Internet-related technologies in the workplace have enabled journalists to collect and disseminate information faster and in more media than ever before. In Gubrium and Holstein's book The Handbook of Interview Research, sociologist David Altheide proposes that the journalistic interview is in the midst of a fundamental shift. He says the reality of modern financial considerations, such as global convergence of media outlets, integrated newsrooms and more frequent deadlines support his theory, as together they contribute to changes in not only how journalists produce content but what they produce as well. Altheide suggests these pressures are challenging some of the fundamental principles of good journalism:

Such changes make journalistic interviewing more interesting and more entertaining, but, with exceptions, such evocative approaches are less useful for truth seeking. (428)

These more evocative approaches, says Altheide, clearly aimed at bringing in larger audiences (and more money to media organizations), are at the root of the changing journalistic interview. This thesis does not aim to tackle these topics; rather it acknowledges their influence on the practice of journalism and is informed by how they may relate to what journalists understand about the interview process. To that end, this 
thesis frames the question of how journalists approach the interview process in the context of stretched resources in a fast-moving and competitive media landscape.

\subsection{Assumptions about the journalistic interview (or, how to do an interview)}

If journalism is a craft, interviewing is an art. There are a lot of unrelated skills to master and, like learning to drive a car, interviewing is daunting and difficult at first. But with practice, setting off smoothly, signaling, changing gear, steering and watching the instruments become second nature. So it is with interviewing. (Adams and Hicks 4)

This observation about the interview from Interviewing for Journalists by journalists Sally Adams and Wynford Hicks sums up what at best can be described as a mixture, and at worst, a hodgepodge, of advice about the technique of journalistic interviewing. It acknowledges the dependence on intangible skills as well as a reliance on instinct and good judgment. As is the case with all art, it also recognizes the importance of talent, confidence and poise in the pursuit of a successful interview. In this section, the authors suggest:

The most useful characteristic for an all-round interviewer is to be likeable, the sort of person who can get on with almost anybody and is interested in everybody: a person who people are happy to talk to, who comes across as a human being first, a journalist second. The most valuable attribute is probably curiosity, followed by charm, keen powers of observation, doggedness, flexibility and fairness. Then add the ability to think fast, analyze, keep a poker face when necessary, a broad general knowledge and plenty of skepticism (...) It's a rare journalist who can master the complete range of styles interviewing demands. (Adams and Hicks 5)

As the authors acknowledge, not all journalists embody the above attributes. However, and thankfully, numerous authors have published guides, made lists and offered up tips of what constitutes a good interview. These lists and bibliographies are long, so this thesis draws from some of the more prominent texts in the field of journalistic interviewing, as well as from online resources and interviews with journalists. As mentioned earlier, this 
thesis does not pretend to be a complete collection of all the interviewing guides available-it will exclude many texts-but it does contain a broad and thorough overview of theoretical and practical approaches to the journalistic interview that enables us to understand some of the assumptions made by journalists when carrying out their work. Furthermore, for the purposes of this thesis, and in terms of comparing the journalistic interview process to oral history methodology, both examinations (in chapters two and three) will be broken down into three parts: 1) Preparation 2) Actual live or taped interview and 3) After the interview: publication or broadcast.

\subsubsection{Preparation}

\section{a) Background research}

The vast majority of texts on interviewing say the better prepared you are, the better the interview will be. The online website called Loosening Lips: The Art of the Interview, written by investigative reporter Eric Nalder of PBS, offers all kinds of tips on interviewing. In this comprehensive "e-tool," Nalder refers to interviewing as both a science and an art form, calling preparation as "important as execution":

Obviously, a well-researched interviewer will know better what to ask, but there's another advantage in all this preparation. A well-researched interviewer is an empowered conversationalist ... Yacht buyers candidly described their multi-million-dollar tax breaks and tanker captains admitted their mistakes to me because I could converse so easily about their boats, their lives, and their businesses. (pbs.org)

The Committee of Concerned Journalists has published a methodical online list of ten tips to a successful interview that seems to sum up much of the advice. Being prepared-both in terms of the topic and the technology you're using - is number one: 
Always read up on the subject you are reporting about and the person you are interviewing. Your source will appreciate your effort, and you will be able to skip questions that can be answered by an assistant, book or document. When scheduling the appointment, ask your source to suggest documents or other sources of information about the topic you will discuss. The interviewee will appreciate your interest and often share valuable documents before the interview. Make sure your tape recorder has batteries that work. Bring an extra tape as well as pens and notebook. (icfg.org)

Preparation is obviously critical to entering an interview situation with confidence and knowledge. All the major texts encourage background preparation. Depending on the nature of the story being pursued, the research can take many forms. In Digging Deeper, the authors explore all kinds of sources and methods of finding information, ranging from online data bases to past news articles. They explain in clear, concise and practical terms how to use public records, access court documents, navigate the Internet and retrieve historical material. Overall, most of the literature reflects both old and new ways of intelligence gathering including the obvious-to check facts from one document against another. With the exception of beat reporters, the reality in most media organizations is that journalists frequently find themselves covering stories they know little about. In Talk Straight, Listen Carefully: The Art of Interviewing, Susan Paterno and Meyer Stein claim this should not be a deterrent, even when interviewing an expert in another field:

A journalist can easily educate himself on a particular subject so that he can ask intelligent questions of a source whether he or she be an aerospace engineer, football coach, psychologist...success is boning up on the subject or source to enable you to ask intelligent, probing questions. (14)

The value of being prepared for any story, whether a feature or investigative piece, cannot be underestimated. John Sawatsky says journalists who don't enter interviews with evidence that prove fundamental facts-facts that the interviewee must agree 
with-will pay a price later in the actual interview. The authors of many interview guides, including Paterno and Stein, draw from the views of Sawatsky on this matter:

Without agreement...reporters spend most of the interview trying to force sources to accept their version of events, Sawatsky warns, usually resorting to coercion and leading questions. (qtd. in Paterno and Stein 17)

Paterno and Stein point to an example frequently used by Sawatsky. It's a wellknown interview between Dan Rather and Professor Mirjana Markovic, the wife of former Serbian president Slobodan Milosevic. In the interview Markovic is dominant in the sense that she gets her message out, which is to deny the scope of atrocities committed in Bosnia. The authors argue if Rather had included hard evidence in his questions, instead of asking open-ended questions that allowed her to speak without specifics, Markovic would have been forced to react to the facts $(18-23)$. This example illustrates what happens when a journalist doesn't have the necessary hard evidence in the question to force a direct reply to the question, which can result in an interviewee running roughshod over the journalist. The warning here is clear; the result of not being prepared for the content of the interview can lead to an interviewer asking substandard questions, which creates a number of problems for the journalistic interview process.

b) Questions - to pre-write or not to pre-write?

Most interview guides recommend preparing some questions before an interview; however, they vary widely in their level of detail. Eric Nalder likes to jot down cue words, indicating key areas he wants to cover in his interviews. The pages of Paul McLaughlin's book on interviewing feature a variety of conflicting evidence from experienced journalists on this point. Journalist Terrence McKenna drafts and redrafts questions for interviews, whereas Quebec journalist Pierre Pascau prefers all notes to be 
put away and looks for a "conversation" or a "dynamic exchange," believing that a set of written questions will limit the interviewer's ability to concentrate on what the interviewee is saying (123-124). This view is echoed to some degree by the guide published by the NPR-sponsored program "Radio Diaries":

A good interview is like a conversation. Prepare questions, but don't just follow a list...If your questions are rehearsed and hollow, the answers will be too. (radiodiaries.org)

Paul McLaughlin's style is somewhere in between, with "a mixture of rehearsal and spontaneity" (124). He does recommend developing "an overall strategy for the interview":

By mapping out the questions, key information and strategies emerge. How many questions do I have? What points are missing, weak, unprovable, or likely to be challenged? Where am I vulnerable to attack? Why? How do I respond? What questions require careful wording? What are the major transitions? What themes are emerging as the strongest? How prepared and confident am I? (125)

Both Nalder and McLaughlin engage in a kind of meditation before the interview. Nalder refers to it as "inner interviewing" which includes imagining a successful interview and meditating just before beginning the interview.

Often an interviewee wants to see the questions in advance of an interview. The guides are almost unanimous in recommending against this. CBC's 2010 Journalistic

Standards and Practices sums up the widely undisputed position:

We inform the interviewee of the subject of the interview. We do not provide in advance the questions they will be asked. That could give a false impression of spontaneity in the interviewee's responses and unduly limit the interviewer's ability to react to interviewee statements with supplementary questions. (cbc.ca)

As this study revealed very little, if any, policing of the habits of individual journalists in the story-gathering process, the practice in newsrooms may differ from the recommended policy. Anecdotally, most journalists would likely know of 
cases in which they or a colleague shared questions with an interviewee in advance. However, it is clear, based on the literature, that journalistic organizations agree that allowing interviewees to preview questions would pose a threat to both journalistic integrity and consumer trust.

c) Ethics and relationship with source

While there is a vast quantity of literature and attention devoted to the topic of journalism ethics, this thesis must limit its inclusion to questions surrounding the interview process. Basic concepts about ethics are universally accepted and included in some, but not all, texts on interviewing. Clearly, the size and scope of a project determines to some degree how much consideration is given to questions of ethics when preparing for an interview. In general, the texts that examine specific types of journalism provide more information on ethics, whereas the "how to" interview guides mostly ignore the topic. ${ }^{15}$ In The Canadian Reporter, authors and journalism professors Catherine McKercher, Carman Cumming and Allan Thompson say most ethics guidelines cover "things like conflict of interest...protection of sources, acceptance of favours and invasion of privacy" (368). But they go on to acknowledge that teaching ethics is extremely challenging:

Reporters learn these standards almost by osmosis. They are exposed to them through talking to their colleagues, journalism instructors and editors. They watch how other reporters behave. They may absorb them through reading cases studies in a reporting or ethics class. (368)

The authors of Digging Deeper: A Canadian Reporter's Research Guide are succinct in their outline of basic journalism ethics: “Don't lie. Don't steal (e.g. documents

\footnotetext{
${ }^{15}$ For example, in Telling True Stories; A Non-Fiction Writer's Guide, the editors devote 29 pages (12 articles) to topics about ethics in narrative journalism.
} 
from somebody's desk). Don't misrepresent yourself" (25). They refer readers to the website of the Canadian Association of Journalists for a more detailed understanding of ethical conduct. ${ }^{16}$ Most of the texts reviewed for this study approach the ethics of an interview in legal terms. In Digging Deeper, for example, the authors cover circumstances in which a journalist might have to go undercover, warning that this should only be considered when public interest is "overwhelming" and there is no other way to get the information.

Making up a false name, lying about credentials, secretly recording what people say or do-such conduct has the potential to undermine public trust in the journalist or the media as a whole....their stories should explain the methods used and why they were considered necessary. By coming clean, journalists allow readers, listeners, or viewers to judge whether the ends justified the means. (23)

The approach of these authors reflects a self-monitoring industry, one that seeks to make the right decision based on circumstances, interviewees and nuance. Some journalists, including Canadian journalist Anthony Wilson-Smith, believe the Canadian media landscape is lacking in clear, ethical and professional guidelines:

Journalism, despite frequent claims to the contrary, is not a profession. A true professional, by comparison, is a doctor or lawyer, both of whom must pass rigorous tests and can be barred from practicing if they violate rules regarding their conduct. Journalism has no universal code of conduct, although most organizations establish guidelines of acceptable behavior. And while most journalists today have attended university, there are no specific requirements to become a reporter. (11)

Guidelines do exist, however, and as previously mentioned, are posted on most journalism organizations' websites. Three recurring themes relevant to this discussion are

\footnotetext{
${ }^{16}$ To see the Ethics Guide in full from the Canadian Association of Journalists' website, go to www.caj.ca
} 
i) objectivity and fairness in journalism, ii) relationship with source and iii) off the record material.

\section{i) Objectivity and Fairness}

The idea of the objective journalist was a pillar of the "free and responsible press" that developed in the 1900s. It implied a sort of detached, balanced reporter, whose stories were devoid of personal bias. More recently, though, objectivity in journalism has been the subject of intense debate, as most journalists agree that complete and true objectivity is difficult to define, let alone achieve. In the book Online Journalism Ethics: Traditions and Transitions, Cecilia Friend and Jane Singer outline some concerns raised in the discourse about objectivity:

Journalists rely on witnesses and sources with restricted points of view, not to mention personal agendas. Language itself is not value-free and can shift meanings from person to person. (10)

In The Elements of Journalism, Kovach and Rosenstiel characterize the discussion surrounding objectivity as "a trap."

The term has become so misunderstood and battered, it mostly gets the discussion off track....Originally it was not the journalist who was imagined to be objective. It was his method....Our contemporary understanding of this idea is mostly a muddle. (41)

This concept of objectivity is frequently replaced by other concepts, believed by some to be more achievable. For example, the Canadian Association of Journalists doesn't mention objectivity in its ethics guidelines; instead, fairness and accuracy figure high on the list. The guidelines clearly state that favoured treatment to advertisers or special interests is unacceptable. And, when in doubt, full disclosure and transparency should rule. This is under the heading "Conflict of Interest": 
There is a tradition in Canada of media organizations that support and advocate particular ideologies and causes. These ideologies and causes should be transparent to the readers, listeners or viewers. Journalists for these organizations sometimes choose to be advocates or are hired to be advocates and this too, should be transparent. (caj.ca)

The literature shows a shift away from pure journalistic objectivity towards terms like independence, impartiality, transparency, fairness and balance in ethics guidelines. Some authors, however, such as Kovach and Rosenstiel claim the new terms can muddy the waters in the pursuit of truth:

Fairness is too abstract and, in the end, more subjective than truth. Fair to whom? And how do you test fairness? (...) Balance, also, is too subjective. Balancing a story by being fair to both sides may not be fair to the truth, if both sides do not in fact have equal weight. (46)

In their commitment to finding truth, Kovach and Rosenstiel focus on the second element of journalism: "Journalism's first loyalty is to citizens" (51). This concept underpins most journalism ethics guidelines. For example, the Society of Professional Journalists (SPJ) in the U.S. bases its code of ethics on the idea that the fundamental role of the journalist is to enlighten the public by pursing the truth. It states the job must be done honestly, accurately, fairly, and with minimal harm. It also calls on journalists to be accountable, by practices such as admitting mistakes, creating dialogue with the public and inviting criticisms from viewers, readers and listeners. Most journalism organizations have mechanisms by which members of the public can participate in the public discourse, as well as complain about unethical behaviour by journalists. However, as are all codes of ethics in journalism, the SPJ code is voluntarily accepted by journalists, without any formal policing or legal consequence, and indeed calls itself a "resource" as opposed to a set of rules (spj.org). The authors of The Canadian Reporter acknowledge the pressures under which journalists attempt to get information to the citizens: 
The public interest is often in tension with the commercial interest - the need to make profits or sell advertising. (369)

The authors of this text suggest many journalists learn about ethics "through osmosis," and they suggest combining personal values with professional ethics when carrying out their work (332).

\section{ii) Relationship with source and "The Get"}

This survey of journalistic interview guides reveals that the briefer the guide on interviewing, the less likely it is to make any mention of the importance of the relationship between interviewer and interviewee. However, it is clear that most ethics guides emphasize the importance of not harming people through the journalistic process. The SJP code, for example, lists "minimizing harm" second in its ethics guidelines, including in situations involving tragedy:

Be sensitive when seeking or using interviews or photographs of those affected by tragedy or grief (...) Only an overriding public need can justify intrusion into anyone's privacy. (spj.org)

A fundamental part of a journalists' job is "getting" the interview, a practice that sometimes requires persistent, or even assertive or aggressive, behaviour, presenting potential ethical dilemmas for journalists. For example in Paterno and Stein, there is an acknowledged pressure to deliver material, therefore "the reporter must use any ethical means to crack the wall set up by reluctant, shy, hostile, or tongue-tied subjects" (65). Even the title of Eric Nalder's web advice_Loosening Lips: The Art of the Interviewimplies an element of coercion during the interview process. On that site, Eric Nalder gives 15 suggestions (or "plays") on how to convince a source to do an interview on the record. These include everything from finding common ground ("you have a poodle. I have a poodle"), to ratcheting (increasing the stakes gradually), to detours (acting as the 
lost reporter), to "the Statue of Liberty play" (put your name behind what you say) (pbs.org). In The Canadian Reporter, the authors acknowledge reluctant sources, but they encourage journalists to approach the chase by framing it in terms of understanding how the source may benefit from the exposure.

Many people think that a media interview will put their case or their cause before the public effectively. There's also a personal status reward in getting on the 6 o'clock news or in being quoted in the newspaper. (112)

For the journalist, the authors suggest the rewards lie primarily in the development of the story, but also "the accumulation of interview experience can be seen as the richest part of a journalist's life" (114). Some of the more in-depth texts, such as Adams and Hicks, provide a more cynical view of the nature of the journalist's relationship with a source.

First, it's important to realize what the interviewer/interviewee relationship entails. You will use people and you will be used. You will find some people who divulge little, others who tell you more than you wish to know. You will be trusted with secrets, you will be lied to. You will be bombarded with what seem like irrelevancies and only later realize what a key piece one of them is in the information jigsaw. You will be rebuffed, you will be courted. (6)

Adams and Hicks emphasize the importance of persistence while chasing a story (24). In some journalistic texts, the relationship is only relevant in the context of getting the information you need for the story. Most of the texts agree that engaging in some form of small talk will help relax the guest or "build rapport," whatever the goal of the interviewer (Adams and Hicks 35). However, in cases where the story is less investigative and more feature-oriented, the relationship with the source is approached more thoroughly. For example, narrative journalist Walt Harrington:

I make it clear that an intimate story is a cooperative project between reporter and subject and it can't be done without a subject's enthusiastic involvement. I try to define their role as one of helping me to tell the story. (xxxiv) 
On a website offering up interview tips to journalism students, Paul McLaughlin also considers the relationship between journalist and interviewee:

Trust is one of the most important aspects of interviewing. If the person trusts that you are a sincere and straightforward person, the potential for a successful communication increases dramatically. (cane.ca)

This is consistent with McLaughlin's more personal approach to the interview process. Based on the literature, it is a widely understood principle that being polite with a source-at least at the start-will result in better outcomes from interviews. While this is an example of something quite basic and obvious that most texts include, there do appear to be gaps in the literature in terms of a discussion about what responsibilities, if any, the journalist may have to the interviewee throughout the interview process.

\section{iii) Off the record}

It is generally agreed upon that a journalist should be as forthcoming as possible about the purpose and goals of the story during the setting up of the interview. This includes clarifying whether or not 'off the record' information will be accepted. The primary reason for this is to preserve and maintain journalistic integrity, and the second is to avoid misunderstandings about what 'off the record' actually means.

Although most government officials have enough experience with the media to indicate when something is "off-the record" or "on background," other experts may not understand the differences. Remember that an upfront clarification may be required (especially when your source's job or life could be endangered by being quoted). (icfj.org)

Cribb et al. provide clear definitions of the various scenarios in which interview sources request some variation of their name not being used, or information given only as background (130). They state that the commonly accepted approach to requests of anonymity is that "a source cannot withdraw his or her name after speaking the words. 
The request must come first" (131). The authors recognize that a journalist may use discretion in this policy, especially when dealing with people unaccustomed to media interviews. However, their conclusion is unequivocal:

...if the person's information is vital to the story-if they are providing important corroborating information, for example-you may have no choice but to use their name. It is difficult, but a journalist's first obligation is to the audience. (131)

Former journalist and Ryerson journalism professor, Don Gibbs, advises that journalists "approach every story with the idea that it is paramount to name names." According to Gibbs, "names enhance the credibility of stories and force people to stand behind what they say" (18). Most texts and guides concur with this view. Although the texts on investigative reporting are somewhat more understanding of the need to protect sources on occasion, it is never a first choice, and must be done only in extreme situations. Eric Nalder is very clear about this:

Don't accept information "on background" blithely. Even if it means going back several times, convince people to go on the record. (Absolutely "offthe-record" information is useless, since you can't use it under any circumstance. Avoid it. It's a waste of time.) (pbs.org)

In Canada, there have been two significant cases in which the courts have ruled in favour of the right of a journalist to protect their source. According to Cribb et al., such a decision upholds basic requirements for a free press in a democratic society (130). McKercher, Thompson and Cumming provide an extensive list for journalism students that they call a "defacto code of ethics" in which they list many ethical guidelines by which to work. However, due to the independence to which journalists must adhere, they view journalism ethics as a personal issue to be considered on a case by case situation: 
The challenge, then, is to examine ethics while holding one part of the mind aloof, one critical part that recognizes that ethical norms may lead to conformity or to defensive, self-justifying thinking and that the highest ethical duty may be to turn against group ethics. While journalism is very much a collective activity, the ethical decision is personal. (332)

The idea that journalists must somehow combine ethical guidelines with personal morality is supported by Kovach and Rosenstiel in The Elements of Journalism. "Journalists have an obligation to personal conscience," is the ninth element, they write (181). This is the underpinning of their approach to ethics, as the freedom to express individual views (that may challenge established authority) is crucial to a healthy press in a democratic society.

\subsubsection{The interview}

When journalists go out to do the actual interview, they may be juggling several balls at one time. They need to consider their preparedness (or not) for the content of the interview. They have to be comfortable with the technology. Then, they need to begin the interview process. That means asking the right questions. These topics-the "how to" of interviewing-comprise the most comprehensive material available in the form of advice from journalistic texts. It almost always begins with listening.

a) Listen, listen, listen

The importance of listening to the interviewee during an interview cannot be underestimated. As obvious as it seems, every guide devotes a considerable amount of space to the concept of listening (Adams; NPR "Radio Diaries;" McLaughlin; Sawatsky; CBC). Paul McLaughlin states "if I could write only one chapter about interviewing, it would be about listening" (1). McLaughlin refers specifically to what he calls "active" listening: 
...when...you listen deeply, your response assists and inspires the person to speak with more clarity and eloquence. The simple but demanding act of listening with total concentration, which includes hearing more than just the person's words, enables the speaker to concentrate and to reach more deeply for ideas and ways to express them. (2)

There is an understanding in the journalistic community that learning to listen is not as straightforward as one might think. Author and journalist Sally Adams says "interviewers need to master the non-questioning skills of eliciting information and quotes" (32). She says they need to be taught skills that help them listen to interviewees:

Listening is not the same as hearing. Good listening is hearing and understanding. (33)

The authors of Digging Deeper point out that listening well-that is, avoiding all the distractions that may be in your head or around the room-will benefit you in two ways: first, you'll hear what the person is saying and be able to follow the interview; second, you will get better answers from an interviewee who thinks you're interested in what they're saying (122). The author of Sound Reporting: the NPR Guide to Audio Journalism and Production actually offers tips on how to show you're interested:

If you sound like you're just collecting facts to put in your notebook, you'll tend to elicit a recitation of facts. If you seem interested when you pose your question, you'll often get interested and energetic replies. Show some emotion! Sound engrossed or surprised-even if you already know what they just told you or the subject is not intrinsically fascinating. (55)

One of CBC's (and Canada's) most famous interviewers, former Morningside host Peter Gzowski, considered listening to be the first step in "mastering" the craft of interviewing. Using the analogy of being in a canoe together, Gzowsky describes the interview this way: "The subject paddles, the interviewer steers" (28). 
b) The questions

The most exhaustive but contradictory advice on the journalistic interview comes in the prescription for question style. John Sawatsky says this is where his interest in the interview was cemented, during a course he taught at Carleton University many years ago. He had sent students out to do interviews and was amazed at the different results they brought back on their tapes:

And that's where my eyes really opened up, when I realized that a certain question would get a certain result. And if you changed the wording of a question, you'd get a different result. (2010)

Although Sawatsky has gone on to study the interview in the bigger context of communication (and, as previously mentioned, input and output, with questions being just one component), his advice on question style is what most people know about him. The following is a combination of the most common and accepted advice on question types, drawn from the many journalism guides, as well as from Sawatsky's basic rules:

\section{i) One question at a time and keep it simple}

This is consistent with one of Sawatsky's deadly sins: Don't ask double-barreled questions. Sawatsky says interviewers have to make a demand during a question, as opposed to simply making a statement and leaving it up to the interviewee to respond in whatever way they choose. By asking one single, and simple, question, the interviewer is in control of the content of the interview. The literature reflects a commitment by most interview instructors to ask questions that do not require supplementary explanations. Based on the literature, this is a fundamental rule for good interviewing.

ii) Ask open-ended questions (almost always) 
Asking open-ended questions is the most famous of Sawatsky's teachings, although it is also the cardinal rule of the majority of interview guides, including the National Public Radio guide (NPR):

Avoid questions that can be answered with a simple yes or no. Instead of, "Are you a doctor?" ask, "Tell me how you became a doctor." (npr.org)

This idea is repeated in various forms, always focusing on some version of asking an interviewee why and how they did something instead of confirming that they did it. While most agree that open-ended questions lead to more substantive answers (McLaughlin, Adams, Sawatsky, Nalder, Scanlon), the literature is not unanimous. For example, Sally Adams points out cases in which closed questions (yes or no answers) are necessary, such as when the interviewee is evading the question, or when there are some basic facts that are needed for the record:

Closed questions are ideal for establishing essential statistics, names, job titles, locations, once the interview is under way. (39)

\section{iii) Avoid leading questions and statements (or don't)}

This is closely connected to the first point regarding one question at a time (in Sawatsky language: one demand at a time), but requires more clarification, as the texts don't agree on this point. Most texts and guides are against any line of questioning that may manipulate the interviewee's answer. Some authors, however, such as Sally Adams, are less definitive on disallowing leading questions or statements. Adams encourages a more case by case approach to interviewing. She does warn "as a matter of course the methodology should reject questions that are loaded, leading, biased or unreasonably confining" (18). She hints at the commonly assumed "angle" or "spin" of the story-a source of much derision and mistrust by the public_-as the reason journalists ask leading questions, which she says are... 
...unattractive and manipulative, not recommended, but regularly used by unfortunate journalists who have to return with quotes to fit a pre-set formula, slot into a known space or support a management opinion. (42)

In the shorter, more concise guides, statements are generally frowned upon in interviews. However, for those who study the subtleties of interviewing in more detail, a statement can be a very useful interview tool. Eric Nalder uses them to prompt an interviewee to offer up new information:

Sometimes making a statement is better than asking a question. Read from a document or repeat something someone said. A question might produce nothing more than a "yes, no or I don't know." A statement will provoke a comment. On one occasion I inadvertently repeated something that was inaccurate to a cop. In correcting me, he dragged out a report I wanted to see. (PBS.org)

\section{iv) Don't interrupt or participate too much during interviews (or do)}

Most interviewing texts strongly condemn any form of interruption during an interview, primarily because it's rude, but also because it suggests the interviewer is not listening. However, there are exceptions. Knowing that a journalistic interview is ultimately for public consumption, the public must understand it. The International Centre for Journalists condones interruptions that serve to clarify the topic. On a website hosted by the Canadian Association of Newspaper Editors, Paul McLaughlin updates highlights from his book in a feature called The Art of an Effective Interview. On this subject, he offers advice on how to interrupt (politely) and the importance of admitting you don't understand if that is the case.

If a person rambles on and time (or your patience) is running out, interrupt politely by saying something like, "I'm sorry to interrupt but because there's so much I want to ask you I wonder if I could direct my next question to..." or a variation on the theme. (cane.ca) 
The American interviewer, Ira Glass, host of This American Life on Public Radio International (PRI), presents "Ira Glass's Manifesto Parts One, Two and Three" on Transom.org. Although he doesn't encourage interrupting the guest, he does suggest an increased amount of interaction with interviewees, as he believes hearing the exchanges makes the interview more interesting to listeners.

Even today, if I had to give just one piece of advice to beginning reporters about the single fastest way they could improve their stories, it'd be to get themselves into the quotes. Asking tough questions. Cajoling the interviewee. Joking with the interviewee. Thinking out loud and chatting with the interviewee. (transom.org)

It must be acknowledged that this is one area in which the style and purpose of the interview would call for a situation-specific action. In a feature interview, there is room for social interaction: comments, laughter, and exchanges between the interviewer and the guest, for example. However, for interviews in which the atmosphere is not as friendly and in which the goal is more pointed, such as an investigative piece or documentary, the value of interruption or participation might be viewed differently. While some journalists, in relaxed situations, may treat an interview as a conversation, this is not the case for many, such as John Sawatsky:

Remember, an interview is not a conversation...in a conversation, you exchange information. In an interview, you gather information.

(qtd. in Stein and Paterno 36)

Sawatsky raises the issue of asking "tough" questions. It is of course widely acknowledged that in an investigative story, the journalist might be forced to interrupt, even repeatedly, or to push beyond the regular conventions of polite conversation to get an answer to a question. How to handle these situations, especially if a guest becomes put off or angered, is subject to much debate, and may simply come down to the 
individual personalities and topics involved. According to Sawatsky journalists are trained to appear "tough," a default mode that is inappropriate (qtd. in Paterno and Stein 37). Indeed, some narrative and literary journalists complain that their work is traditionally viewed as less important than what the "tougher" news journalists do. In the book Intimate Journalism: The Art and Craft of Reporting Everyday Life, Walt Harrington highlights the tension between feature and news reporting.

At every newspaper there simmers animosity between the "hard" and "soft" journalists-with the soft faction always holding less power. (xiii)

This is a debate that is ongoing and often a question of personal taste. That said, those who watch interviewers closely have tracked the journalists who elicit good answers and those who don't. John Sawatsky says there are more theatrics than substance in the work of many journalists, such as American network interviewer Mike Wallace and his toughguy image. Sawatsky says the approach is not effective because it doesn't result in answers.

Bluster and the appearance of confrontation provide fireworks on the television screen, but not accountability. Quite the opposite. There's a difference between sounding tough and being tough. Wallace's adversaries catch onto his act quickly, and merely respond with stronger and more vehement denials, and use him to get their points across. (espn.go.com)

Some journalists believe being tough and even argumentative can enhance the interview content. Former CBC Radio and Television journalist Barbara Frum, whose reputation for doing high-quality interviews on As It Happens endures years after her death, is quoted in Don Gibb's interview guide, saying: "When guests aren't obliged to like you, or you them, you can't beat the liberty and possibility that opens up on all sides" (9).

Sawatsky points out that finding the balance between being a tough interviewer and pleasant-enough is not always easy: 
One of the tough parts of interviewing is learning to shed the social niceties-the notion that there are some questions it's not nice to ask. Sometimes you feel sorry for the interviewee, but there is a fine line between showing sympathy and showing empathy. There is no need to cry alongside the grieving person; there is, however, a need to try to convey to readers what has so affected that grieving person. (29)

The concept of including a certain amount of sensitivity, good manners and even compassion while interviewing is consistent with most of the journalism ethics guidelines. However, balancing rigorous questions with good manners is not always easy, and there appears to be no clear method for measuring the success of such an endeavor.

v) Follow-up, amplification or clarification questions

All the guides on journalistic interviewing recommend some version of a followup question. The purpose could be to provide clarification to an imprecise response. It could also be to obtain some kind of specific information, when the answer was vague. The clarification question can also serve to follow-up on something someone said earlier. Every guide has a different moniker for these questions. Sally Adams refers to them as "amplification questions."

Amplification questions are a sub-category of open questions used to elicit detailed extra information. The task here is to get the interviewee to give specific examples-the valuable 'for instances' that are the hooks of communication. (40)

A recent example of excellent use of an amplification question is when CBS News anchor Katie Couric asked Republican Vice-Presidential candidate Sarah Palin to give examples of cases in which her running mate, John McCain, had called for more oversight on Wall Street in the past. Palin deflected the answer three times, when Couric finally said this: 
Couric: I'm just going to ask you one more time - not to belabor the point. Specific examples in his 26 years of pushing for more regulation. Palin: I'll try to find you some and I'll bring them to you. (cbsnews.com)

Different interview guides have different names for the same question style. For example, Joe Scanlon introduces the "concept of building; building on what the interviewee has just said to get towards the topic you want to ask about" (8). Sally Adams distinguishes between "amplification" and "clarification," describing the latter as the question that ensures you (the interviewer) "realize how important it is to check you've understood what you've been told" (40).

vi) Don't be afraid of silence

Although many of us who came up through the broadcast world understand the words "dead air" as being synonymous with disaster (and indeed, Mark Feldstein describes this perception of silence in his article on journalism and oral history), this is absolutely not the case in the journalistic literature on interviewing. The CBC Radio guide says dead air is not a problem (20). "Silence can be golden" states Sawatsky in an article by Joe Scanlon (8). Adams recommends that in certain cases the interviewer pause for four seconds to see if the interviewee adds anything to their last answer (34). On the International Center for Journalists' website, silence is promoted as an effective tool to prompt your interviewee to talk:

When you start asking those provocative questions, the answers most likely will be short, useless or carefully worded. You may not get an answer at all. If this occurs, look your source in the eye and don't say a word. In most cases, your opponent will begin to feel uncomfortable and begin to share information again. (icfj.org)

vii) The mop up question and snowballing 
Most interview advice includes some version of a final question that allows the interviewee to raise anything they might consider relevant to the interview.

Before you leave... ask your source if there is anything that you might have forgotten to ask. Perhaps the interviewee is burning to tell you useful information, but you did not even think to ask that question. Don't leave without getting a contact number or e-mail address and a good time to call with follow-up questions. (icfj.org)

Many people call this the mop-up question (Desjardins 13). Both Scanlon and Sawatsky advise asking "do you have anything else to add?" (29). The CBC Radio Guide on making short documentaries suggests asking the question with the recorder running so that responses may be recorded from the start (21).

Many guides also recommend that journalists use their interviewee, not just in the interview, but as a source for other potential interviewees. This is known as "snowball" interviewing.

Always ask for other sources. Colleagues or friends of the interviewee may be more knowledgeable or willing and able to speak to you. (icfj.org)

This is a common suggestion in most texts on interviewing, especially in feature documentary and investigative pieces where more perspectives and a more diverse interview slate will help tell the full story.

\section{viii) Chronological order}

Not many texts discuss the order of questions in journalistic interviews but those who do refer to the subject generally recommend following a chronological time frame. Eric Nalder argues that at the input level, going through a story chronologically helps the journalist meet a number of key objectives:

You will understand the tale better, and you will spot gaps in the timetable. You'll organize the interview subject's memories this way, straightening out their messy mental file cabinet. (Nalder) 
Carleton University Journalism professor Dave Tait underscores the importance of chronology in broadcast news to ensure the listener understands the story:

...the closer the storytelling is to an orderly "unfolding," the more easily the audience will absorb it and the more accurately they'll remember it. That's been scientifically tested, as they say on commercials. People remember stories best when they're told in the classic stages we've talked about. Those who are told a story that's out of sequence will predictably make errors retelling the story at precisely the points where the story's natural sequence was broken. (6)

If one is preparing questions from which they will eventually craft a news story, it is worth noting a shift taking place in the newsroom landscape in how stories are structured. At the turn of the last century, the inverted pyramid became the news story model. According to Friend and Singer, it would be used for the next hundred years (5).

The inverted pyramid, which begins with the most important information and ends with the least important, supplanted earlier chronological and expository forms over a span of several decades. With its emphasis on the "facts" of who, what, when, where, why, and how, the inverted pyramid signaled a shift in the worldview of the society it chronicled. (6)

The authors draw a direct line between the inverted pyramid and the principle of objectivity - a detached, give-me-the-straight-goods kind of approach to journalism. In The Canadian Reporter, the authors trace the rise, then fall, now rise again (because of increased demand for short news flashes 24 hours a day) of the inverted pyramid style. In many ways, it serves both audience and journalists: the audience gets important information off the top and can choose to stop listening, watching or reading when they have sufficient detail; the journalist, editor or producer can easily cut the piece to size if the important information is always at the top end (136). The authors suggest it works best for short, newsy stories.

There are, however, several disadvantages to the structure-the big one being that it is almost impossible to sustain the structure beyond a half- 
dozen paragraphs or so. The pyramid is not built for handling a chronology or for relating a sequence of events. It is unable to sustain a story that has complex ideas, concepts or themes, or multiple sources. (137)

Just as objectivity has come under scrutiny from modern-day journalists, so have the structural restraints of the inverted pyramid style. Friend and Singer point to both the resurgence of literary and narrative journalism as well as the emergence of the public journalism movement as forces that are changing the way journalists are telling stories (11-12).

\section{ix) Be observant and include details}

All the texts on feature and investigative journalism emphasize the importance of including diverse and contiguous details in the story. This could include almost anything: facial expressions or body language, objects near the interviewee, weather descriptions and other physical observations from the environment. Sally Adams says these details often come easily to the naturally inquisitive journalist:

Good interviewers are long-time people watchers and eavesdroppers. They look, they listen. They ask themselves: what does that gesture mean; why did that person look down then; why such a dramatic response to such a casual question; are those two squaring up for a row; why doesn't she interrupt him; who's the dominant person in that group; what do those three have in common? (32-33)

The value of these details is partly narrative, as they help to make the story more interesting, but it is also widely understood that the simple act of looking around can serve as a tool to develop new sources of inquiry. This is a tip from the website of the International Center for Journalists:

Be observant! Observe details of the place and of your interviewing partner; this can add color to your story. If you are interviewing people in their home or office, be sure to get a good look around and note what you see. For example, they may have some old photos that show them in a 
more personal light. You may start an interview with assumptions about a person and leave with a completely different impression. However, this may be exactly what your source intended. Perception is a tricky business! (icfj.org)

Many seasoned journalists tie the powers of observation with the willingness to get out of the office and into the field. For most journalists the idea of getting out from behind a desk is stating the obvious. However, it is worth noting that increased fiscal restraints in newsrooms limit the resources available to spend time in the community and put pressure on reporters to churn out material from their desks.

\subsubsection{After the interview}

a) Telling the story

If journalism's first loyalty is to its citizens, then producing work that is "significant, interesting and relevant" is a major part of the interview process (Adam 13). This public element seems obvious, but is sometimes overlooked. If an interview is to be used in any capacity beyond live-to-air (heard or seen as the interview is taking place) the journalist needs to carefully consider how it is used. According to the CBC Radio Style Guide:

It's obviously a waste of time to broadcast programs or stories unless people listen to them and understand them. We are the storytellers. When we fail to communicate clearly, we fail as journalists and as broadcasters. (35)

The responsibility of the journalist to the reader, the listener, the television viewer, or the "customer" as some call it, cannot be underestimated. The CBC Radio guide tells us:

We must always keep the listener in mind. We must tell our stories so she can understand them on her terms, relate to them, identify with them, in some way. (40)

While this thesis does not focus on the end product of an oral history or journalism interview, acknowledging that there is a product, and to whom that product is aimed, is 
important. Kovach and Rosenstiel state that journalists, writing or broadcasting to a public audience, must present their work in a manner that their audience will understand. Indeed, for them, the seventh element of journalism is "It must strive to make the significant interesting and relevant" (148). This is a key point in the examination of how journalists conduct interviews as well as how the collected material is used in publication or broadcast form.

Journalism is storytelling with a purpose. That purpose is to provide people with information they need to understand the world. The first challenge is finding the information that people need to live their lives. The second is to make it meaningful, relevant and engaging. (149)

It is clear the effectiveness of the editing, writing and publishing or airing process is important. This thesis does not look at the content of the end products, but focuses on the issues that shape the process as they relate to the treatment of interviews.

Journalists are frequently accused of presenting information "out of context," a common accusation that tarnishes the reputation of the profession as a whole. It is understood that live-to-air interviews stand alone and air without alterations. For obvious reasons, the following section refers to the interviews that will be used to assemble longer-form news, feature or investigative stories or documentaries and thus need further thought and attention. The assembly process of this kind of story is as important as the interview itself. Interviews that will be used as part of a bigger piece, perhaps edited and combined with other material to make up the final product to be published or broadcast, require more detailed consideration when putting them together. It is not uncommon to hear people complain about journalists' "angles" and how they pick and choose segments from interviews just to prove their story's point, without thought or concern to the individuals in the story. The literature reflects awareness of this reputation, and mostly 
appeals to journalists to understand the implications of their work. Sally Adams places the responsibility on the journalist:

As a result of what you write, based on what you learn during an interview, people may lose their jobs, companies may close, lives may be ruined. (6)

Keeping this duty in mind, most journalistic guides return to basic concepts in advising how to go forward. Paterno and Stein state "making your story fair and accurate is your most important objective" (33). Following from this principle, there are a number of recurring points in the literature.

\section{i) Review notes immediately}

The International Center for Journalists sums up what is universally accepted as good journalistic practice:

Review your notes right after the interview! Don't wait until the end of the day or later in the week to review your notes. Go over them right away, while everything is fresh in your mind, filling in your shorthand and elaborating on your observations. Skip that date for drinks with your office pals until after you have reviewed and organized your notes. (icfj.org)

\section{ii) Choose a focus or an angle}

The idea of a "focus" has long been the foundation of training for CBC radio journalists, although it is advised to have it set up before doing the interview. CBC encourages reporters to write a focus statement defining what the story is about. It reflects the idea that the journalist should tell one story at a time.

It helps the storyteller decide what to include and what to leave out. It helps the storyteller decide the appropriate language to use... (42). 
Paterno, Stein and Burnett use the term "focus" interchangeably with "angle." They, like the $\mathrm{CBC}$, encourage journalists to solidify the angle/focus before beginning the writing process:

At some point in your reporting, you should have fixed on an angle, approach or theme, and discussed it with your editor. Does your editor agree with your angle? If not, better to argue now. (49)

iii) Choose a structure

Advice regarding the style and structure of a story clearly depends on the medium, length of story and nature of program or publication for which the journalist is reporting. As we have seen, the most famous structure for news stories in journalism is the inverted pyramid (Stein, Paterno and Burnett 50-51). Whether a story is constructed in chronological order, using first person reports, or in the case of an audio report as a traditional sound-script-clip style, it largely depends on the medium in which the journalism is being made public. What is certain is that the "how" part of constructing a story represents perhaps a very creative—and therefore individual—part of the process of what happens after a journalist completes an interview. The literature on this subject ranges from the obvious (don't invent quotes) to the absolutely subjective, such as writing style. In the book Telling True Stories, based on writers of non-fiction, Roy Peter Clark traces the history of embellishment in journalism from columnists and crime reporters of the past century to the blurred lines between journalism and infotainment today.

The principles Do not add and Do not deceive should apply to all nonfiction all the time, not just to the text of newspaper stories. (165)

This has been the subject of some debate in broadcasting, where editing can purposefully leave impressions that are not quite accurate reflections of reality. For example, if a 
reporter records sounds of the Rideau Canal, then goes to an indoor location and interviews a guest about skating, and then edits the guest's voice on top of the sound from the Rideau Canal to make it sound as though they were out of doors, is that wrong? It's a practice that is done frequently in radio journalism. According to National Public Radio's guide, stretching the truth is wrong, but the author acknowledges the murky waters:

For better or for worse, public radio has relatively few hard rules about how to mix and edit audio; these and most other tricky cases are judgment calls...In any case, the same ethical principles apply to producers as to reporters: Be fair and responsible, never mislead or deceive people-and always aim for the truth. (247)

v) Writing style and editing words

On the subject of writing style, there is little room in mainstream news organizations for variation from the company's accepted writing or broadcast style (such as $\mathrm{CP}, \mathrm{BN}$ or otherwise). In features and longer-length reports though, and especially in the current technological environment, journalists appear to have more latitude in how they present their story.

As mentioned above, the reputation of journalists has often suffered by the way in which quotes are used in stories. Although feature and investigative journalism have the luxury of more time and space, there is still a challenge in selecting how and when to use interviewee's words. The editing process, whether for print or broadcast, remains a very unscientific exercise for which there is not unanimous advice. Most broadcasters, for example, automatically edit out superfluous words from an interviewee's story. They may even tighten up places where the interviewee took a deep breath or paused to think, especially if their report has a time limit. A print reporter may transcribe the words of an 
interviewee, but will not indicate pauses, and likely will take out repetitive words, or words that seem to give no added meaning to the text. Or, they can leave those repetitive words in. These actions can seriously influence the public's perception of an interviewee. For example, in her bid to become a U.S. Senator, Democrat Caroline Kennedy undertook a media blitz in which she was lambasted for her verbal "tics." In an article in the New York Daily News, Kennedy is said to have repeated the phrase "you know" more than 200 times in 30 minutes. Here's a sample:

When The News asked if President Bush's tax cuts on the wealthy should be repealed immediately, Kennedy replied: "Well, you know, that's something, obviously, that, you know, in principle and in the campaign, you know, I think that, um, the tax cuts, you know, were expiring and needed to be repealed."

The Ottawa Citizen reprinted an article in which the author comments on the challenges faced by public figures in a digital multi-media era. "Just a few years ago, Ms. Kennedy's interviews would have appeared only in newspapers, with her verbal tic edited out," writes Tim Reid. This underscores a major dilemma facing audio and video journalists who have to make the call about whether or not to "tidy up" an interviewee's answers. Narrative journalist Debra Dickerson describes why she doesn't change words, especially when she was writing her own memoirs:

My family uses phrases like "Boy, you better git gone" and "I mighta would." If you render things the way people actually say them, you are accused of condescension. But I believe it's condescending only if you think there's something wrong with the way people talk. My mother speaks the way she was educated to speak; I wanted to render her words accurately. (186)

Sally Adams points to a study that shows sixty percent of American journalists believe it's acceptable to change words or fix grammar to make the text more understandable. However, she suggests this is the wrong approach: 
Take, for example, a desert hermit whose speech is larded with colourful phrases, irreverent observations, and faulty grammar. You would lose the best part of the story by making him sound like an English teacher. (149)

b) Fact-checking and showing the story

The rules on fact-checking are clear: If a journalist is uncertain about an element of the story, he or she should confirm it before publication. Sharing the story with one's interviewees seems to be another matter and divides somewhat into two general camps: news (and in this case, investigative included) versus features. Don Gibb, former journalist and Ryerson professor, has written a number of guides on journalism, including a 36-page booklet entitled How to get the Most from your Interview. As a news person, Don Gibb states "the rules on seeing the story before publication are simple: No, nay, never! You are asking for trouble, not only from your newsroom bosses but also the interview subject" (17). Adams generally agrees with this approach, discouraging reporters from going back to a source to confirm a quote (179). The real world may be quite different, though, and in the absence of a meaningful monitoring mechanism, this rule is commonly broken. A quick search on the Internet reveals the views of a journalist presented as a mentor on the website called The Canadian Journalism Project. ${ }^{17}$ In a feature called "Ask a Mentor" a young journalist posts an inquiry about showing quotes to sources prior to publication. The journalist who answers is Lindsay Kines, a reporter at the Victoria Times Colonist. In an articulate and thoughtful response, she states that she was taught to never show stories to sources due to journalistic integrity, but that she now "comes down firmly in the middle" on this matter:

\footnotetext{
${ }^{17}$ http://www.j-source.ca/english_new/detail.php?id=5437
} 
Despite those concerns, I've found over the years that it's beneficial, in some instances, to read-back quotes and, occasionally, sections of stories to sources in order to ensure their accuracy. This is particularly useful when writing about science, medicine, statistics or other complicated issues. It's probably best to check with your editor to see whether this practice is permitted at your organization, but many media companies have ethics policies that permit selected fact-checking. (j-source.ca)

In the case of feature or narrative style journalism the rules are much more relaxed and appear to conflict with the news approach. In Telling True Stories, Walt Harrington highlights the special circumstances narrative journalists face:

Journalists can always read back quotes and other attributed information to sources. In narrative stories, almost anything can be a fact that needs checking-including such statements as "She enjoyed the warm sun on her face." (172)

Harrington's views reflect a common concern for many journalists, in particular for those who do feature journalism. This can include investigative journalists who focus on ordinary people-people who are likely inexperienced with and unaccustomed to the mechanisms of the media. Journalists who interview victims of crimes or survivors of trauma usually display some empathy toward the interviewee. The struggle to maintain a balance between the natural human connection they make with their subjects and the journalistic commitment they have to their employer and audience can be disquieting.

Walt Harrington articulates the concern:

Narrative journalism brings up special ethical considerations. We spend so much time with our subjects, and we are almost never prosecutorial in our interviewing of them. We want to be genuinely human to our subjects, because we want them to become genuinely human to us. Yet, in the end, we must write our story-one that is not the subjects' version of his or her life but our version. Narrative writers must walk a delicate line to be certain that we are ethically honest with both subject and reader. (172)

The outcome of this discussion appears to be that most journalists make their decision based on a combination of an understanding of the above rules and a certain amount of 
common sense. They assess the situation and they evaluate the relationship with their source, as well as whether or not the journalist's independence could be compromised. From those considerations, they are better able to make a decision.

c) Archiving

If one were to depend on the literature to gauge the relevance of archiving to the journalistic interview process, it would be fair to say that archiving is not very important. As has been the case with other topics, the more in-depth the text or guide on interviewing the more likely attention is given to post-interview collections. Up until recently, the only archived material in most media outlets would have been the final version of published material. In other words, the original full interviews would disappear, along with old tapes, CDs and notepads into bottom drawers, boxes or garbage cans. In the past, one could purchase a copy of a print or broadcast story from a media monitoring organization. Interviews in full have never been available for perusal by the public until the last few years, when some media organizations began posting them voluntarily on their websites as a sort of added dot-com bonus. For example, both CBC Radio and Television make a few full-length interviews available on CBC.ca, primarily in a section of the website entitled "In-depth." ${ }^{18}$ Several shows also offer listeners the option of listening to "uncut" interviews on the Internet. It is not made clear, however, to what extent, if at all, these interviews have been edited. CBC also has an online archive that contains previously-aired interviews from the past 60 years. ${ }^{19}$ This trend is likely more due to technological developments (digital technology) and less to philosophical views.

\footnotetext{
${ }^{18}$ To find out more about CBC's "In Depth" series, go to: http://www.cbc.ca/news/background/index.html

${ }^{19}$ The CBC archives are at: http://archives.cbc.cal
} 
Conclusion

This chapter demonstrates clearly that while there are many approved techniques advised by teachers and practitioners of the interviewing process, there is no single accepted methodology for journalistic interviewing. It provides a solid outline, based on a variety of texts, guides and websites from the past two decades, of the principal themes raised by practitioners and instructors of the journalistic interview. G. Stuart Adam sums up the state of the journalistic interview when he says:

Sometimes interviews are conducted carelessly; sometimes they are conducted with a dedication to truth that would surprise the best historians or lawyers. And sometimes they are incorporated into systems of factgathering and discovery that would please the best empirical social scientists. (30-31)

However, there appears to be very little, if any, evidence of material available to journalists that approaches the journalistic interview in a scientific manner, making any assessment or measurement of what constitutes successful interviewing difficult. While Sawatsky presents his approach to the interview as a rational process that can be affected by analysis of tapes and transcripts, he has yet to conduct an academic study on the subject or to publish any past findings, even in a text for journalists. To his knowledge, no one is doing such a study. ${ }^{20}$ Also, many of the best interviewers in journalism don't appear to follow many of the rules of the interview as outlined above. For example, a recent interview by prominent, and highly-respected, journalist Michael Enright on $\mathrm{CBC}$ Radio's The Sunday Edition exemplifies this observation. Enright interviews Stephen

\footnotetext{
${ }^{20}$ Personal communication, Feb 6, 2010. Also on this topic, Mary McGuire and Dave Tait use a teaching tool at Carleton University that demonstrates an interviewer doing the same interview twice; once in an aggressive manner, full of interruptions and goading; then in a more pleasant, calm manner, with no leading questions or inflammatory statements. The latter clearly results in a better interview. However, to my knowledge, there has never been an empirical study with a larger sample group.
} 
Hess, a senior fellow emeritus at the Brookings Institute in Washington and a former staffer of the White House, about the events surrounding the Tuscon, Arizona shootings. In the 19-minute interview, Enright asks 10 questions. The first, second, and third questions are closed (requiring a yes or no answer). The fourth contains no question; it is over-loaded (by the above definition) and it ends with a statement. The fifth is a closed question. The sixth question is closed and over-loaded. The seventh and eighth questions are both statements, rather than questions. The ninth begins with a question but ends with a statement. The tenth is a straightforward closed question. ${ }^{21}$ The interview itself is enlightening, informative and well-presented. Granted, the interviewee is a professional, and delivers lengthy, substantive answers. The interview fulfills the journalist's primary responsibility, that is to inform citizens; and it does so in an interesting and relevant manner (another goal of journalism). This, despite the fact that it clearly disregards the general interview guidelines, not just as laid out by Sawatsky, but as assumed by the vast majority of the literature on journalism interviewing. The general deficiency of evidence that proves what works and what doesn't in the interview process, combined with the lack of a formal monitoring mechanism of the principles and codes of journalism, limits solid evaluation of the interview process and must be taken into account in the quest for better interviews and any assessment of applications from other fields.

As a final note, this chapter confirms some of the findings of a paper entitled $A$ Very Mixed Bag: What Introductory Reporting Texts say about Interviewing by

\footnotetext{
${ }^{21}$ This interview is available at cbc.ca/thesundayedition on 16 Jan. 2011.
} 
journalism professors Joseph Scanlon and Paul Baylis. ${ }^{22}$ The authors surveyed the eight most commonly used reporting texts of the day (1992), comparing them with a similar study done 10 years earlier. In their conclusion, they highlight gaps in education on the fundamentals of interviewing $(2,14)$, major disagreements on approaches to interviewing $(2,15)$, conflicting advice, even within one text, on interview style $(5,7)$, and limited adherence to reliable research methods or sourcing in their positions on interviewing (2, $14,16)$. Only three of the eight books they reviewed provide students with a general bibliography (16). They also point out topics that were missed altogether, such as listening for internal reliability and corroboration, arguably fundamental elements of interviewing (14). While this study took place almost twenty years ago, it is somewhat surprising to discover that its findings are remarkably relevant today. The research for this thesis illustrates improvement at least on one point: the advent of online guides on interviewing has resulted in an enormous increase of web sites offering "how to" style advice on journalistic interviewing. These guides focus primarily on question types, offering many examples of ways in which questions may be used most effectively. However, the literature still seems to point to dissension about which question styles are most effective, the rules on editing interviewees' material as well as certain ethical issues. It also illustrates significant gaps in the interview guides and texts, such as a lack of research data that may enhance the interviewer's understanding of the interview process. Research on these topics does exist; however, it appears not to be represented in most of the interview guides and texts. In a bibliography on research and writing on interviewing,

\footnotetext{
${ }^{22}$ This paper was prepared for and presented at the annual meeting of the Association for Education in Journalism and Mass Communication in Montreal in August 1992. I haven't quoted it more extensively due to its age; however, many of its observations held true during this study. See Works Cited for paper details.
} 
Carleton University student Robert Desjardins concluded that in general journalists reject the notion of an academic methodology as applied to the interview:

They tend to take a "how-to" perspective on interviewing, but only in a very general, anecdotal way. They are rarely willing to deconstruct interviews word-by-word to illustrate particular principles in action. (v)

The research for this chapter supports the existing views that despite a commonly accepted set of codes and conventions, upon which journalists operate during the interview process, there is not universal agreement on them and there are vast differences in the interpretation and practice of these rules. ${ }^{23}$ John Sawatsky says this all adds up to making interviewing a difficult subject to teach:

My experience in journalism education, both in the academic and the workplace milieu, has led me to the conclusion that the teachers of journalism do not teach interviewing because they do not know what to teach. (15)

Sawatsky remains one of the most vocal critics about the lack of formal instruction devoted to interviewing in journalism schools and organizations. He highlights the fact that the journalistic interview has traditionally been approached as a kind of haphazard, talent-driven operation, instead of drawing on known techniques to raise the bar. Portraying the academic community's approach to journalism interviewing as "lackadaisical," Sawatsky has long called on scholars to "produce an approach to interviewing that makes sense and is theoretically based" (22).

This study clearly points to the fact that while there is much agreement among journalists on basic principles surrounding the journalistic interview, there are also many

\footnotetext{
${ }^{23}$ The research also revealed a number of textbooks and articles that were scientifically-based, such as The News Interview: Journalists and Public Figures on the Air, by Clayman and Heritage, which consists of conversational analysis. This is defined in the book as "an approach to the study of human interaction that involves, at its core, the direct observation of naturally occurring interaction as captured on audio and video recordings" (18). Such studies are generally not quoted in journalistic interview guides
} 
assumptions about the process about which there is no consensus. The research in this chapter shows the vast and varied nature of the literature about the journalistic interview, revealing not just the wide-ranging styles but also the assortment of views on how the interview should best be conducted. Specifically, it finds that the journalism guides focus primarily on "how to" elements of the interview process, such as the importance of listening, specific question types and technology issues. The more in-depth guides offer much more consideration about interviewing, including interpersonal relationships and ethical matters, although to say there is consensus on many of the themes raised would be inaccurate. It is with this knowledge and with an open mind that the focus moves to the next chapter, in order to explore what journalists might glean from social scientists and the oral history interview process. 


\section{Chapter Three: Oral History and the Life Experience Interview}

The interview is the foundation of the academic approach to oral history. No matter which scholarly definition of oral history one accepts, it focuses on the recording of an individual's personal experience as told to someone else. This thesis aims to examine and assess some of the knowledge about the oral history interview process, in order to inform the journalistic interview. Although its origins lie thousands of years in the past and its methodology grew simultaneously in different disciplines (including journalism) on various continents, the modern version of academic oral history study was developed primarily as a research tool in the field of history. ${ }^{24}$ But the oral or life history interview has also been widely used by social scientists, including psychologists, anthropologists, sociologists and others. Given its widespread functions, from the colloquial to the academic, this chapter must begin with definitions. The inter-connected fields and terms-including oral history, oral tradition, life review, life experience, even life history—are used so interchangeably, that without a careful delineation of words and meanings the argument that journalists can learn from oral history interviewing methodology could not be proven.

In order to narrow the potentially infinite scope of this chapter, the research is based primarily on a number of texts by prominent social scientists and oral historians. At the top of that list is the pioneer of oral history books, Voice of the Past, by British sociologist and historian Paul Thompson. American historian Valerie Yow's Recording Oral History: A guide for the Humanities and Social Sciences, also figures prominently.

\footnotetext{
${ }^{24}$ For the historiography of oral history, see chapter one of History of Oral History: Foundations and Methodology edited by Charlton, Myers and Sharpless.
} 
Donald A. Ritchie, historian of the U.S. Senate, has written two significant books on oral history: the first, Doing Oral History: A practical guide, and the brand-new Oxford Handbook of Oral History both reflect the ever-increasing interest in oral history methodology in a variety of fields. Also offering a broader perspective from different people and disciplines is The Oral History Reader, edited by Robert Perks and Alistair Thomson. For general knowledge about oral history and life experience interviewing there are a multitude of other books, papers, websites and journals available. Finally, this thesis draws extensively from the writers in the book Qualitative Research in Journalism: Taking it to the Streets, edited by Sharon Hartin Iorio, as some of these authors demonstrate specifically the potential applications of the life experience interview to the practice of journalism.

\subsection{Definitions: Oral tradition, oral history and the life experience interview}

The extensive modern use of the term 'oral history' is new, like the tape recorder; and it has radical implications for the future. But this does not mean that it has no past. In fact, oral history is as old as history itself. It was the first kind of history. (Thompson 25)

Although dated in technological terms, these words by Paul Thompson illustrate both the maturity of oral history as a practice as well as the confusion that surrounds the contemporary use of the term. Oral tradition, or what Thompson intimates used to be called oral history, began when human beings started communicating through voice and language, and has come to describe the kind of knowledge handed down through generations, especially when referring to "pre-literate societies" (Thompson 26; Wilson 8). Whether speaking of the Chinese, the Greeks, or the African griots, people knew that to survive, they needed knowledge; something that comes from the experience of 
previous generations (Sharpless 9). This description of the oral tradition offers a clear definition:

The human life eventually ends; therefore humans cannot discover everything by themselves. People are taught many lessons through stories passed down from their ancestors. Culture is generally transmitted from generation to generation through stories, myths, and reenactments or rituals and ceremonies. Oral tradition is the spoken relation and preservation, from one generation to the next, of a people's cultural history and ancestry. (allsands.com)

In present-day terms, oral tradition is the concept or practice of passing down stories, songs, myths, rituals and other cultural values through the generations. So what exactly is oral history? Authors and qualitative researchers, Hesse-Biber and Leavy, place oral history as a sub-category of oral tradition. ${ }^{25}$ In everyday language and usage, oral history may still refer simply to stories from the past, in any and all forms. The Canadian Oral History Association (COHA) defines oral history as "recorded interviews with individuals about the past, or first-person reminiscences." This thesis employs historian Valerie Yow's very similar definition: "Oral history is the recording of personal testimony delivered in oral form" (3). Reviewing Yow's full definition (from chapter one) is crucial to understanding potential applications to journalism:

But what is the oral history? Is it the taped memoir? Is it the type-written transcript? Is it the research method that involves in-depth interviewing? The term refers to all three. (3)

The scope of Yow's definition is imperative in accepting that a study of oral history methodology - that is, the theory and the practice—does not limit itself to a single interview or the transcript alone, rather it encompasses the entire process of using the

\footnotetext{
${ }^{25}$ Journalism might also be considered a sub-category of oral tradition, leading to comparisons framed in terms such as Mark Feldstein's "Kissing Cousins" reference.
} 
interview as a research method. Donald A. Ritchie, who includes memory and the search

for meaning as a central component of his definition of oral history, puts it this way:

An interview becomes an oral history only when it has been recorded, processed in some way, made available in an archive (...)By preserving the tapes and transcripts of their interviews, oral historians seek to leave as complete, candid, and reliable a record as possible. (24)

The point that an oral history is neither just the interview nor the final project, but rather is both, must be emphasized. As previously mentioned, the Oral History Association (OHA) defines oral history as a method and an end product. It also identifies the general kind of interview with which it is concerned:

Oral history is distinguished from other forms of interviews by its content and extent. Oral history interviews seek an in-depth account of personal experience and reflections, with sufficient time allowed for the narrators to give their story the fullness they desire. The content of oral history interviews is grounded in reflections on the past as opposed to commentary on purely contemporary events. (oralhistory.org)

Naturally, for historians, oral history projects are those that by and large tackle matters of historical significance. However, two points must be clarified: First, that oral history interviews are not just the purview of historians. Many other fields use oral history methodology to collect evidence. ${ }^{26}$ Donald A. Ritchie observes that...

...oral history conferences are notable for the variety of participants, among them radio and video documentary makers, museum curators, archivists, journalists, gerontologists, anthropologists and folklorists. Regardless of their diverse interests, they share many common methods of interviewing. (26)

The second important point is that the kind of interviews used in the oral history process (whether in history projects or otherwise) go by many different names. Valerie Yow uses the term interchangeably with others "such as in-depth interview, recorded memoir, life

\footnotetext{
${ }^{26}$ For example, for a broad description of the purposes for which oral history interviews are used, see the Canadian Oral History Association.
} 
history, life narrative, taped memories, life review." They all suggest there is an interviewer who "frames the topics and inspires the narrator to begin the act of remembering, jogs memory and records and presents the narrator's words" (4). This practice has been embraced in the humanities and social science fields far beyond departments of history. Psychology, sociology and anthropology, for example, all use oral or life history methodology as a research tool. To clarify even further, many practitioners of oral history use the term interchangeably with life history. Others differentiate between the two terms, primarily at the content level, as is the case of former journalist Renita Coleman, now professor of journalism at the University of Texas:

Oral histories are often organized around an event or a subject-the history of a certain ethnic group or community, for example. Life histories are defined somewhat differently from oral histories in that they are autobiographical, recounting people's entire lives...otherwise the procedures of life and oral history are the same. Both methods are particularly focused on the personal experiences and inner feelings of the people involved, not just external facts. (Coleman 94)

The distinction helps to clarify the language, and as such, this thesis follows Yow's lead and uses the term oral history as the methodology referring to the entire interview process. Therefore this thesis generally employs the terms life experience, oral history or in-depth interview interchangeably. ${ }^{27}$ The purpose of this study is not to examine content of interviews; rather it seeks lessons from the theory and method of oral history interviewing. The methodology for those three types of interviews is virtually identical.

Donald A. Ritchie is past president of the Oral History Association (OHA), the principal resource in the U.S. for outlining guidelines and professional standards for oral historians. He writes:

\footnotetext{
${ }^{27}$ For more definitions on oral history, life review and life history interviews, see Ritchie (40).
} 
There are interviewing skills to be learned. There are right and wrong ways to conduct an oral history. There are great differences between useable oral history and useless ones, and there are far too many of the latter. (25)

The OHA and its accompanying website represent the culmination of sixty years of serious consideration, debate, and, ultimately, some consensus about the academic approach to oral history and the ethics and principles upon which the field should be based. Ever since journalist turned historian Allan Nevins launched the "Oral history project" at Columbia University in 1948, oral history interviewing has been at the centre of a lively and dynamic discussion across the disciplines. Every aspect of the process has been studied, from reliability of evidence to interviewing techniques. This chapter focuses on that deep and profound discourse with a view to applying lessons to the journalistic interview. There are a number of key themes that emerge from the discourse. In order to illustrate associations wherever relevant and possible, the material is divided into three main categories that mirror those of the previous chapter. While they are not exact in every detail, they echo the themes in a way that will draw parallels between the oral history methodology and the journalistic interview process where appropriate. The categories are: 1) Background knowledge, 2) The actual interview, and 3) After the interview. We begin with an understanding of the interview in the context of qualitative research.

\subsection{Qualitative research and the reliability of oral testimony}

The reliability of oral evidence is at the core of this debate. All good investigators use evidence to verify what they're looking for, whether they are scientists, lawyers, police, journalists, medical doctors or others. Indeed, Canada's Supreme Court issued a landmark decision in 1997 regarding the admissibility of oral histories of aboriginal 
societies in court as these are often the only records available to the search for truth. ${ }^{28}$ In the academic world researchers have methods for getting answers to their inquiries, or tools used for gathering data, called research methods. Those methods must be seen as reliable, in order for the results to be considered valid and authentic. In quantitative research, scientists generally depend on measurements and numbers to seek answers to questions. The qualitative researcher, on the other hand, is concerned...

...with text and words as opposed to numbers. Thus, qualitative researchers build and analyze themes embedded within transcripts they have helped create...(this) is a way qualitative researchers try to extract meaning from their data. (Hesse-Biber and Leavy 8)

The interview is one such research method. Hesse-Biber and Leavy identify a diverse range of interview styles used by qualitative researchers in the social sciences and humanities including: "ethnography, in-depth interviewing, oral history, auto ethnography, focus group interviewing, case study, discourse analysis, and content analysis" (19). Focus groups involve interviewing in which the exact same question is asked to many people. In ethnographic studies, the researcher is embedded with the interviewees. Both civic mapping and polling include interviewing large samples (many people) during their data collection (Iorio). As already pointed out, this study is concerned with the qualitative research interview known variously as the in-depth, oral history or life experience interview. These interviews are used to create oral history projects or, in fields other than history, they contribute to a larger sample group as data

\footnotetext{
${ }^{28}$ Canada's Supreme Court issued a significant landmark ruling that trial courts have to consider oral testimony in Aboriginal land claims cases where documents may not exist. The decision regarding Delgamuukw v. British Columbia says: “... aboriginal perspective on their practices, customs and traditions and on their relationship with the land, are given due weight by the courts. In practical terms, this requires the courts to come to terms with the oral histories of aboriginal societies, which, for many aboriginal nations, are the only record of their past (and which) play a crucial role in the litigation of aboriginal rights (par. 84)." This court decision highlights a growing acceptance of oral evidence as reliable and valid data in the Canadian justice system and the wider society.
} 
for the research project. These projects have a clear purpose, or research question, and the interviews with a number of individuals are used in a collection that contributes to the final product. Hesse-Biber and Leavy warn, however, that traditionally, and to some extent still today, the quantitative approach carries more academic weight:

Quantitative instruments of measurement are simply assumed to be rigorous, and accordingly, data resulting from their use takes on the presumption of validity. Open-ended and thematic qualitative methods of interview, observation, and content analysis are dichotomously assumed to lack validity in their pursuit of depth and authenticity. (19)

Without delving too deep into historiography, there has always been a struggle between the value of quantitative research (considered to be the more empirically sound) and qualitative research as evidence for scientific study. Paul Thompson traces the use of oral evidence in historical research, in particular to the favouritism given to statistical approaches right up until mid-1900s. Both Thompson and Yow note that while many researchers now recognize the value of qualitative studies, doubt still lingers in some parts (Thompson 79). Valerie Yow states:

Many sociologists and other social scientists today still hold the view that quantitative research is the only way to be certain about evidence. They have grave reservations about qualitative research because they view it as uncontrolled and lacking in the rigorous procedures followed by quantitative researchers. They are uncomfortable with the subjectivity inherent in qualitative research and strive to get rid of it as much as possible.

In qualitative research methods, where researchers frequently go into the field to gather data, interpretation is a fundamental part of the process. According to Sharon Hartin Iorio, there is a basic link between journalists and academics in this type of evidence collection.

The emphasis on observation and in-depth interviewing to gather information, the skeptic's approach to interpretation, and the importance 
of perspective in explanation-all are principal foundations of traditional journalism as well as qualitative methods. Common to both the journalist and the qualitative researcher is the concern with current phenomena and the action of individuals. (7)

The discourse about oral history also includes the identification of potential weaknesses of oral evidence. The following list is a paraphrased version of possible flaws identified by Valerie Yow:

- Retrospective evidence (or memory, which has a whole area of study unto itself and will be reviewed in more detail) as it contains obvious limitations, especially in cases where someone is extremely old or sick.

- The reliability of the interviewee must always be considered.

- The size and scope of the sample group is a primary consideration of all social science research; a lack of contextual perspective, in other words the testimony often gives no understanding of the bigger socio-economic picture (17).

- The subjectivity of the selection of interviewees (again connected to the sample group) as it is almost always at the discretion of the interviewer (18).

These are all aspects of oral evidence that should be considered in conducting an oral history interview. These concerns have prompted oral history practitioners to develop safeguards, including questions, to test the reliability of interviewees, as in this sample list from Yow:

- How close was this witness to the event itself?

- How informed is this witness about the event observed?

- What prior assumptions did the witness bring to the observation?

- What kind of details has been omitted? (19)

Another safeguard against academically weak data is the choice of whom to interviewgender, status, numbers-or "sampling" as it is known in social research. Regardless of 
the discipline using oral history interviewing, Renita Coleman says this is a key factor in the methodology:

...designers of an oral history project should also be concerned with representativeness-that is, making sure that the people interviewed represent the entire range of roles or social strata in the group being studied. A project about the history of an occupation-journalism, for instance-should include people from executive editor to news clerks. (96)

Valerie Yow considers this broad and inclusive approach to research another benefit of the oral history interview as a valid alternative to quantitative research methods. She points out that interviews can reveal all kinds of information that is either excluded from, or wrong in what many call factual documents, such as the census process, church records, diaries, and other "historical" documents that many trust as "truth." This unreliability of written documents is reflected in something Thompson calls a social purpose - something he believes is innate to all documents.

Social statistics, in short, no more represent absolute facts than newspaper reports, private letters, or published biographies. Like recorded interview material, they all represent, either from individual standpoints or aggregated, the social perception of facts; and are all in addition subject to social pressures from the context in which they are obtained. With these forms of evidence, what we receive is social meaning, and it is this which must be evaluated. (124)

Yow describes the in-depth or oral history interview as a way to open up and question the myriad issues that need further clarification.

The in-depth interview enables the researcher to give the subject leeway to answer as he or she chooses, to attribute meanings to the experiences under discussion, and to interject topics. In this way, new hypotheses may be generated... Whatever the particular approach or discipline, the recorded in-depth interview can offer answers to questions that no other methodology can provide. (9) 
Yow points to lessons learned in fields such as sociology and anthropology where academics seek to understand how people interact within communities, and find answers only through recorded interviews, underscoring the kind of valuable details that would not be included in "official" records of the day. These include women's roles in society, children's lives, marriages (in particular underage marriages), accidental deaths, illnesses and many other aspects never officially recorded. Thompson points to the absence of this kind of evidence as having been a gaping hole in history books before the middle of the last century, when oral history took off.

Without its evidence, the historian can discover very little indeed about either the ordinary family's contacts with neighbors and kin, or its internal relationships. The roles of husband and wife, the upbringing of girls and boys, emotional and material conflicts and dependence, the struggle of youth for independence, courtship, sexual behavior within and outside marriage, contraception and abortion-all these were effectively secret areas. (8)

The idea that unexpected, unanticipated, and perhaps most important, marginalized information is revealed through oral history (and in-depth or life experience) interviews is intrinsic to oral history theory and one that will be explored in greater detail later in this chapter.

\subsection{The development of oral history: social purpose, tape recorder, interviewing}

\subsubsection{Social purpose}

Historian Paul Thompson perceives oral history as an opportunity to achieve social change:

Oral history is a history built around people. It thrusts life into history itself and it widens its scope. It allows heroes not just from the leaders, but from the unknown majority of the people. (23) 
The emergence of modern-day oral history study coincided with a number of political and social movements in North America and Great Britain. Early oral histories were done in the U.S. during the 1930s and "40s as part of a program called "The Federal Writer's Project" (FWP) which was a series of "life histories...designed to document the diversity of the American experience and ways ordinary people were coping with the hardships of the Great Depression" (historymatters.gmu). During these tumultuous times, it became apparent that most of history recorded (and therefore appeared to value) the experiences of mostly white, powerful and privileged males from the political and economic elite (Thompson 4). Aside from a few initiatives (such as the FWP), the first organized oral history projects continued to focus on the memoirs of famous men such as former presidents (Sharpless 12). It was a journalist turned historian, Allan Nevins, who articulated the need for a more structured approach to capturing and preserving these stories, using interviews.

He conducted his first interview in 1948 with New York civic leader George McAneny, and both the Columbia Oral History Research Officethe largest archival collection of oral history interviews in the world - and the contemporary oral history movement were born. (historymatters.gmu.edu)

By the 1960s, a number of significant social changes had taken place in American society; the civil rights movement, protests against the Vietnam War and the feminist movement were all in full swing. Rebecca Sharpless says "the philosophical underpinnings of the oral history movement...lay with the democratic impulses of the social history movement" (14). What followed were projects that approached historical topics from the point of view of traditionally marginalized groups. Oral history projects on African American people (Alex Haley), working-class people (Studs Terkel), women 
from various cultures, minorities, domestic workers-they all became eligible material for historical study, providing new perspectives. Paul Thompson points to the colossal significance of the social history movement (what is commonly known as "from the bottom up") and how it changed the face of history.

...by introducing new evidence from the underside, by shifting the focus and opening new areas of inquiry, by challenging some of the assumptions and accepted judgments of historians, by bringing recognition to substantial groups of people who had been ignored, a cumulative process of transformation is set in motion. The scope of historical writing itself is enlarged and enriched: and at the same time its social message changes. History becomes, to put it simply, more democratic. (8-9)

This democratization of history carried on through the latter part of the $20^{\text {th }}$ century with ever-expanding projects in nations such as Asia and Africa, Europe and South America. Oral historian and author Donald A. Ritchie says the political and social changes had the effect of confronting "historians with the inadequacy of archival documentation, which often reflected a discredited government rather than the resistance against it" (23).

\subsubsection{The tape recorder}

Any discussion referring to the democratization of history, and its connection to oral history interviewing, cannot continue without mentioning the importance of technology. In 1963, the Phillips Company produced the first ever portable cassette recorders. The widespread availability of these machines meant that what had begun in academic and elite circles, extended to Main Street; people from all walks of life could now tell their stories on tape. The phenomenon continues today in what some call the second such technological shift, a "digital revolution" that will change way history is recorded (Hardy 392). People are telling their own stories in books, on the radio, on television and, most of all, on the Internet in record numbers. Valerie Yow explains how 
this new frenzy of access to individual perspectives reflects a fundamental element of the oral history tradition.

In the past, only the well-to-do documented their lives. They not only had a sense of their own importance and were literate, but they also had the leisure and staff support to write. Because they were the ones who held power, their accounts of their lives were usually consonant with accounts in official documents ... Oral history research thus becomes crucial to obtaining a picture of the total society because the viewpoints of the nonelite who do not leave memoirs or have biographers are presented. (1011)

Yow's views illuminate two key fundamentals of oral history's development: first, the awareness that the dominant narrative may be inaccurate; and second, that accessible technology can result in a new understanding of history through voice recordings of previously marginalized populations. This thesis does not intend to examine the impact of technology on the emergence of oral history in academia or elsewhere, but it does acknowledge the enormous contribution it has had (and continues to have) on the field.

\subsubsection{Academic interviewing}

As historians began to use oral history theory and methods more and more in their search for historical truth and meaning, other academic fields were also noticing the ways in which interviews could enhance their search for knowledge. Whether the interview style was called life history, life experience, in-depth, or simply oral history, a number of academic disciplines were developing their own standards and criteria for using interviews to gain a better understanding of the human experience. As previously observed the interview's reputation as a reliable research method in qualitative research studies has gained ground over the past several decades. At the same time, university departments have grown in size and scope and have sought answers collectively to what 
makes an effective interview. The following section provides an overview of some of the common themes that emerge from that discourse.

\subsection{Oral history interview methods}

\subsubsection{Preparation and central themes in oral history interviewing}

\section{a) Memory}

Oral history interviewing (whether in-depth interview or life history) is fundamentally dependent on a person's memory, as it is an essential ingredient to assessing the reliability and validity of oral evidence. The contemporary study of memory is exploding with new experiments and findings that can help academics and professionals from all fields explore the significance memory has on meaning. Notably, the journalistic guides reviewed in the previous chapter contain virtually nothing on the topic of memory. For the purposes of this study, the information is limited to material that could be relevant to the journalistic interview process. Valerie Yow presents a summary of memory work as it pertains to oral history, dividing memory into two main categories: the personal or autobiographical, and the collective or social memory. She acknowledges that human memory is selective and faulty but she says there are ways to achieve academic rigor in oral evidence by testing the...

... consistency in the testimony (or reliability) and accuracy in relating factual information (or validity). Consistency within the testimony can be easily checked, and questions about inconsistency pursued. Accuracy (the degree of conformity with other accounts) can be checked by checking other sources and comparing accounts. (20)

Knowledge about these forms of memory and the ways in which oral history methodology applies the knowledge is potentially significant to anyone who does 
interviews as it can help determine the reliability and validity of the narrator. ${ }^{29}$ The following is an overview of some of the knowledge about memory.

i) People remember what interests them

Why do we remember all the details of our first day at school or on the job? Or our first date? Or the minute details of a terrible event? Based on her survey of memory studies, Yow says by constructing narratives about our own experiences we find meaning in our lives:

We use such stories not only to make sense of our experiences, but also to justify decisions, to profit from past experience in making current decisions about present and future, and to reassure ourselves that we have come through life's challenges and have learned something. (35)

Yow quotes Katherine Nelson's definition of personal and autobiographical memory as "personal, long-lasting, and (usually) of significance to the self-system" (36). Basically this means people remember things that are important to them and their own lives (39). As simple and obvious as it seems, Donald A. Ritchie puts it this way:

People remember what they think is important, not necessarily what the interviewer thinks is most consequential. (32)

ii) People's memories change over time

In his overview on memory, Ritchie points out that people are constantly changing their views on the past, depending on new insights, circumstances, and information (33). He highlights how important it is for interviewers to understand how memory works, as it can affect the reliability of an oral history project. Indeed it may affect the number of people used for the project (known in social science research as

\footnotetext{
${ }^{29}$ Yow credits this perspective to Alice Hoffman, "Reliability and Validity in Oral History", in Dunaway and Baum, Oral History: an Interdisciplinary Anthology (67-73).
} 
sampling), as combining information from various interviews may produce more valid results:

Perceptions that were originally flawed will produce distorted memories. Distant and second-hand information is more susceptible to distortion. By contrast, direct, dramatic and emotional situations tend to produce more fixed and lasting memories. For these reasons, oral history projects attempt to collect a wide range of interviews, to piece the puzzle together from various points of view. (33)

Yow explains that research shows the human brain uses a combination of different areas to remember events. It stores these memories as fragments, which may or may not be recalled in the same way they were initially absorbed.

Given the fact that we sometimes change perceptions of events as we move from one life stage to another, it is reasonable to assume that we may change meanings of remembered events. (44)

Yow points out that the interviewees' recollections may change over time due to a number of conditions, including past feelings, present-day moods, physical sensations, and other external factors (37). Political, social and economic events can also affect people's individual memories (as contrasted with collective memory, which will be viewed in a moment), in that people will change the role they played in an event to a more desirable or interesting position. For example, Linda Shopes quotes a study that suggests individual memories changed after the assassination of John F. Kennedy.

Although Kennedy was elected with just $49.7 \%$ of the vote in the fall of 1960, almost two-thirds of all Americans remembered voting for him when they were asked about it in the aftermath of his assassination. (Trillin qtd. in Shopes)

iii) Long-term versus short-term memory

Observations about how people remember long-ago events better than recent ones still fascinate students of memory. Psychologist David Rubin's work shows that after age 
fifty, people have more memories from childhood to young adulthood than from recent years, possibly because those earlier times are when we define ourselves (Yow 35-36).

Donald A. Ritchie points to a number of projects in which interviewers observe elderly people who can't remember current telephone numbers or names of relatives, but can recall specific events of a day decades in the past or names of childhood friends (31). On the topic of why elderly people are willing to talk so much about their past, Ritchie quotes gerontologist Robert Butler:

....all people, as they grow older and perceive that they are approaching death, undergo a mental process of life review accounting for depression and despair in some, and for candor, serenity, and wisdom in others....Older people will review their lives whether anyone asks them about their memories or not, either mulling over their thoughts silently, or regaling family, neighbours, and visitors. (31)

iv) Trauma memories

There is an enormous volume of work on the way memory works and its effect during interviews with victims of trauma. Yow addresses the phenomenon of repressed memory syndrome, in which people don't speak about, and possibly forget, painful memories. In the case where a narrator is willing to recount a traumatic memory, the oral historian should be aware that;

Research suggests that to reduce present anxiety, people sometimes remember themselves as being safer than they actually were at the time of the traumatic event. We may try to minimize the impact of negative events, if possible, by downplaying our distress over them. (46)

Yow also introduces research that shows people may remember different parts of a traumatic event at different levels of intensity and accuracy:

For experiences characterized by strong emotion, the oral historian can expect the "central core" or gist of the experience to be well remembered, but he or she should also be alert to the possibility that peripheral details may not be remembered accurately. (46) 
Ronald J. Grele is an oral historian and former director of the Columbia University oral history research office. He explains that oral history trauma studies began with interviews with Holocaust survivors, but quickly expanded to include survivors of many other horrors. He suggests the interviewer should be aware that in such cases, the interview can play a role in the interviewee's healing (or further trauma).

...the interview process itself as an experience became a moment in the resolution of the conflicts over the past, or a moment in the revivification of the original emotions of powerlessness and victimization and all the attendant consequences of that re-emergence. (Charlton et al. 52)

The above examples represent vast amounts of literature that exist in the study of trauma and how it affects the human memory, much of which relates to the interview process.

v) Meaning in memory

Academics who conduct oral history or life experience interviews are exploring how people give meaning to their memories, more than simply what those memories are. Italian oral historian and author Allessandro Portelli describes it this way:

The first thing that makes oral history different, therefore, is that it tells us less about events than about their meaning. (Perks and Thomson 36)

Portelli goes on to explain that while oral sources need to be checked for reliability and veracity, the simple facts are not necessarily what the academic is looking for. In other words, even if one does find factual inconsistencies, the researcher might find meaning as to why those errors in the oral interview exist.

Oral sources are credible but with a different credibility. The importance of oral testimony may lie not in its adherence to fact, but rather in its departure from it, as imagination, symbolism, and desire emerge. Therefore, there are no 'false' oral sources. Once we have checked their factual credibility with all the established criteria of philological criticism and factual verification which are required by all types of sources anyway, the diversity of oral history consists in the fact that 'wrong' statements are 
still psychologically 'true' and that this truth may be equally as important as factually reliable accounts. (Portelli in Perks and Thomson 37)

The idea that meaning can be sought-and truth found-from people's imperfect memories is a fundamental concept in oral history methodology, and is an area that is explored in more detail in the following section.

vi) Group memory

Collective or social memory is a central aspect of oral history interviewing, in that it helps to understand how groups of people interpret a given event or experience. Yow defines this as the phenomenon of remembering "as a group; that is, we listen to people who have shared the same experience with us, and we gain a feeling of identity with them when we remember as people in our group remember" (36). Collective memory can be defined as when a group of people adopt the same basic views and remembrances of an event or time, whether due to political and social pressures or otherwise. The importance of recognizing and utilizing collective memory is underscored by Paul Thompson as he makes the case for the rare occasion that it may be better to interview more than one person at a time, such as cases that involve a group of elderly people:

There will be a much stronger tendency than in private to produce generalizations about the old days, but as they argue and exchange stories among each other, fascinating insights can emerge from these forms of collective memory. (234)

In times of war, opposing sides would likely have collective memories in which the entire group views the opposition and events surrounding the war in a certain way. According to Ritchie, this kind of memory, also known as "public memory," comprises stories, symbols, and parades, celebrations among other forms - both institutional and personal in their nature (36). Yow tells us there is often some kind of pressure exerted by the 
government with a goal "to influence us to forget some experience and remember others and to interpret these shared memories in a certain way" (53). The most well-known example of this is the work of Alessandro Portelli. He has examined the collective memory of Italians surrounding specific historical incidents during World War II. Based on traditional methodological tools, he determined that the collective memory was full of factual errors and misconceptions. Portelli conducted hundreds of interviews with witnesses to specific events as well as those who just lived in the city at the time. By cross-referencing his oral history interviews with other historical documents, he was able to disprove the popular narrative and then to examine how it came about. Ultimately it wasn't only about uncovering a myth and searching for truth; rather it was an investigation into meaning and the way collective memory affects a bigger narrative.

Subjectivity is as much the business of history as are the more visible 'facts'. What informants believe is indeed a historical fact (that is, the fact that they believe is), as much as what really happened. (Perks and Thomson 36)

Portelli claims to be "fascinated by the pervasiveness of erroneous tales, myths, legends and silences, such as those that have been woven around these events" and proclaims oral history the means to resolution.

When an incorrect reconstruction of history becomes popular belief, we are not called on only to rectify the facts but also to interrogate ourselves on how and why this commonsense took shape and on its meanings and uses. This is where the specific reliability of oral sources arises: even when they do not tell the events as they occurred, the discrepancies and the errors are themselves events, clues for the work of desire and pain over time, the painful search for meaning. (16)

Portelli uses traditional methodological techniques to investigate his story; he draws from mainly existing, published sources. It is, however, his adherence to the methodologies of oral history that propels the story forward, enhancing existing material and illuminating 
both past and present views on the story. In The History of Oral History, Ronald J. Grele believes Portelli's books have taken memory studies to a new level in oral history academe.

In many ways, Portelli's work stands as the culmination of a generation's thinking about the role of memory in oral history and the transformation in ways in which we have conceived our tasks. (72)

Within the concept of collective memory exists the term official memory. This refers to when the state manipulates documents, records, media or other factors that influence the memory. Yow gives a great example of this in which she compares coverage of the release of kidnapped army Private Jessica Lynch from a hospital in Iraq. She points out that in the U.S., viewers of major television networks saw video released to the networks by the U.S. army showing a daring rescue operation. In Canada, the Canadian Broadcasting Corporation interviewed witnesses who disputed the American version of events. Yow uses this to conclude:

The American public believed an official memory-a memory based on the film their government delivered to the television networks. A different film was seen in Canada, and there the government was not involved. Canadian citizens have a collective memory of the same event far different from the American public's memory. (55)

vii) Other memory findings

The following are some other points that emerge from Valerie Yow and other oral historians' works (often quoting psychologists and others who study memory) that refer to memory and the oral history interview process:

- People forget most of their life before age five, but after that "constituents of a memory may remain intact for fifty years and more" (Yow 35). 
- A concept known as "memory trace" describes how one sensation, such as a smell, a taste or a particular visual cue, can elicit immediate memory recall (Yow 48).

- Similarly to the senses mentioned above, the use of props, such as photographs, can trigger memories (Morrissey 168-169).

- Older adults make better interviewees: Researchers found that "young adults were better at verbatim recall, but older adults made better sense of the story. The older adults had richer vocabularies and could call on wide networks of facts and associations" (Yow 38-39).

- People do not appear to remember exact times during personal experience interviews (Yow 49).

- People often remember events based on a sequence of importance, rather than chronologically (49-50).

- Men and women remember differently, largely due to the socialization process. Women are much more apt to expand on their feelings than men. Men recount stories in a more linear fashion than women. There are many studies on gender and memory (Yow 50).

b) Ethical considerations, including the interviewer/interviewee relationship

In order to fully appreciate the attention academics pay to ethics when conducting oral history interviews, one must have an understanding of their role as social scientists. Academics who conduct oral history or life experience interviews go to great lengths to meet the criteria necessary to produce a credible and academically rigorous product. In the University environment, the requirements for ethical treatment of research subjects is 
stipulated and enforced by an ethics committee or like body. The ethics committee requirements consist of a series of forms that must be filled out stipulating all details surrounding the research project including: who and how many will be interviewed, the questions they will be asked, an assessment of risks involved and documentation of correspondence. Universities aside, all best practice scholarly oral history projects include strict procedural requirements such as: drawing up a project plan, selecting the people (or sample) to be interviewed, sending out letters, having them sign consent forms, conducting the interview, transcribing the interview in its entirety, writing thankyou notes to the interviewees and offering various degrees of ongoing involvement or offering copies of the final product as a gift, writing up the research into some kind of final product, arranging for a permanent archival location, and finally, documenting every single step of the project. The procedures as well as the ethical treatment of personal narrative are both overriding requirements in a valid oral history project. In Canada, the Canadian Oral History Association (COHA) provides links to reference material on the subject, as does the Concordia University Oral History Lab website. Both recommend that researchers look at the evaluation guidelines as set out by the (American) Oral History Association (OHA), where a lengthy and exhaustive framework for conducting and evaluating oral history projects is outlined. ${ }^{30}$ Written shortly after the Oral History Association was founded in the U.S. in 1967, these guidelines have been expanded and updated periodically. Although intended to cover the entire process of conducting, processing and preserving oral history interviews, it is acknowledged that they won't apply to every project. The following overview looks first at the general ethical

\footnotetext{
${ }^{30}$ For easy reference, this is at: http://www.oralhistory.org/do-oral-history/principles-and-practices/
} 
framework, and then at the guidelines as they refer to the relationship between interviewer and interviewee (also known as the narrator).

i) The ethical framework

The leading document for evaluation and ethical considerations for oral history interview projects is on the OHA website. It identifies ethical considerations for those involved in oral history. Entitled simply "Principles and Best Practices," it contains a thorough and concise summary of the principles and standards of oral history during the pre-interview, interview and post-interview stages. While the OHA directs its guidelines toward a primarily academic audience, it fully acknowledges the broad range of people who do oral history interviews with very different end goals, including "to create archival records, for individual research, for community and institutional projects, and for publications and media productions." Therefore, at the beginning of the evaluation guidelines it states:

Regardless of the purpose of the interviews, oral history should be conducted in the spirit of critical inquiry and social responsibility and with recognition of the interactive and subjective nature of the enterprise. (oralhistory.org)

The principles and standards of the OHA emphasize that the primary responsibility of oral history interviewers is to the interviewee. It outlines everything from the importance of clarity in terms of legal rights, to being sure the technology reproduces the voice as accurately as possible. The ideas may be characterized by an emphasis on honesty and openness with the interviewee, as well as a commitment to treating the interviewee with respect. The following are some of the major points included in the guidelines: 
- It recommends primarily that oral historians know their material, do background research and ask good questions in order to carry out a research project with depth (in part as their responsibility to the public and the profession).

- It reinforces the responsibility researchers have to their interviewees as they assess and interpret the interviews. There is a big emphasis on sensitivity to the feelings of the interviewee and not using their words out of context.

- It also suggests interviewers be sensitive to the communities from which they have collected oral histories. They shouldn't promote stereotypes and should consider consequences of interviews, good or bad.

- Interviewers should take every effort to make the interviews accessible to the communities. It also stipulates making the material available for "general use" through a reliable archive institution.

- It also emphasizes the importance of good documentation of interviews and methods throughout the project.

In order to meet these expectations, academics who uses interviews to do their research must take a number of steps before embarking on a project. Copyright laws in Canada are different from those in the United States. In Canada, the interviewer holds the copyright to a recorded interview, although most organizations recommend that the interviewee sign a consent form, stipulating how the interview material will be used in the future. ${ }^{31}$ In the U.S., the academic is not exempt from copyright laws regarding the use of a person's voice recording.

\footnotetext{
${ }^{31}$ For a more detailed description of the use of consent forms, see arthistory.concordia.ca/rvacanada/oralhistories.html
} 
Interviewees hold the copyright to their interviews until and unless they transfer those rights to an individual or institution. This is done by the interviewee signing a release form or in exceptional circumstances recording an oral statement to the same effect. (oralhistory.org)

Aside from the legal release form, interviewees should be informed of the mutual rights in the oral history process, such as editing, access restrictions, copyrights, prior use, royalties, and the expected disposition and dissemination of all forms of the record, including the potential for electronic distribution. In order to fulfill these requirements, the vast majority of academics who use oral history methodology (regardless of nationality) implement a similar protocol:

1. An initial formal letter of introduction that includes the following: information about the purpose of the interview and, in the event that it is part of a larger project, the clear purpose of that project; a statement about who is supporting or sponsoring the project (such as the University); an idea of how the long the interview will run and the kinds of questions they may expect. It may or may not include the contact name of an ethics representative (in the case of a University) and/or supervisor in the event of a complaint.

2. A signed consent form outlining the purpose, procedures, as well as risks and benefits of the interview. It would advise them of their right to drop out of the interview at any time, and would definitely have contact information of the supervisor or ethics representative. It would also include an agreement regarding how the interview may be used in the future: whether in a research paper, edited, archived, or in a broader forum that may be published and made accessible to the public. Some call this the "donor" contract, others refer to it as a "deed of gift" contract (Shopes 131-133; Coleman 103). 
3. In oral history projects, it is also common that the researcher present the interviewee with a gift of some kind. Sometimes this is a gift upon beginning the interview, but more frequently this gift is a copy of the transcripts of the interview or a copy of the finished product (Ritchie, Coleman). This practice is directly connected to the profound connection oral history imparts on the relationship between interviewer and interviewee, which we look at in the following section.

ii) Interviewer/interviewee relationship

Valerie Yow contends that when an academic approaches someone about participating in an oral history interview, and by extension, in telling their story and perspective, there is a value attached to that process. The experience itself has significance and is important:

The presence of a listener who records the narrator's words for a story of the past gives the process a sense of drama and importance a casual conversation cannot impart. Through the use of the tape recorder, the narrator can speak to the present community and to generations to come. (159)

This presence of a listener is part of what sets life review/oral history interviewing apart from the field of autobiography and memoirs. There is an interviewer and an interviewee in the oral history interview process. As previously noted, that relationship is the crux of the ethical debate. Journalist turned oral historian Mark Feldstein, in an arguably exaggerated passage, notes the difference:

For journalists, ethics is largely a matter of weighing which means can be used to achieve which ends: for example, is it acceptable to "bluff" a source into revealing something incriminating-telling a lie in order to uncover the truth? For historians, ethical debates do not center on such issues of technique - which are generally much more straightforward-but on the interviewer's relationship with the subject. Thus, academics worry about the often-unequal status between interviewer and interviewee. (Feldstein par. 25) 
Researchers in different fields use a variety of terminology to describe their interview relationships. With his practical approach in Doing Oral History, Donald A. Ritchie talks about the person conducting the interview as "interviewer" and the person talking about his or her life as "interviewee." He also sometimes refers to the latter as "informants" (27). In the book A Handbook for Social Science Field Research, authors Ellen Perecman and Sara R. Curran reflect a more social science perspective, as they talk about interviewees as "informants" and "tellers," with the interviewers always being "researchers." Valerie Yow highlights the most common term used to describe the interviewee in oral history.

Most often, I use the term narrator, rather than interviewee, because narrator places primary importance on the person telling the story. Interviewee uses the suffix $e e$, which is a derivative form, secondary to the primary noun, interviewer. (157)

In most oral histories, especially in certain disciplines, the narrator is the person being interviewed. This underscores the importance given to the testimony of the interviewee in an oral history interview. It often extends to the co-author situation, such as Julie Cruikshank's book, Life Lived like a Story: Life Stories of Three Yukon Elders, which lists the three aboriginal women interviewed for the book as co-authors (Angela Sidney, Kitty Smith and Annie Ned). Social scientists, in particular in sociology and anthropology, have explored the interviewee/interviewer relationship with a view to creating a more equal footing between the two. Feminist theory has incorporated this relationship into their ideas with intense study of the effect of the research process on both the interviewer and the narrator. For example Yow describes a shift in power in which the scholar, formerly considered "almighty" in academia, is now on a more equal 
footing with the person giving evidence. The entire process becomes more collaborative, even extending to questions about authorship of the final product. Michael Frisch coined the term "a shared authority" to describe this dynamic approach that challenges conventional scholarship.

Who, really, is the author of an oral history, whether this be a single interview or an edited book-length narrative? Is it the historian posing questions and editing the results, or the "subject," whose words are the heart of the consequent texts? $(\mathrm{xx})$

The collaborative approach to interviewing does raise a number of issues, including questions about the degree to which an interviewer should accept the interviewee/narrator's story. How much interference or professional distance is appropriate? Questions about objectivity, subjectivity and independence are raised when an interviewer appears to be overly sympathetic to the interviewee/narrator. While the discourse surrounding this is important, Yow reflects the general consensus on this point:

In striving to see the world as the narrator sees it, we realize that this stance compels some degree of compassion for the narrator. We cannot and do not wish to - pretend to complete objectivity. (2)

Clearly different academic fields approach this issue with varying degrees of concern, but

Yow hearkens back to some of the greatest oral communicators in history:

...the subjectivity of the process did not bother the Greeks: they knew that their witnesses and they themselves were human beings involved in the process of living and observing what was going on around them and to them, even as they recorded memories and observations. They realized that they could not extract themselves from the story. I argue that awareness of our biases and preconceptions, the limitations of our experience and preferences, brings us closer to an understanding of how we influence our research and interpretation, whether it is qualitative or quantitative. (4-5) 
The OHA guidelines do provide suggestions to avoid a conflict (perceived or real) regarding the relationship between interviewer and interviewee. They recommend asking these questions, among others:

- Do the biases of the interviewer interfere with or influence the responses of the interviewee?

- What information is available that may inform the users of any prior or separate relationship between the interviewer and interviewee?

- Do interviewer and interviewee collaborate with each other toward interview objectives?

- Is there a balance between empathy and analytical judgment in the interview?

- If videotaped, is the interviewer/interviewee relationship maintained despite the presence of a technical crew? (oralhistory.org)

As noted in the section on memory, one body of research that is rapidly growing, and worth drawing to the attention of journalists, is how to interview victims of trauma. Usually this situation requires some level of compassion and empathy from the interviewer. Although the interview will have different purposes and outcomes depending on who is conducting it (sociologists, psychologists and anthropologists will be looking for different elements of the interviewee's story), the literature is fairly consistent on this front. Historian Mark Klempner addresses the methodology of handling such situations.

Interviewing a trauma survivor requires a greater degree of both sensitivity and sturdiness than is normally brought to a life review. The interviewer becomes part of the trauma survivor's process by hearing the stories and being a witness to them. (Perks and Thomson 208)

This acknowledgement of, and commitment to, the significant role of the interviewer to the interviewee's storytelling is a key concept in life experience interviewing across the 
academic world. As with memory, there are a multitude of specific topics connected to the interviewer/interviewee relationship being explored in academia. The following examples derive from Yow's review of a number of these studies:

- Research has shown that an interviewer who shares personal information about themselves will gain more trust from the interviewee (51)

- Interpersonal relationships are affected by age, race, gender, social class, status, ethnicity, and subculture. Studies have found that if the interviewer and interviewee share similar backgrounds (such as age, gender, class, and race), the interviewee will be more likely to open up. Yow concludes "the interviewer must be conscious of the ways in which these basic social attributes impinge" (179). ${ }^{32}$

- There are many studies about the effect of racial and gender differences and between interviewer and interviewee. For example, it has been found that men interrupt more often than women (170).

- Cultural norms are a big consideration when doing interviews. For example, in many cultures around the world, men are allowed to talk about many more subjects than women in many parts of the world. Sex is one example of this (171).

- An interviewer's own issues—anxieties, fears, and mood—can affect his or her ability to listen and to understand what the person is saying (170).

\subsubsection{The interview}

The practical and technical lessons from oral history interviewing are the least likely part of oral history methodology to be applied to the journalistic interview. Indeed,

\footnotetext{
${ }^{32}$ On this point, Linda Shopes points to a case in which the same narrator was interviewed by two different people; one African-American, one white. The differences are stark. http://historymatters.gmu.edu/mse/oral/question $2 . \mathrm{html}$
} 
it is generally considered that when it comes to question style and technical points, academics have more to learn from journalists than the other way around (Feldstein).

However, there are some-perhaps more theoretical-elements of the academic interview that could be instructive to journalists who conduct interviews.

a) Narrative and the life history/experience interview

A close examination of the life history interview style uncovers a vast and multidisciplinary body of work about storytelling, personal narrative and biography that could provide much insight to journalists. It is not all new to journalists; indeed, this is an area where narrative journalists are leaders in the field. For example, the Neiman Foundation at Harvard University used to host an annual conference on narrative journalism that attracted journalists from around the world. ${ }^{33}$ For that reason, and as pointed out in the previous chapter, this section focuses only on narrative ideas connected to the life story interview as it is used in academic contexts. Valerie Yow points out that the use of narrative techniques has been a fundamental component of human interaction since the beginning of human communication, but that it has mainly gained academic respect in the past several decades. She says: "scholars recognize that storytelling is a compelling endeavor that is universal" (14). She quotes Mia Leiblich, Rivka Tuval-Mashiach, and Tamar Zilber from the book Narrative Research: Reading, Analysis, and Interpretation, with their observations:

In the fields of psychology, gender studies, education, anthropology, sociology, linguistics, law, and history, narrative studies are flourishing as a

\footnotetext{
${ }^{33}$ To read the blog about the final conference go to: http://ncni09.blogspot.com/ For information on the Nieman Foundation go to: http://www.nieman.harvard.edu/NiemanFoundation.aspx\#
} 
means of understanding the personal identity, lifestyle, culture and historical world of the narrator. (14)

Life narrative in oral history interviewing draws on the works of linguistics scholars, anthropologists, psychologists, sociologists and historians to illustrate the value of the life history or narrative form of the oral history interview (15). It applies to everything from understanding how a person's early experiences shape them, to concepts about healing and recovery from traumatic events. Valerie Yow notes that as a society, we are interested in much more than just the public deeds of famous people:

Now readers want to peep behind the mask, to understand the ways the individual sees himself or herself, the inner struggles and motivation, the way psychological makeup influenced the subject's interpersonal relationships, the interpretation the subject gave to life's events. (...) Oral history techniques of questioning about motivation, feelings, and meanings are an effective way to get this information, as well as the details of deeds and events. (220)

As noted earlier, one advantage of the personal experience interview is that people are more likely to reveal parts of their lives when telling it in a story form. Yow makes the point that the oral history interview can draw out information that traditional informationgatherers (such as government officials) cannot get.

The life review reveals other kinds of information that do not get into the public record. People would rather not admit some things to the census taker-such as who is living with whom. Nearly everyone underestimates the value of renovations to property when filling out forms for the county tax office. And underlying the official accounts of "accidental death" are stories of despair on both the personal and societal level. (10)

Through a life review style of interview, all this information becomes part of the public record, thereby providing context of an element or time period in society. Author Robert Atkinson says the life story interview process offers a mutually beneficial experience, in 
that it gives some people the opportunity to share their experiences and others to hear and learn from those stories.

There may be no better way to answer the question of how people get from where they began to where they are now than through their life stories. Life stories are essential in gaining a full understanding of the human life, especially the individual human life in relation to others, in knowing what matters most to people as they live, and in recognizing how each generation is linked to others. (Life Story 20)

The form and content of oral history narratives can also be affected by the length of interviews used in oral history projects in the social sciences and humanities. These interviews are truly of indeterminate length - they can range from 90 minutes to day-long interviews recorded over a period that scans several years (although the OHA recommends two-hour sessions at one time). Whether used by gerontologists, psychologists, historians, or others, these interviews are often auto-biographical and frequently cover the person's entire life. Ritchie refers to in-depth interviews that are more single topic-oriented (still in the category of oral history interviewing) as "episodic" interviews. Hesse-Biber and Leavy say while oral history does include the story of an individual's life; it is not biography, rather "oral history allows for the merging of individual biography and historical processes" (156). They also acknowledge the importance of building trust and rapport with the interviewee (158-159), as does Ritchie, who recommends conducting more than one interview with each person $(40,87)$, primarily to develop a rapport, but also to give the researcher some opportunity to review and refocus material.

Consistent with the commitment to a high ethical standard during the interview process, the oral history interview process includes stringent protocol and social niceties. Valerie Yow suggests setting up a "preliminary interview" in which the interviewer visits 
the interviewee in advance: to put a nervous participant at ease, to establish ground rules about the recording session(s), and to scout out the physical location (93). On the website History Matters, feminist and oral historian Linda Shopes offers an accessible online guide for doing oral history. She recommends creating a "social space" during the interview.

As researchers, then, we both find it useful to affirm certain commonalities - a shared social milieu, common ethnic bonds, similar life experiences, even the mutual effort to "do" the interview - as a way of equalizing the interview encounter. (historymatters.com)

There are other considerations that Shopes advises be taken into account when conducting oral history interviews. She points to a number of examples in which the setting can affect the kind of material that will be discussed.

Interviews in a person's office, for example, tend to be more formal, less intimate, with the narrator emphasizing public rather than private life. Likewise, an interview with more than one person simultaneously or the presence of a third person in the room where an interview is taking place can constrain a narrator, turning a private exchange into something more akin to a public performance. (historymatters.com)

These points are reflected in other academic guides, all of which place an emphasis on understanding how the physical situation and circumstances can affect how both the interviewer and interviewee will present.

b) Interview questions

When it comes to carrying out the actual interview, most academics using oral history interviews borrow many of the practical techniques from journalists (Yow 71-87). Ritchie says the following applies to all types of oral history interviewing:

...do your homework: be prepared; construct meaningful but open-ended questions; do not interrupt responses; follow up on what you have heard; know your equipment thoroughly; promptly process your recordings; and always keep in mind the practice and ethics or interviewing. (84) 
Most guides-both hard copy and online-offer similar tips, with slight variations depending on the particular objectives of the interview. In Recording Oral History: A Guide for the Humanities and Social Sciences, Yow provides extensive advice ranging from the obvious "ask broad and comparative questions" (76-77) to the polite "as soon as possible, write the interview notes and thank-you letter" (116). Yow suggests interview topics should be approached either chronologically or by general subject matter (73). Many oral historians, in an effort to ensure the interviewee feels free to express ideas and stories that they want heard, set up the interview in three stages. Paul Thompson attributes this tripartite approach to German sociologist Gabriele Rosenthal:

The interview is opened by a wide, non-contentious question, and in the first phase the interviewer simply offers non-verbal encouragement; in the second phase details may be drawn out by asking the interviewee to say more about themes already mentioned; only in the third can new topics and missing themes be raised. (227-228)

Valerie Yow recommends that every researcher prepare an overall plan for the interview which she calls the "interview guide." The guide serves as an overall strategy for the interviewer, but it also offers freedom to stray from the line of topics or question, so that the narrator may raise whatever issues he or she deems significant:

The topics and their specific questions cover the information that the interviewer needs, but leeway is built into the situation to allow for the emergence of the unanticipated. This flexibility allows the narrator to teach the interviewer things he or she did not already know, while ensuring that the information the interviewer sought is also obtained. (71)

Yow believes this format requires more skill than simple questionnaires, as the interviewer must be well-prepared and must clearly understand the objectives of the research project. Yow also suggests always discussing nonthreatening topics first, saying people like to talk about their "birthplace, early childhood memories, and significant 
people and events in the years they grew up." She says this can be useful both to the immediate project but also to future researchers who may want to place the person "in a specific time and place to understand how the narrator came to do what he or she did" (72).

In general, the questioning of life story and oral history style interviews depends on the subject matter: A life experience interview that is part of a bigger study on a political episode, for example, will include more focused questions to confirm facts and clarify events. On the other hand, a life history interview in ethnography or sociology may be very open-ended in question style, including few specific questions, preferring to allow the "narrator" to lead. The great, popular oral historian, Studs Terkel, has this to say about oral interviewing style.

The questioning's important - but what's the most important is that it shouldn't sound like questioning. What time did you get up yesterday morning, what time did you go to bed, what did you do in between - none of that...Making it sound like you're having a conversation, not carrying on an inquisition, right? (Terkel in Perks and Thomson 126)

By and large, the literature on oral history interviewing suggests scholars look to journalists for tips, especially on questions of technology. Guides are replete with suggestions such as: make sure your recording device works, take extra batteries, and know how to hold the microphone for best audio results. Due to the essential component of archiving in oral history interviewing, technology is frequently determined based on compatibility with the institution that will house the oral history.

c) Listening and Meaning

In oral history interviews, as in journalism, listening is the key to truly understanding what the interviewee is saying. But while journalists usually seek details 
about events that can then be related to the wider public (accounts of what happened according to the interviewee), academic oral history interviewers are often looking for meaning, rather than just the facts of the story. Valerie Yow notes that in-depth or life history interviewing needs extra vigilance for unanticipated lines of inquiry that may arise during the interview:

In in-depth interviewing, because you seek the unexpected, the information you do not already know, you give the narrator scope to develop his or her train of thought. The narrator may tentatively offer another line of investigation, and careful listening enables you to pick up on this. (98)

As previously noted, the search for meaning in oral history interviews is frequently as significant, or more so, than the content itself. Also, the length of interviews is usually longer, allowing for deeper levels of exploration. Renita Coleman emphasizes the importance of understanding how people view their own experiences:

...oral history is particularly interested in people's interpretations of these events years later, not just the facts of the events themselves. How events have changed in people's minds reveals how people have tried to make sense of their past. (94)

While all the texts on oral history underscore the importance of listening, an article by academics Kathryn Anderson and Dana C. Jack provides very practical advice that shows how listening can be done in a methodical way, that will enhance the interview experience. In writing about oral history from a feminist perspective, they offer up useful insight into how an interviewer should listen during an oral history interview. They begin by establishing the concept of "listening in stereo" (130). In a nutshell, it means being aware of two levels during the interview: First, the woman's role in the society in which she lives, as that will affect how she sees herself and describes herself. Second, the interviewer must listen for the woman's personal experience, the things that are part of 
her daily life. The authors write that women may use words a certain way, dependant on the cultural or religious mores of the day. In cases such as this it is up to the interviewer to be sure to ask the narrator to explain further:

When they use words and phrases like 'nervous breakdown,' 'support', 'close', 'visiting', and 'working together', they should have an opportunity to explain what they mean in their own terms. With letters and diaries we can only infer what individuals mean by the language they use, with oral interviews we can ask them. (135)

Dana Jack lays out three steps that could improve listening in interviews. She calls the first, listening for 'moral language' (137). This means the interviewer must pursue avenues that will allow the narrator/interviewee to explain more about why they perceive something they way they do. Jack uses the example of marital breakdown and how it is perceived by women in some cultures, including the idea that it signifies moral failure. It is critical that the interviewee give the woman time and space to explain her language, in order to gain a broader understanding of her experience.

An oral interview, when structured by the narrator instead of the researcher, allows each woman to express her uniqueness in its full class, racial, and ethnic richness...During the interview, the researcher's role is to preserve and foster this freedom, and to restrict the imposition of personal expectations. (137)

The second step in good listening is being aware of 'meta-statements' or "places in the interview where people spontaneously stop, look back, and comment about their own thoughts or something just said" (138). Jack suggests that these statements help the interviewer understand the way in which the narrator looks at herself, thus providing a window into some of the parameters she places around her own self-image. Finally, Jack recommends listening to what she calls the "logic of the narrative" or listening for internal consistencies and contradictions. Again, statements by the narrator that may 
conflict with one another are opportunities for the narrator to be heard. If ignored, the interviewer overlooks a chance to pursue a potentially valuable avenue of inquiry (139).

\subsubsection{After the interview}

The process of transcribing and archiving the interview is an intrinsic part of the oral history method. Making transcriptions of the interview available in their entirety, so that interviewees, members of the public, journalists or other academics can review them, is essential to the reliability and validity of whatever interpretation or conclusions result from the interviews (Ritchie 6). Mark Feldstein notes the significance of this process:

...by preserving the entirety of oral history interviews, other scholars can check the material for accuracy, context, and nuance. Unlike journalism, oral history can be independently verified - a fundamental requirement of scientific inquiry. (par 28)

This section outlines key points and guidelines that academics follow as they bring an oral history project to completion.

a) Transcription

Most academics who use life experience or oral history interviews in their research transcribe their entire interviews word for word. While the original recording is always the primary document, the transcription is important for a variety of reasons, albeit as a different kind of record (Ritchie 68). The researcher or transcriber's goal (many researchers hire transcribing services) is to stay as faithful to the words and the meaning of the narrator. The oral history guides do allow for exceptions (including financial considerations), but the view on transcribing interviews is almost unanimous: The researcher should transcribe every word. This is primarily due to the fact that the transcription must be as precise a reproduction of the original recording as possible. It's 
also due to the principle that oral histories must be made available and accessible to everyone, as well as due to the potential loss or technological deterioration of the audio recording (Ritchie 64). Transcription is extremely time-consuming and is therefore very expensive. All the texts on oral history estimate that it takes between five and eight hours to transcribe one hour of recording (Thompson 257). This may be prohibitive to many, but it is a necessary component of oral history methodology. Oral history projects call for precise transcription guidelines-being sure to label the recordings with correctly spelled names, geographic places, dates, times and lengths of interviews, as well as providing the correct spelling and definitions of all technical terms. It is also recommended that researchers provide a thorough index of the interview for future reference. The study of transcription has become a field unto itself, and includes developments such as voice recognition systems that may have a major impact on the interviewing process. ${ }^{34}$

There is one tricky question still that generates a lot of debate in academic discourse. It's a question of content, and how-or even whether-to transcribe vocal tics and other oral habits, such as slang, false starts, dropped letters, speech impediments, and various other features of human speech. Both Paul Thompson (34) and Donald Ritchie point to what is lost in transcription.

Viewing transcripts as only a partial rendering of the recordings, they note the importance of such additional features as pitch, stress, volume, and

\footnotetext{
${ }^{34}$ For example, see article "Improving accuracy of transcripts in qualitative research" Communication Abstracts, L.M.MacLean, M.Meyer, A. Estable. Qualitative Health Research, vol. 14, no. 1 pp113-123, 2004. Also, Michael Frisch is working with Concordia University to develop software that will digitize, annotate and index videotaped oral history. For more information on this and other digital developments: http://storytelling.concordia.ca/oralhistory/programme/building.html
} 
rate of speech, as well as facial gestures and body movements, which are not captured on audio tape. (Ritchie 67)

Paul Thompson describes transcription as a "literary form," saying it can be done well, almost the way musical notation indicates tempo, volume and notes, through careful and creative use of punctuation, symbols and things like italics to indicate certain words that were stressed in the recording (262). Keeping this in mind, the debate about whether or not to transcribe every "uh" and "you know" continues. Thompson is in favor of keeping anything that lends itself to understanding more about the interviewee. Michael Frisch generally advocates full transcription, but isn't willing to commit to the practice all the time.

To transcribe each pause or false start or tic would make an otherwise clear tape absolutely unreadable on paper, inevitably suggesting to readers an inarticulateness anything but characteristic of the speaker-as-heard. On the other hand, to eliminate them all arbitrarily might risk a distortion of a different kind. In the final analysis, rules cannot substitute for judgment in such matters. (85)

Frisch points out a number of observations that can be made from transcription details, such as class differences. He says he would not change certain grammatical errors, such as "gonna" to "going to," because of this (85-86).

The final point that must be made about transcription is the common practice of returning the written transcript to the narrator for review and corrections. Donald Ritchie says "interviewees may add material that was forgotten during their interviews, or may remove comments that they have had second thoughts about" (67). Some do recognize potential drawbacks with this practice. Paul Thompson points out that informants sometimes rewrite their words as well as change the details of some memories (263). He recommends that in most cases the researcher... 
...write asking only for a few clarifications of confusions, uncertain names, or vital details missing-which will usually be gladly supplied. (263)

Despite the consent forms signed at the outset, and depending on the exact purpose of the project, there is a general consensus that the life experience interview is a collaborative effort, and that offering the transcript to the narrator for review is correct protocol.

b) Critical analysis and interpretation

Critical analysis and interpretation is a fundamental part of the oral history interview process. As the OHA guidelines state, "a critical approach to the oral testimony and interpretations are necessary in the use of oral history." It is through this exercise that the academic study makes a contribution to the knowledge of history, sociology, psychology, anthropology or otherwise. Michael Frisch writes that by seeking evidence directly from the mouths of witnesses, oral history helps us understand history "the way it was", as a kind of alternative "short cut" to historiography's conventional frameworks (187). He emphasizes its ability to provide new information:

In this sense, it is seen as a kind of searchlight throwing a beam of inquiry into an ordinarily unreachable corner of the attic of history. This presumes that what is discovered in this beam will then be incorporated into more traditional historical understandings, and evaluated for validity and significance with and against other kinds of information. (186)

The process of analysis and interpretation takes myriad forms, depending on the academic discipline and purpose, the project size and scope, as well as consideration of who is expected to learn from the results. In general, books and websites published as "oral histories" for public consumption include minimal analysis, if any. As qualitative research however, which is the stated interest of this thesis, oral history interviewing produces reliable, academically sound and insightful interpretations of society. The 
process includes: testing oral evidence for internal reliability, measuring the interview for factual inconsistencies and conflicting memories, verifying that all corrections are made, and checking in with the narrator/informant/interviewee in order to clarify any ambiguous material. The transcript must also be tested for external reliability, meaning it must be measured against other documents and evidence that speak to the same topic, event or time line. Also, within the context of a bigger project with a large sample population, oral evidence should be tested for consistency with parallel interviews. Obviously the degree to which one needs to delve into this differs according to the project. Part of this process takes place during the interview, as previously mentioned. Other parts take place during tabulation of data, another important component in the assessment and interpretation of oral history. According to English historian, Trevor Lummis, there are many details that can be included in this sort of measurement including age, gender, number of siblings, religion, education, and political preference (Lummis 257). He highlights a number of areas the researcher should be aware of on this front:

- The existence of gaps in topics (or "silences" as they are called by some oral historians), due to taboo or negative historical experiences, or otherwise (254).

- The challenge of seeking a social interpretation from individual interviews and the connected tendency to generalize.

- The importance of defining parameters for groups of interviewees (257).

- An emphasis on understanding the way memory functions (257).

Linda Shopes offers practical tips to those who use oral histories interviews as they embark on the process of the interpretation of the data. 
Each interview is a response to a particular person and set of questions, as well as to the narrator's inner need to make sense of experience. What is said also draws upon the narrator's linguistic conventions and cultural assumptions and hence is an expression of identity, consciousness, and culture. Put simply, we need to ask: who is saying what, to whom, for what purpose, and under what circumstances. (historymatters.com)

The oral history life experience interview method also offers warning lessons regarding the perils of interpreting another person's words. In one well-known example of post-interview analysis gone wrong, professor and folklorist Katherine Borland interviewed her grandmother about a childhood incident in which, as a young girl, the grandma had been very determined and outspoken. Borland interpreted her grandmother's words and actions as those of a feminist, although a feminist in disguise, as the events took place long before the feminist movement. When her grandmother reviewed Borland's interpretation of the interview (and the incident), she was horrified and offended. Borland warns against a rush to judgment when interpreting an interviewee's words:

...we hold an explicitly political vision of the structural conditions that lead to particular social behaviors, a vision that our field collaborators, many of whom do not consider themselves feminists, may not recognize as valid. (311)

c) Archiving and final product

In most scholarly settings, once the essential elements of an oral history project are complete - the preparation, the interview and the analysis - there are two stages to follow. First, the original recording and transcript must be archived in an institution that can support the technology as well as the indexing system so other scholars (or members of the public) can access them. Then, as Ritchie tells us, it has to be "processed in some way," whether it ends up in a paper, report, book or other form. While this thesis does not 
address either of these topics in great detail, it is imperative to the study of oral history interviewing that one understand the significance of archiving, as well as the possible public results of the process.

Archiving the original interview (in digital format) is of utmost importance to oral history methodology. As part of its academic reliability, an interview must be accessible for future reference and review by academic peers and members the public (Ritchie 6). In their raw form, there are thousands of scholarly oral history collections around the world. They are housed in national archive institutions, broadcast centres, libraries, political organizations, educational institutions (at all levels), non-profit groups, even on the Internet, to name a few locations. Some are intellectually scrupulous, conducted with the academic rigor stipulated in this chapter; others are informal, badly-recorded and often lost in the confusion of a flawed filing system. The discourse surrounding the archive guidelines and expectations is expansive and not without controversy. Some of the issues include: perpetually changing technologies, making it challenging to access old collections and to confidently invest in new technologies; vast differences in indexing systems, rendering many collections virtually unusable; the risks associated with putting oral history collections on the Internet, as there are significant ethical, if not legal, issues regarding the "use and manipulation" of oral recordings that have to be considered when uploading files to such an uncontrolled situation; and the simple question of determining how much is too much when it comes to archiving people's recorded experiences.

Clearly, the shape and form of an individual oral history interview or project depends on the field being studied and the line of inquiry initiated by the researcher. The OHA says "a verbal document, the oral history, results from this process and is preserved 
and made available in different forms to other users, researchers, and the public." Oral histories as used in anthropology, political science or history may result in a book that covers an element of a certain culture or topic, such as the works of Alessandro Portelli. Oral histories undertaken in education may end up being used as data to help develop future curriculums. Oral history interviews used in psychology might show up in a study that helps to understand why people behave the way they do. This thesis does not even consider the myriad non-academic oral history projects conducted and turned into projects of some kind. History professor Charles Hardy III writes that in today's everchanging technological environment, the variety, shape and form of this process is multifacetted, often finding its way into the realm of journalism, especially broadcast journalism. There are books, print and CD combinations, audio and video productions, as well as multi-media publications on the web (Hardy 392). Scholarly oral history efforts have changed the face of public history as they contribute to the popularity of interactive museum exhibits. Hardy proposes that this may represent more than just a neat way of learning about history; indeed it may challenge traditional thinking about history as a linear process and turn it into a more shared experience "privileging multiple rather than univocal perspectives" (Hardy 398). In the university environment, there are some basic rules that most serious social scientists follow in an attempt to bring the fruits of their research to wider academic or public attention. As with all facets of the oral history project, the OHA provides guidelines for the use of interviews. As previously noted, they focus primarily on the ethical treatment of the interview. They also suggest that all projects adhere to strict citation and documentation standards, as well as have accompanying explanations of the entire project. As demonstrated, this part of the 
methodology begins with transcription, followed by analysis and interpretation. Then, when preparing for the final report, journal article, paper or other publication of the research findings, there must be some kind of selection or editing process. Clearly, the widespread nature of fields in which oral history interviewing is conducted will have some bearing on what the final product will resemble. Michael Frisch says the editing process is "shrouded in considerable mystery" (81).

...most manuals, guides, and oral history courses focus on intake rather than output, providing little help at such an editorial juncture. (82)

Frisch makes a distinction between the exercise of using oral history interviews in one's research (doing oral history), and preparing an historical documentary (83). He draws attention to the editorial choices that one must make when shaping the material into a radio or television documentary or any other kind of public document. It's an exercise that requires careful consideration about each and every detail of the process so that the narrator/interviewee's meaning is not altered or compromised (84).

...a film, radio script, exhibit, or magazine documentary text must not simply express historical content and ideas, it must also communicate this material-and communicate it to specifically imagined audiences who encounter the materials in forms and under conditions that directly affect the meaning that can be communicated. (83)

This is a challenge Rebecca Jones tackles in an article about bringing oral history projects to publication, a process she calls "a meandering journey" (1). She uses a case study of one of her own publications to examine some of the major dilemmas academics face as they attempt to turn hours and hours of interview recordings into something to be shared with a greater audience (academic or public). At the heart of the quandary is the editing process: How much and in what ways is it acceptable to edit and condense another person's words? 
When publishing for a general audience, extensive editing is required to create a document that is not only readable and accessible, but also conveys the flavor of the experiences. (26)

Jones uses a case study of one of her own projects, a book about the immigrant experience in Australia. She followed four principles during the entire process:

1) The purpose of the project and its audience

2) Enhancing communication with the audience

3) The responsibility of the author to the narrator

4) The necessity of allowing the narrator to review the edited version (27)

These principles guided Jones in all her editing and preparatory work. Since many of her narrators did not speak English as their first language, she removed awkward verbal tics, re-ordered phrases thematically and generally fixed up any language in order to better represent their meaning for the English-speaking audience/reader (33). For Jones, to leave the original grammar that may be incomprehensible to the "public" audience would be unfair to them and would not serve the purpose of the project. She also concludes it would be "demeaning" to the narrators to leave those errors in the text when being offered up for public viewing (34). An important point must be made, of course, which is, that Jones presented the edited version of her book to the narrators, true to Frisch's "shared authority" concept in which the end result is a collaborative work and process. According to Jones, some narrators even added valuable written documents to go into the final version of the book (35-36).

Creating the story is not an event frozen at the moment the tape recorder is switched off, but is an ongoing process by which the meaning is constructed jointly by the editor/interviewer and the narrator. Editing is an extension of the construction of meaning. (39) 
Conclusion

In order to evaluate the application of oral history interviewing concepts to journalism, it is necessary to have a clear understanding of oral history methodology. This chapter provides a broad look at the scholarly oral history approach to interviewing. It is not intended to be a definitive guide to oral history; rather it is meant as an introduction for journalists to some of the major concepts that comprise oral history methodology, as a starting point for a discussion about possible applications to the journalistic interview. The next chapter will observe how some of the themes that emerged can inform journalistic practice. 


\section{Chapter Four: The Intersection of Journalistic and Oral History Interviewing}

The preceding chapters have outlined the fundamentals of both the journalistic interview and the methodology behind the oral history interview, as it is used in academic research. It is important to emphasize that this thesis does not seek to be a definitive guide to either practice; rather, it aims to continue a dialogue already begun about the lessons journalists may take from the scholarly approach to oral history interviewing. The literature reviewed in chapters two and three provides a clear overview of assumptions about the journalistic interview process as well as key themes from oral history interviewing. In this chapter, new research material will be added to the knowledge, in the form of in-depth interviews with three experienced journalists. The combination of this material will inform the research question—whether or not the journalistic interview can be informed by knowledge from oral history interview methodology—and will allow conclusions to be drawn. The themes in this chapter are organized as they emerged in chapters two and three, in order to draw as direct applications as are possible from one field to the other. Therefore, the themes fall into these three sections: (1) Theory and Preparation; (2) The Interview; and (3) After the Interview. It will first address the concept of what some call "oral history as journalism," that is, the extensive use of personal narrative in contemporary journalism practice; and concludes with a brief assessment of points raised during the research on how some of the ideas raised might fit into journalism education.

The research participants selected for the interviews were chosen based on a number of criteria, primarily for their reputations as highly respected, experienced radio 
broadcast journalists. Bob Carty has worked in radio since 1981, specializing in longformat documentary pieces, both human interest and investigative. He is currently a producer for two CBC Radio programs, The Current and The Sunday Edition. Dick Miller began working as a technician and announcer for CBC Radio in 1976. Since then, he has worked as a host, a producer, and a TV reporter. He has produced many stories for CBC's now defunct Outfront, a show that offered airtime and production assistance to Canadians who wanted to tell their own stories. Miller is now senior producer and documentary editor for The Current, helping to produce about 60 to 70 documentaries each year, as well as many tape/talks (reports in which journalists present recorded material in an interactive style with the host of a program). David Gutnick is a CBC Radio documentary maker, primarily for The Sunday Edition, but as we heard recently in the case of the earthquake in Haiti, he files long-format current affairs and feature stories to the The Current also. He hosts the CBC Radio program In the Field, a show that celebrates storytelling through the radio documentary. All three interviewees are award-winning journalists and have experience either teaching journalism in a University setting (both in Canada and internationally) or training young journalists within the $\mathrm{CBC}$. They were selected for this thesis based on three factors: First, the nature of their work (long-format feature and investigative stories using voice recordings) and the relevance of oral history applications to their work: second, the length of their careers, with the assumption that the breadth and depth of past interviews allows them to provide maximum insight into this topic; and third, the fact that through their own teaching, they have invested time considering the theory and practice of journalism, and that their knowledge can inform this thesis in its effort to offer a new ways of approaching the journalistic interview. 


\subsection{Oral history as journalism}

In order to evaluate the applicability of oral history concepts to journalism interviewing, it is valuable to note how journalists are already employing personal narrative in their work. This review does not scrutinize examples of oral history as journalism in a critical sense; rather it serves to acknowledge the various uses of the lived experience in today's media landscape, albeit only in the published media. To that end, this review excludes the myriad of oral history projects that end up on personal websites, in schools or other local institutions that use interviews to broaden their own knowledge. Indeed, it is the plethora of material "out there" that fuels some criticism about oral history, causing some to speculate that it all amounts to a lot of wasted tape and recording time. Feldstein quotes an award-winning writer, Barbara Tuchman, who says:

With all sorts of people being invited merely to open their mouths, and ramble effortlessly and endlessly into a tape recorder, prodded daily by an acolyte of Oral History, a few veins of gold and vast mass of trash are being preserved which would otherwise have gone to dust. We are drowning ourselves in unneeded information. (qtd. in Feldstein 9)

Others have also raised doubts about the prevalence of so-called oral history projects in the public realm. British historian A.J.P. Taylor is quoted in an online Canadian encyclopedia as describing oral history as "old men drooling about their youth." ${ }^{135}$ What is more apt for this study is a limited look at examples of what some call "oral history as journalism," or journalistic works that draw from oral history-type interviews. The quality of this journalism ranges from terrible to spectacular, and while they employ the

\footnotetext{
${ }^{35}$ There are many other critiques of the volume and nature of popular oral history collections. This quote is found at: http://www.thecanadianencyclopedia.com/index.cfm?PgNm=TCE\&Params=A1ARTA0005959
} 
use of personal narrative in creative and innovative ways, they do not follow oral history methodology as laid out in chapter three.

According to oral historian Paul Thompson, oral history has been used in what he refers to as "historical broadcasting" longer than the term has actually existed (14). Thompson names a number of broadcasters that pioneered the use of historical programming on radio in Great Britain and in Sweden. He notes that dramatic programs such as Roots and Shoah reached millions of people by being aired on television, heralding social change as well as a new way of telling stories. More directly related to journalism, Thompson points to a case study in Poland in which a newspaper held a competition for people to submit their memoirs for publication. When published in the newspaper, the series sparked a national discourse about post-war society (18). The quantity and variety of personal experience-based journalism has amplified in the past sixty years. In the print media there are weekender pieces and magazine stories that reflect personal experience through in-depth examinations of various issues. Canadian Living magazine as well as The Ottawa Citizen both run stories with the interviewee as the author, but with the words "as told to (a journalist)" also in the by-line. These stories are presented entirely in first-person format, with the reporter's questions edited out, but there is implied collaboration between the interviewer and interviewee in the process of writing the story. ${ }^{36} \mathrm{CBC}$ Television is also experimenting with presentations that focus on personal and lived experience through no narration style, first person reports. CBC

\footnotetext{
${ }^{36}$ For example, the story of a woman whose husband was addicted to cybersex is told by the woman to journalist Susan Mcclelland at: http://www.susanmcclelland.com/pdf/CyberSex.pdf. Also, the story of a mother raising a brain-injured child is told by the mother, Gillian Irving (as told to Leah Macpherson) at: http://www.canadianliving.com/family/parenting/how to deal with a brain_injured child.php.

See works cited page for reference to Ottawa Citizen example.
} 
Television's The National recently aired two such examples. The first is a series of interviews with friends and relatives of Canadian soldiers who have been killed in Afghanistan. In the pieces, there is no interviewer in the final cut; rather, the "narrators" sit alone on camera, often with a memento or prop from the deceased person, simply recalling stories about that person; any questions from the interviewer are edited out, although the presence of an interviewer is implicit in the production. The other is a lengthy report by Canadian-Afghan journalist Nelofer Pazira commenting on the changes she's noted in Afghanistan. The absence of a reporter in the final cut, combined with the prolonged, very personal, narrative signifies a shift in journalistic style reporting, one that employs a number of oral history methods, including the narrator's own interpretation of events and the meaning she draws from the experiences. On CBC Radio the programming that represents direct personal experience, as opposed to those filtered through a host or formal presenter, has increased in recent years. For example, the program Outfront (recently cancelled during financial cuts, although still available as podcasts), offers stories from a completely personal perspective, in first-person form, resulting in very intimate revelations being introduced to the public sphere. Outfront is also the source of an initiative that attempts to capture some of the socio-economic issues facing northern Canadian communities:

In July 2008 the CBC Radio program, Outfront, gave five local kids recording equipment, a bit of coaching, and made a simple request. Tell us about where you live. Tell us about your life. The result, which was created from their recordings, is a four part radio series called "My Life So Far". It is also a half hour documentary that is part of Global Perspectives. This is a series of documentaries broadcast in Hong Kong, the UK, South 
Africa, New Zealand, Australia, the United States, the Netherlands, as well on $\mathrm{CBC} .{ }^{37}$

Living Out Loud is another CBC program that seeks personal experience in its programming. Describing itself as "a topical mix of documentaries and monologues, poems and personal portraits" the show reflects one of the most fundamental tenets of oral history theory, that it include the voices of those who otherwise would not be recorded by history. Living Out Loud states: "No 'pontificating experts' here, just people like you who take the microphone and show us what life is like where it's actually lived" (cbc.ca/livingoutloud). In the Field, hosted by David Gutnick, celebrates the art of the radio documentary and promises that listeners "will hear journalists capture the world with their microphones and make stories that may well change the ways you think and feel" (cbc.ca/inthefield). In the U.S., Public Radio International (PRI) distributes This American Life, a show hosted by Ira Glass, which addresses a current affairs or news theme each week through a very personal perspective, frequently using first-person narrative (thisamericanlife.org). American Public Media produces a show called The Story, hosted by Dick Gordon, a former CBC Radio journalist. This is how the show describes its goal:

At a time when "celebrity rules" and the only "ordinary" people we see are faces in the crowd, The Story reminds listeners that their stories and their lives matter. We believe that by creating a space for first person stories we are choosing not to accept a pollster's version of our thoughts and attitudes. (thestory.org)

There are hundreds of oral history interview endeavours on the Internet, both public and private, some of them with elements of what one might consider a journalistic

\footnotetext{
${ }^{37}$ http://www.facebook.com/group.php?gid=65963830239
} 
perspective. StoryCorps is a project initiated by National Public Radio (NPR) in 2003, in which more than 30,000 interviews of ordinary Americans have been recorded and archived (storycorps.org). The book version, Listening is an Act of Love, edited by NPR host Dave Isay, presents a sampling of the transcribed interviews.

The most obvious examples of oral history as journalism are the books that are called "oral histories." As previously mentioned, the staff at the Columbia Journalism Review published the book Reporting Iraq: an Oral History of the War by the Journalists who Covered it, in 2007. The book offers very personal accounts by journalists who were in Iraq during and after the fall of Saddam Hussein. The perspectives of the journalists are revealing, enlightening and chilling. For example, U.S. network news coverage of the toppling of Saddam Hussein's statue portrayed widespread celebrations in the streets by Iraqi people. However, this is how NPR's Anne Garrels describes, in the book, what she witnessed:

The toppling of the statue-yes, there were people celebrating, but there were as many people standing in shock. It was not just one big party, as I think the cameras tried to make it out to be. In fact, Morning Edition called me after the first feed, and they were seeing the TV coverage, and said, "Do you want to redo it for the next feed, because it seems like the pictures are people celebrating." And I said, "Well, there are so few people trying to pull down the statue that they can't do it themselves; the marines have had to intervene, rightly or wrongly, with a crane to pull it down." (24)

Since then, there have been many studies looking at how the media handled the toppling of the statue and how the event affected public opinion. Journalist Peter Maass deconstructs the episode in an article in The New Yorker magazine, in which he describes journalists pressured by their editors to increase coverage of the event. Maass describes what characterized coverage on television screens around the world: 
Closeups filled the screen with the frenzied core of the small crowd and created an illusion of wall-to-wall enthusiasm throughout Baghdad. It was an illusion that reflected only the media's yearning for exciting visuals... (51)

Calling the coverage "a disservice to the truth," Maass suggests Anne Garrels' oral history testimony was more accurate than the coverage itself. American journalism professor and oral historian, Mary Kay Quinlan, also applauds the narratives recounted in this book, noting the important connection being made between history and current events. She also observes that it lacks some of fundamental requirements of scholarly oral history, such as information about questions asked, transcript availability and archiving (305).

There are countless other examples of the way in which journalists use personal narrative and life experiences in interesting and compelling ways. Canada's History (formerly The Beaver), is full of stories that bring to life the experiences of ordinary and famous people from the past. International development programs in war zones or developing countries make extensive use of personal narrative in journalistic projects to explore past and current conflict, as a way to help society understand and move forward. ${ }^{38}$ While the above examples do not constitute all the elements of oral history interviewing as defined in this thesis, they all employ components of the oral history methodology, signaling a conscious inclusion of the lived experience as stories worth telling. Awareness of some of these cases serves to highlight the possibilities of academic oral history applications to the field of journalism and can serve as a backdrop to the following analysis.

\footnotetext{
${ }^{38} \mathrm{CIDA}$ is a leader on this front. See also, for example: http://www.farmradio.org/english/donors/home.asp
} 


\subsection{Analysis}

Any discussion about this topic must begin with Mark Feldstein, an academic and journalist who knows first-hand the similarities between oral history and journalism and has studied the fundamental differences as well. He notes that they both record information and follow many of the same procedures in their search for truth. Feldstein goes on to say the two fields...

...grapple with parallel issues of empathy, ethics and evidence. Like kissing cousins, with similar family roots and genetic material, they are related but separate: and each has much to teach the other. (par. 7)

Feldstein notes the differences lie for the most part in three areas: purpose, depth of ethical considerations, and the time they take to achieve their goals. This thesis, through the research in the previous two chapters, largely supports Feldstein's findings. The literature demonstrates:

- Both oral history and journalism seek a greater understanding of societal issues (whether historic or current) through a pursuit of the "truth"; the approach to the definition of truth is different, however, and the methods used to discover truth differ in fundamental ways.

- The purpose of the oral history interview is to seek meaning from an individual's lived experience by engaging in a process that includes interpretation of the interview; the journalistic interview also aims to make sense of the world around us, but the interview process is a more straightforward exercise whose goal is primarily to collect information from an interviewee and to disseminate information to the public. 
- The scholarly oral history interview is part of a process of inquiry that includes strict and rigorous components in its methodology; journalism is based on a looser set of codes and conventions.

- While both fields give serious consideration to the ethical treatment of interviewees, the oral history interview is strictly defined by clear deference offered to the interviewee on all levels; the ethical conduct during the journalistic interview is less predictable and to some degree distrusted both inside and outside the field of journalism (McKercher, Thompson and Cumming 368; Feldstein par. 18). It also encourages the dependence on personal conscience in decision-making throughout the process.

- Academics who use oral history interview methodology have a much more collaborative relationship with their narrator/interviewee than do journalists, whose "first loyalty is to citizens" (Kovach and Rosenstiel 51).

- The difference in end product dictates differences in methodology: Journalists grapple with the competing forces of relevance and interest to their audience, while academics are more concerned with validity and reliability.

- There are other differences, such as time lines, financial pressures and final product, although these are not explored deeply in this thesis as they are not central components of the oral history interview methodology.

The literature also demonstrates a number of clear parallels between the two fields:

- Both oral history and journalism have a long tradition of using interviews based on personal experience to achieve their respective goals. 
- Both fields consider background preparation on the subject paramount to the success of an interview.

- The general interview question advice, while not entirely consistent within the journalistic literature, is similar in both oral history and journalism, with only slight variations.

The identification of these differences and similarities between oral history interviewing methodology and the journalistic interview facilitates the discovery of potential applications from one to the other. The rest of this chapter examines in detail some of the methodological themes that emerged in chapter three and their potential for being of value to the practice of journalism.

\subsubsection{Theory and preparation}

a) The interview as qualitative research

In Sharon Hartin Iorio's Qualitative Research in Journalism, academics and journalists discuss qualitative research applications to the journalistic process, largely from a public journalism perspective. Iorio portrays a contemporary media landscape facing enormous financial and political pressures, presenting journalists with challenges on how to better represent and connect with the public. She suggests journalists in the Internet age could improve from "training beyond traditional reporting skills":

...journalists trained to know effective methods to expand reporting of grassroots problems overlooked in a media-rich atmosphere and how to apply the methods in an interactive media environment surely would not hurt the situation and likely would help it. While challenging in many respects, the milieu of abundant information and direct feedback has potential to open opportunities and correct some of the problems of the past. (4) 
Iorio's book adds to a substantial body of knowledge that examines potential applications of social science research techniques to journalistic endeavors, however, it is unique in its detailed attention to shared information about the interview process. Journalism professor Renita Coleman, the author of a chapter entitled Oral and Life Histories: Giving Voice to the Voiceless, reviews a case study of real-life journalism that uses many elements of oral history methodology. She examines in detail a feature series by reporter Roy Wenzl that ran in the Wichita Eagle in May 2000. The series applies what Coleman calls "a melding of oral history about a topic (the social problem of runaway teens) and life history (the story of Karen's short but eventful life)" (104). The article illustrates ways in which the journalist incorporated oral history interviewing theory in his job, but it also highlights the circumstances that may not be available to many working journalists, such as the 15 months that Wenzl told Coleman he spent working on the series (although not full-time, the implication is that it was most of the time) (105). Time restrictions aside, there are a number of methodological lessons about the use of oral and life history interview techniques to be learned by other journalists, according to Coleman:

- She notes Wenzl's use of social science style representativeness. He interviewed a wide variety of people, ranging from a judge to other runaway teens.

- Coleman applauds Wenzl's extensive background research before heading out to conduct the interviews.

- By the time the series was published, Wenzl says he interviewed the protagonist in the story (Karen) "30 or 50 times." Coleman notes "Wenzl found that 
numerous interviews were needed to establish the trust and intimacy necessary for Karen to open up and offer a true and searching account of her life" (104).

- Coleman draws attention to how Wenzl introduced official records, statistics and court documents to corroborate interview findings, enhancing the reliability and validity of the journalism.

Coleman reserves her highest praise for the way in which Wenzl included analysis for the citizens who would read the series:

...the topic of analysis and interpretation, so ingrained in journalists to avoid, was skillfully handled in this series by allowing the people in the stories to offer their own interpretation and analysis....this reporter maintained his objectivity and provided background for broader cultural and social patterns, but incorporated interpretation and analysis provided by others, not himself. (105)

The above list demonstrates clear ways in which techniques from oral history methodology can be applied to journalism in an effective way. While it is unclear whether or not Wenzl was consciously applying any social science tools as he constructed his report, it is apparent that the effect was successful and resulted in valuable journalism. Coleman says more journalists stand to gain from this kind of knowledge:

By paying more attention to some of the social scientific details of the oral history methodology, they will increase their own credibility and therefore improve their own reporting skills. (106)

b) Concepts relating to the value of oral testimony

For the most part, the oral history literature is profound in its discourse surrounding oral testimony-its history, its significance, as well as its potential flaws. In contrast to the journalism guides (with the exception of a very few, such as Sawatsky, who is unpublished), oral history explores in depth, the context in which oral testimony 
can be used as a data source, shedding light on its relationship with existing documents and other forms of research. The literature also identifies necessary checks and balances to verify authenticity and reliability of oral sources. Also, while many journalists seek more than facts and figures through the work they do, the search for meaning is intrinsic to all academic oral history projects, resulting in a much greater depth of knowledge about finding meaning through oral testimony. This depth of study does not appear in journalistic guides. Those who use oral history interviews in their research also praise the methodology for its ability to generate new and unexpected avenues of inquiry in their research. While some of the more specialized texts on journalism covered some of these points, the overall review of journalistic books revealed far less attention devoted to understanding the strengths and weaknesses of oral testimony.

c) The nature of oral history as "history from the bottom up"

A large component of oral history study devotes attention to the idea that oral history interviewing came of age during a process of immense social change and indeed, continues to focus on what is known as "history from the bottom up," or the democratization of history by interviewing people who are not in positions of power. Coleman writes:

One of the advantages of the oral history approach is the ability to fill in gaps left by reporting norms of the time or history written from the perspective of dominant social groups. (94)

This approach stands in sharp contrast—and for good reason, in the sense that their purposes are divergent— to the mainstream journalism guides that call for "fairness and accuracy" in interviewing, as an alternative to the less realistic "objectivity." While not everyone supports the idea that all oral history interviewing is done in the context of a 
social purpose (Feldstein, for example), the consideration given to marginal groups of people, and thus the appreciation of their perspectives, as a way of understanding the world in which we live, is a concept consistent with the goals of most journalists in western democracies. It is clear from the literature that the depth of theoretical discussion on this topic in oral history academe could inform journalistic practice as the latter seeks to generate public discourse in a free and democratic society.

d) Knowledge about memory

If there is any single theme to emerge from the literature on oral history interviewing, it is the matter of memory. Oral history interviews are meaningless if they are not reliable and valid, and understanding the workings of human memory is at the heart of achieving that kind of academic legitimacy. To summarize, there are a number of points that surface repeatedly in the literature, including: people remember what interests them; peoples' memories change over time; there are differences between short-term and long-term memory; there can be value to a researcher in understanding a "false" memory; collective memory is very different from individual memory, and can reveal valuable insights into a community; physical environment and surroundings can have an impact on a person's memory; and the fact that there are studies into virtually every facet of memory (for example, as it relates to gender, age or trauma) of which the results are published and available. The literature reveals some parallels with journalism knowledge (for example, recommending the use of props to trigger memories), but the profound understanding of the significance of memory to the interview process in oral history interviewing methodology is notable and could be highly instructive to journalists 
conducting interviews. CBC Producer Dick Miller would welcome such instruction as a way of enhancing the quality of his job:

If there is something that could be designed to help me understand oral history, how people remember, how they put it into words, what elements of memory come into place, how memories jog, how memories are created, all of that stuff would go a long way to help me be better at collecting material I need.

While it's unlikely journalists such as Miller will sift through the enormous volume of emerging studies into the way memory works, highlights from the oral history literature could be beneficial to journalists. In the book The Oxford Handbook of Oral History, Alistair Thomson sums up the challenge for oral historians as the literature on memory studies soars.

First, oral historians can help to ensure that memory studies do not retreat into an arcane intellectual world of rarified debate, but rather are informed by our relationship with the men and women who tell us their memories and by our efforts to engage memory in political debate for social change. Second, oral historians need to keep abreast of a daunting interdisciplinary literature in the field, including new scientific research about the ways that memory works. (81-82)

Given the similarities established between oral history interviewing and journalistic interviewing, the knowledge gleaned in academia on questions of memory could certainly contribute to the field of journalism.

e) Ethical issues and interviewer/interviewee relationship

The two previous chapters demonstrate that journalism and scholarly oral history share a rich history in striving for high ethical standards during the interview process. Their differences in purpose, though, result in a significant divergence in methodology. In the oral history literature, there is virtually no dissension as to what the basic ethical requirements are of an academically rigorous oral history project. It focuses on two 
elements: First, the relationship with the interviewee, or narrator, as they are most often called; and second, the meticulous process involved in securing, conducting and archiving the interview, all aimed at fulfilling the institution's high evaluation and ethical standards. The following is a summary of what the literature tells us academics must do as part of the oral history interview process:

- In the case of a University study, they must seek permission from the ethics committee, which requires information on who will be interviewed, why, whether it will cause any harm, what exactly will be asked, by whom, where, when, etc.

- They often offer anonymity to their interviewees, sometimes as a default (although the Oral History Association recommends this only in extreme cases).

- They do not begin until interviewees have signed release and/or consent forms, informing them of their rights within the research project, exactly what topics are being pursued, how the material will be used, who to contact in the event of a complaint, and that they can drop out at any time.

- They encourage sensitivity to the point that potentially painful topics (including age of an elderly person, or memory of a divorce) may be avoided during the interview (in other words, they agree to "off-limits" questions).

- They send the transcripts of the interview to the interviewees and allow them to review it, to clarify and/or to make changes, with the implication that if something is deemed undesirable, they will not use it in their research or in any published form.

- They consider, in great detail, such factors as gender, ethnicity and class on how the interview might proceed, as well as the content that will come from it. 
- They are very concerned about the effect the interviews (with or without publication) might have on individuals or communities in question.

- They write complete reports that include the methodology used during their research, so that others may assess their reliability and validity.

- They deposit their original material in an archive (university, museum or otherwise) so that others may refer to it in the future.

There is little doubt that the above requirements, in their entirety, could sink even the best journalist on his or her way to a good story. However, there are valuable points to consider that could inform journalistic practice. It is clear from the literature that journalists have a bad reputation when it comes to ethics. Journalist and historian, Mark Feldstein, offers up this assessment:

Indeed, while oral historians rarely try to push unwilling subjects into interviews, some journalists simply do not take no for an answer. Investigative reporters especially can be experts at getting information by virtually any means necessary; they might cajole, flatter, trick, seduce, infiltrate, or bully. Only law-breaking and paying for information is proscribed, and even these strictures are occasionally set aside. (Feldstein par. 18)

Feldstein's view (some of which he admits are extreme cases) is certainly not reflected in the journalism guide literature, which generally calls for accuracy, fairness and balance, but it does highlight the perception of some, and the depth of the divide between the two fields on the point of ethics. In the journalism realm, the perception of what is a mandatory code of conduct varies widely (the authors of The Canadian Reporter call it a "rough consensus" 367). The question then, as to whether or not journalists can be informed by ethical standards of the oral history interview 
methodology is best discussed on two points: Academic ethical requirements and interviewer/interviewee relationship.

\section{i) Ethical and procedural requirements}

There is general agreement among journalists that adopting any version of the strict set of rules required by oral history projects would be a detriment to journalistic practice. The understanding that a journalistic interview (in which the journalist is evident) will likely be used for publication effaces legal responsibility and ethical debate about getting written permission. All the journalists interviewed for this research agree that mandatory signing of release forms or letters, follow-up calls and allowing interviewees to veto stories before publication would be prohibitive in most journalism settings, not to mention at odds with certain journalistic concepts, such as independence. While describing interviewing people around the village well in a remote Ethiopian community, Dick Miller says "if I had to get all those people to sign release forms, nothing would have happened." David Gutnick says he interviewed people about female excision in Mali, where many of the community had never met a white person, let alone a journalist. He says he put them at ease and explained what he was doing, but does not believe official forms would have helped secure better interviews. The research discovers a number of other points on which more paperwork and legal requirements would present challenges to journalists, including: the pressures of time, in that it would take too long to seek and receive permission; the barriers such protocol could create when carrying out the practice known in journalism as "snowball" interviewing; the removal of journalistic freedom to make autonomous decisions about whom to interview. These concepts all 
constitute elements of the journalistic interview and would be compromised by more formal written requirements prior to interviews.

\section{ii) Interviewer/interviewee relationship}

The specific subject of the oral history approach to the interviewer/interviewee relationship holds more promise to journalists. The literature shows that the interviewer/interviewee relationship is at the crux of the oral history interview, while for the journalist, that relationship is more a means to an end, that end being to inform the citizens. However, both the literature and original interviews reveal ways in which the oral history interviewing approach could be valuable to journalism. $\mathrm{CBC}$ journalist Bob Carty applies certain oral history-like techniques during the preparation for interviews:

Before I even turn anything on, I have discussions on the phone about the use of this, how it will be processed, how it will be edited, who are the other voices. These are things I do not need to tell from a journalism ethics point of view. Clearly we're not to do it in certain cases. But when dealing with the life story type these kinds of stories require not just sensitivity but what I call contract. So the interviewee knows what we're going to do.

Carty's approach is based largely on trust, a personal value rather than an externallyimposed decree. Chapter two shows that the journalistic guidelines such as reviewing questions prior to the interview or explaining in detail how the material may be used exist primarily to ensure journalistic impartiality. However, the journalists interviewed for this thesis agreed that establishing a connection with their interviewee that goes beyond what most journalism guides recommend can be more beneficial to the end result. Several oral history concepts revealed in chapter three—such as Linda Shopes' "social space" idea, Michael Frisch's notion of "shared authority," and research demonstrating that interviewees who trust their interviewer are more likely to reveal more-could positively influence journalism interviewing. The journalistic literature reveals general instructions 
that journalists be friendly and polite to interviewees (notwithstanding investigative interviews that involve reluctant or hostile interviewees), but there is not much consideration given to behaviour beyond that basic advice. By engaging the interviewee in a shared and agreed upon goal (as Bob Carty does), the journalist is, in many ways, creating a social space in which he/she and the interviewee carry out their respective roles. CBC producer Dick Miller frequently uses the term "narrator" to refer to the journalist in some stories. This definition makes the journalist (or interviewer) the storyteller, as opposed to oral history methodology, in which, as shown in chapter three, the interviewee is considered to be the primary storyteller. This not only highlights a different use of terms, but it underscores the role of the journalist as the director of the story. Miller notes that the role of "narrator" in radio documentaries is changing. He sees a shift from the traditional "standard traffic director-style" to journalists who "have a stake in the characters and the story."

The narrator needs to be involved in the story in order for me to connect with them. We need to bear witness. We need to be there. We need to be in the moment with them. The process is still the same. The better the story is. Objectivity is lost and replaced by inquisitiveness.

Miller suggests that an interviewer who places him or herself into the narrative of the story is a "desired outcome," something he acknowledges is very different from the previous recommended styles of journalism. He suggests it signals a move away from the purely objective and emotionless journalists of the past, hinting that the interviewer/interviewee relationship could stand a deeper examination. Research for this thesis shows examples, whether planned or not, in which the shared authority concept appears in journalistic work. For example, Dick Miller participated in a project with CBC Radio that involved recording the stories of First Nations people in their original 
languages, then translating them into English for dramatic airplay on Ideas. In a move reflective of the idea of gift-giving in oral history, the $\mathrm{CBC}$ gave finished recordings to communities for their own educational and cultural uses. The Corporation currently sells the stories and sends proceeds back to the communities. Full narrator credit is also given to the story-tellers. While this does not constitute "daily" journalism, it is an indication of changing attitudes about collaboration, and could lead to new ways of thinking about story-gathering within the $\mathrm{CBC}$ and elsewhere.

Ultimately the research suggests that journalism ethics regarding the interviewer/interviewee relationship can certainly be informed by oral history interview methodology. David Gutnick, for example, comes to his own conclusion on the question of showing material to his interviewees before it goes to air:

A lot of journalists refuse to allow their subjects to see what they're going to publish or put on the radio before it goes on the radio. It's considered some kind of misstep if I show the material before it goes to air. I think it's the opposite. I have no problem allowing someone to hear the interview before it goes to air. Now, they have no right to change anything unless it's a fact. (...) It's amazing how many facts get wrong because we're too lazy. We use that laziness as an excuse, because of journalistic integrity (...) that's nonsense.

Bob Carty also combines his approach to interviewees with a merge of professional ethics and personal values; however, he doesn't recommend entrenching any new ethics practices into journalism codes. Mark Feldstein's view-that most journalists don't adhere to any single code or set of procedures, nor can they be enforced in the real 
world—-supports the findings of this thesis. ${ }^{39}$ Sharon Iorio quotes a study on journalism ethics that comes to a similar conclusion:

Rather than refining professional codes of ethics, the challenge for journalists is the moral life as a whole-no harm to innocents, truth telling, reparations for wrong actions, beneficence, gratitude, honor contracts, human dignity. (55)

f) Background knowledge and story preparation

Both journalists and oral historians strive for a high level of knowledge as they carry out their work. There is universal agreement on the value of being well-versed in a subject prior to recording an interview with a source. The fundamental difference on this point is the time issue, a factor outside the realm of this thesis. Furthermore, there are many books and articles that recommend ways in which journalists can improve and increase their preparatory work by incorporating various elements from social science research methods. However, some interesting ideas emerged about how journalists might borrow from oral history research in particular. The literature on journalistic interviewing encourages background research during the story development process, but the reality of daily schedules, even on longer-term projects, is highly restrictive, frequently limiting research to quick online searches of prior news articles or superficial reading. Drawing on oral history or other academic works could enlighten journalists in ways that media documents can't. For example, in anticipation of a trip to Mali in which he was doing a story about the Dogon people, David Gutnick turned to the pages of a 100 -year-old book written by a French anthropologist.

\footnotetext{
${ }^{39}$ For example, Feldstein uses the example of anonymity of sources as a frowned-upon, yet frequently used, tool in both oral history and journalism.
} 
I didn't read journalistic articles on Mali before I left, I actually read an anthropology book before I left because I thought an oral history preparation would be more appropriate than a journalistic one.

While this suggestion has more to do with the content of oral histories as opposed to the methodology applications to journalism, the value of drawing from a field with so many similarities is worth noting. Gutnick says it's only after years of doing journalism and understanding the value of such sources that he thought to turn to an academic source. The resulting knowledge earned him respect from the elder whom he interviewed. It also resulted in a more comprehensive story than he otherwise would have been able to tell (Personal interview, 2009).

\subsubsection{The interview}

\section{a) Question type}

The literature demonstrates that on the technical points of interviewing, oral historians have generally adopted and incorporated techniques from journalism into their practical interview guides. The advice in Valerie Yow's, Donald A. Ritchie's, Paul Thompson's and the vast majority of other guides about oral history interviewing includes specific question suggestions that reflect knowledge based on journalism methodology. The recognized expert on interview questions, John Sawatsky, journalist and trainer of journalists, is quoted in both journalism and oral history books (Ritchie, for example). Indeed, the literature shows that journalism's strength is in the type of questions to ask during the interview. Comparatively, oral history devotes much less time to this element of the methodology, drawing its research primarily from journalism sources. 
However, there are some points from oral history question styles that could be informative to journalism. For example, while the literature illustrates the necessity of confrontational questions during journalistic interviews in which an interviewee is being held to account, there is a virtual absence of confrontation in oral history interviewing. This does not denote softer questions, rather it addresses the collaborative nature of the interview process, as well as the theory that it will result in more forthcoming material. This is valuable advice to journalists who may face reluctant guests and who may opt for a more gentle approach to get the information they seek.

b) Time, repeat visits and recording

The research supports existing studies showing that time is a major difference in the methodology of journalism and oral history interview: For the former, time is cited repeatedly as a stress factor throughout the interview and story-gathering process, whereas in oral history interviewing, time is rarely mentioned. The cause of time restraints in journalism is the subject of another study. However, Bob Carty considers the question of time to be central to this thesis, observing that some applications from oral history methodology could have a place in all journalistic media-whether radio, TV or print, if there were enough time.

It's applicable to a short report and a long report if you have the time. You're going to get the time if you have a longer project. If you have the time I think you use all those techniques because you're going to get a better product. You're going to get a deeper understanding of the character (...) and how they interact and how they're in conflict often too.

All journalists interviewed for this thesis recognize the benefits of taking more time; of slowing down and being patient, lessons that, given the opportunity, could be instructive to all. David Gutnick says by recognizing that different cultures have various concepts of 
story-telling, journalists could learn from oral history's adherence to intercultural sensitivity during the story gathering process.

...you realize what a complicated relationship it is (...) You learn different cultures tell stories in different ways. A student straight out of journalism school would be completely lost if they were asked to do journalistic interviews with an Inuit elder.

Bob Carty and Dick Miller also value the process of allowing interviewees to take the time they need to tell their stories. They all describe cases in which they either returned to the interviewee in order to conduct further interviewing, or allowed the interviewee to talk for several hours. Although this would not be possible in many situations, clearly it is feasible and could be constructive. Renita Coleman says such repeat visits have many benefits, including "it establishes more intimacy between interviewer and interviewee" (101). A second visit to an interview also offers the opportunity to pursue new or forgotten themes, or to take a new shot at touchy or sensitive issues that were met with resistance during the first interview. David Gutnick says "as a journalist you have to learn to 'take off your watch' from time to time." He suggests that good journalists need to broaden their view of their own craft and understand the extremes - from "the politician who gives you two ten-second clips"- - to the Dogon elder in Mali. He recounts asking the elder to tell him how the practice of female excision began:

Quite literally it was a two-hour answer. Now if I were just trained as a journalist I would have had a heart attack. I would have said 'Oh my god I've gotta focus this guy. How am I going to get this down to a three minute interview?' But instead I just listened.

Gutnick's views support elements of oral history interview structure that calls for much looser, free-form interviewing allowing the interviewees to bring up whatever they 
consider to be important (the tri-partite approach is one such method), in contrast to the journalistic interview that proposes a more focused, directed interview style (with the exception of the "mop-up" question).

Coleman suggests one way to avoid missing significant points made during the interview is to follow oral history's requirement that interviews be recorded. She notes the potential benefits to journalists range from the obvious, such as the ability to review the recordings, to the more philosophical purpose, that is creating another level of credibility in the entire interview process. Recording interviews can also offer the interviewer additional time in the sense that they can do repeat or "snowball" interviews or conduct further research without having to worry about revising or writing down notes immediately. What emerges from this study is that journalists who are patient and take the time to do longer interviews, allowing sources to speak freely even if it means not using vast amounts of recordings, may end up with surprising, unexpected and valuable material.

\section{c) Listening}

Listening is obligatory for all interviewers. However, in the literature for both oral history and journalism, it is clear that listening is easier said than done. In journalism, the advice centers on a more literal meaning of the word, denoting details such as: paying attention, hearing the words that a source speaks, not interrupting, and following up on gaps or ambiguous statements. Oral history methodology approaches the concept of listening in more theoretical manner. For example, listening on more than one level-to the words, to the interviewee's self-assessment, and to the internal inconsistencies-can result in new and unexpected information as well as a better understanding of the 
meaning behind the words. A deeper grasp of this concept could enhance a journalist's work during the interview process.

\subsubsection{After the interview}

a) Transcribing and archiving

The post-interview oral history process presents a number of challenges for journalists. While many journalists transcribe some or even much of their material, the idea of spending 10 hours transcribing for every hour of interview time is unrealistic, except in rare circumstances. Chapter three shows transcription to be paramount to oral history interviewing. Feldstein considers this one of the areas in which journalism could change:

....journalism would do well to emulate oral history's exhaustive and nuanced approach to research evidence, especially its preservation of interview transcripts that allow public inspection and verification. (1)

In the case study from the Wichita Eagle, Renita Coleman points out that Wenzl did not use a tape recorder, indeed sometimes didn't even take notes, preferring to "write it down" after the interview (Coleman 105). This would indicate that it is possible to create successful journalism using some oral history interview ideas and not others. Coleman doesn't address the issue directly, but is fair to assume neither Wenzl, nor other mainstream journalists engage in a regular practice of transcribing or archiving their entire transcripts. However, as demonstrated in chapter three, full transcription as required by oral history interview methodology, can allow the interviewer to make observations that may have been missed during the actual interview. It can also be an opportunity to support any analysis or interpretation made by the researcher. Valerie Yow 
offers an example in which only complete transcription would accurately reflect the interviewee's meaning:

QUESTION: Did you try to stop the argument?

ANSWER: Well, I couldn't do ... Well, but it wasn't, don't you know, any of my business. No. I didn't try.

Here the repetition of "well" is not just a speech pattern; the speaker is troubled about admitting something. (317-318)

Despite the advantages, there are obvious limits to the practice of transcription in journalism. Time restraints are a major challenge. Another is the nature of constructing a finished product, as chapter two shows. Journalists cut clips, extract edited sequences and assemble them in a product that meets certain criteria. To transcribe every word, expression and grammatical tic would be superfluous to their job. In practice, there is a trend in the electronic media that is allowing more material from journalists' work to reach a public audience. As demonstrated in chapter two, the CBC offers longer, fuller, interviews-often on the "In depth" section of its website, but also on the websites of individual programs - as an added bonus to the "cut" versions that air on radio and television. Whether these interviews are highly edited or not is unclear, but they do provide an opportunity for context that is often lost in the fast-moving production of a Current Affairs or News program. Newspapers now frequently direct readers to their website where they can hear the "full" interview (recorded video and/or audio) as opposed to just short excerpts inserted into a longer print story. Technology has also increased the ability for journalism organizations to archive much more easily, affording greater public access. Bob Carty has material archived at both the CBC archives (generally the finished product that was broadcast) as well as "eight boxes" of original interviews at Library and Archives Canada. The Canadian Broadcasting Corporation has 
made hundreds of old video and audio recordings available through its website, allowing unprecedented public access to Canada's recorded history. While the difference between original, untouched material and edited products must be identified and understood, the increased public access to material in general does reflect some oral history values, in the sense that it demonstrates the ability of the public to review and corroborate elements of oral evidence.

b) Interpretation and analysis

The interpretation and analysis component of oral history is an area from which journalism professor Renita Coleman believes journalists can benefit by adopting a more methodical approach:

The method of oral or life history, mostly practiced by historians, sociologists, and anthropologists, is one research method that closely mirrors what journalists do...for longer journalistic projects the oral history method can be adapted to suit journalists' work and can enhance the credibility of their reports with the more rigorous attention to issues of validity and reliability, and greater focus on interpretation and analysis that is the hallmark of social scientific research. (96-97)

Two points must be acknowledged in assessing potential applications from the way in which scholarly oral history interviewing methodology approaches interpretation and analysis of interviews. First, as noted in chapter two, superior journalism and respected interviews, depending on their audience and purpose, already include a degree of independent corroboration, context and analysis. To suggest otherwise would be to undermine the work of commendable journalism organizations and media outlets. The second point is that the level of interpretation and analysis required in scholarly oral history interviews would present challenges to the purpose of journalism, that being to educate the citizenry. Factors such as the length of reports, the time required to write 
them, the terminology used, and the style of writing would likely impede the ability to connect with the audience. However, there are elements within the interpretation methodology from the oral history interviewing that could contribute to the way in which journalists analyze their interviews and use them as a technique to examine broader issues in society. Renita Coleman says in the oral history academic community there is consensus "that no interpretation adds little to our knowledge" (94). Coleman encourages journalists to search interviewee's words for internal meaning as well as provide background and social context (102). She points to the series by Wenzl as an example in which the reporter approached the question of analysis and interpretation in a very effective manner, by letting the interviewees comment on their own and each others' situations.

The reporter maintained his objectivity and provided background for broader cultural and social patterns, but incorporated interpretation and analysis provided by others, not himself. (105)

c) Storytelling, editing and the end product

Chapter two reveals that most journalism literature asserts a strong devotion to the concept of storytelling, although there is not agreement on how best to tell those stories. CBC producer Bob Carty has considered and tried many different ways of telling stories in journalism, as he has produced a wide variety of long-form pieces spanning more than thirty years. For Carty, there are two main considerations in terms of the applicability of oral history interview techniques to journalistic practice: storytelling and time. He believes the problem in journalism begins with language:

So many journalists don't know what a story is. Part of the problem is the verbiage. We call everything a story. So a story is a 55-second report; it's a 3-minute long feature; it's a 6-minute pack, a 9-minute documentary, 22 
minutes long. (...) We call everything a story and unfortunately it robs the sense of storytelling.

Drawing on his own vast experience and knowledge, Carty says "storytelling with purpose has power." He emphasizes the value of making reports memorable, with emotion and narrative structure, which, as demonstrated in chapter two, are important elements of the journalistic report. His concern with traditional news models is that they don't allow people's stories to be communicated effectively:

The journalist, because of the principle of inverted pyramid writing style, where you tell the punch line of the joke at the top and then you go backwards down to the least important information...just the opposite way you would ever tell a story if you were with a friend at a pub. You don't start with "I escaped from the jaws of the alligator by two inches." You don't start your story of your trip to the Amazon that way. You start with "I'd never been to the Amazon... it was raining"...and so on...

It appears from the research that experienced journalists, such Bob Carty and others, who are aware of narrative teachings in journalism, already have a solid sense of the value of personal narrative in journalism. However, there is no indication that most journalists have much, if any, instruction on issues of narrative, life experience, and other concepts from the social science use of oral history interviewing. As both Yow and Thompson point out in chapter three, the revelations that become possible during life story interviews, can be both unexpected and socially significant, in that they can reveal truths that would otherwise go unreported. Robert Atkinson describes the benefits of the life story in this way:

The life story interview offers a way, perhaps more than any other, for another to step inside the personal world of the storyteller and discover larger worlds. (Narrative 224)

He also emphasizes the value of appreciating that every person's experience is a kind of truth from which others can learn: 
The life story provides a clear and ordered record of personal truth that, of necessity, consists of both "fact" and "fiction." This is the most we can ask of a life story. It sets the record straight, as a personal explanation or justification, and often in a very touching way, for what people have done with their lives. (Life Story 20)

Atkinson adds that he sees the life story interview in particular as having "limitless applications as a research tool, suggesting it could be used as a "centrepiece for publication" in any field (16). Journalist Eric Nalder, actually recommends that journalists record as much of a life story of their interviewee as is possible:

Get the life story, even in cases where you don't intend to use it. When I interview a lawyer about a case, an engineer about a project, a bureaucrat about a government policy or even a public relations person about their client, I get the life story if I have time. This provides useful information, connections and hints for a better approach. (pbs.org)

The idea that journalists can benefit from spending more time with interviewees and collecting more of their life stories, is one that all the journalists interviewed for this research agreed with. As a documentary producer, Dick Miller is constantly searching for new, interesting and effective ways to tell compelling stories. He acknowledges that he has had only one opportunity for formal instruction on interviewing-the Sawatsky course many years ago. Miller believes knowledge from the oral history interviewing in the social sciences can enhance journalistic quality.

I think that any help that I can get in getting people to understand and reveal elements of their personal story, their oral history, any help that I get would be so useful for me. All I've got is an enquiring mind, a yapping gum and a microphone. And I know I could use help from the people who do this for a living academically; who know where to go, how to recognize patterns.

\subsection{Journalism Education}

Given the conclusion from the research that several oral history concepts could enhance the knowledge surrounding the journalistic interview, the question arises: How 
should this knowledge be imparted to journalists? While this question does not lie within the terms of this thesis, it is important to highlight some of the challenges and ideas raised during the research. The journalists interviewed for this thesis were unanimous in their criticism of the lack of education on general interviewing skills. When presented with notes on specific oral history theory and concepts, they also commented on the potential value of including broader knowledge relating to interviewing and journalistic practice in journalism classes. The literature shows little on this, other than to remark on the lack of interviewing courses in journalism schools (Iorio 5). Despite this, there are journalists who conduct high quality reports that are based on solid qualitative research, although they may not have been schooled in the terms. Sharon Hartin Iorio describes a Pulitizer Prize-winning series about race relations in America by a team of New York Times reporters (led by reporter Michael Winerip) as being "an unambiguous approximation of thorough qualitative research" (17). However, she says "many on the team, including Winerip, were not even aware of the term" (17). Iorio and the other authors in her book contend that an understanding of qualitative research methods, terms and practices could not only enhance the work some journalists are already doing, but could also help them do the work in a more systemic manner. G. Stuart Adam concurs, writing:

...I believe that much of journalism teaching - whether it is concerned with professional practices or with social and political effects - is too functional and too divorced from the higher reaches of authorship and thought. (7)

Carty, Gutnick and Miller all report that the only interviewing course at CBC they know of is the Sawatsky course, offered to some employees during the 1990s. Both Miller and Gutnick believe the emphasis in journalism education is too pragmatic, and 
that students are being taught to worry more about their recording material and question types than the strength of the narrative. The literature in chapter two supports this view. CBC reporter Dick Miller notes that good interviewing instruction needs to draw on greater engagement with people:

I don't even know what we teach anymore...I teach at King's periodically. I don't deal much with interviewing because that's supposed to be done elsewhere. But I listen to the lack of concern, the almost robotic form that people take, there's such a huge lack of general inquisitiveness not just about the facts but about what led to it. What are the forces that you think brought you to this point, and how is that possible, and I can't believe you've actually done that, and you're amazing to me, and just generally actually getting involved in the story, being in the moment, being an active listener.

Miller thinks offering some training in both oral history methodology and interviewing would be beneficial to journalism students, although he is less sure about when such instruction should be taught:

I think journalism school is probably too early, although it's probably worthwhile exposing them to the idea. What happens though is that people in the early years of their journalistic careers end up having to do slash and grab interviews and they're not looking for oral history generally. They are looking for the cop to tell them what happened, they're looking at the mayor to explain something, they're looking at a politician. So generally they don't have access to the kinds of stories you get later in life.

Miller raises the issue that has not come up in the literature at all as of yet, that is, the question of age, maturity and experience as a factor in how journalists conduct interviews. He seems to suggest that younger journalists are given the more timesensitive stories, while veteran reporters are allowed opportunities to dig a bit deeper. Anecdotally one could say this is the case, but it would be interesting to explore that further, as it could inform a discussion about when to teach courses on oral history methodology. Miller goes on to say: 
I would say 5 to 10 years in is a good time to start hammering it in...I think the older and wiser you get the more use you can make use of tools like this.

David Gutnick is unapologetically critical of journalism schools because of their narrow focus:

I actually think they should shut down Bachelor of Journalism schools. I don't think they should even exist. Because I think critical thinking is what's important and wide influences is what's important. I would rather hire someone who's backpacked across Europe with Dostoyevksy (...) rather than someone who's learned how to edit on a computer at Concordia University.

Gutnick says psychology or oral history courses would provide greater benefit to future journalists:

I think it would be way more important for an oral historian to teach us about interviewing and then the professor can say 'ok what parts of this can we use and what parts of this can't we use?' And then you have this grandma who's going to tell you about the depression, but you don't have two days, you've got two hours, so what parts of what you learned can you use and what can't you use?...

The general sentiment from both the in-depth interviewees and the literature is that the journalistic interviewing instruction focuses too much on technical aspects such as question types and not enough on critical thinking, human relationships and solid methodology. However, a superficial review of Canadian schools shows that educators are aware of the importance of educating students in subjects beyond journalism techniques. For example, in the journalism program at Carleton University, students must take only eight full journalism courses out of a total of 20 in order to graduate from the Bachelor of Journalism program. The intent is that by taking courses in other disciplines, the students will be "both trained and educated" (Dornan and Johansen 74-75). In a survey on journalism education in the United States conducted by the American 
organization The Freedom Forum, author Betty Medsger finds the vast majority of journalists believe that studying in a journalism faculty was a better choice than studying something else (115). The same study offers a number of other interesting observations on the question of journalism education that relate to this thesis:

New journalists who never studied journalism are doing as well as or better than the ones who studied journalism-in job satisfaction, in income, in achieving managerial positions and in winning the most prestigious awards and fellowships in journalism. (8)

The study also suggests that there is widespread acknowledgement of the need for professional development courses for journalists, after they've been working in the field:

All parties involved - new journalists, newsroom supervisors, and journalism educators - expressed strong interest in collaborating on the creation of local continuing-education programs for journalists, a tradition never firmly established in journalism, unlike other professions. (8)

Dornan and Johansen point to a number of weaknesses within the system-for example, a lack of consistency in instruction and the absence of an accrediting body (75). The relative youth of the Canadian journalism education system is raised as a factor in Canadian assessments of journalism education. John Sawatsky compares journalism schools to law and medical schools from one hundred years ago, saying they simply need time to "validate their existence and become valuable institutions," something he believes will happen (personal communication). Tensions between academic instruction and "real world education" appear to be at the heart of much of this discussion, a point addressed by Dornan and Johanssen:

The real question is whether postsecondary training makes a concrete difference to journalism practice. To our knowledge, no study has measured the quality of particular pieces of journalism against the education of their individual authors. (79) 
The potential for education is the subject of another study, buts its' relevance to this research as it identifies some of the themes that enter into the debate about academic instruction in journalism cannot be overlooked. Any application of concepts from oral history methodology to journalism would necessitate a solid understanding of when and where the appropriate pedagogic instruction should take place. 


\section{Chapter Five: Conclusion}

This thesis set out to conduct a critical examination of assumptions about the journalistic interview with a view to assessing the applicability of oral history interview methodology to journalism practice and knowledge. Through an analysis of literature reviews of both journalistic and oral history interview guides, as well as using original interviews with experienced journalists, the findings support the use of oral history applications to journalism. The analysis shows that oral history interview methodology, as it is used the humanities and social sciences, is perceived as a means to enhancing the practice of journalism. The thesis contributes to further understanding ways in which applications may be made as it identifies particular themes from oral history theory that can educate journalists and inform them as they do their jobs. The thesis findings raise new topics that are relevant to journalists in their quest for more meaningful stories. The thesis is based on the premise that both journalists and academics who use personal experience interviews in their research share some common goals and that each can learn from the other (Feldstein). Specifically, the thesis seeks to uncover some of the vast, scholarly examination of the interview process in the academic world, in an effort to find constructive lessons for journalists.

\subsection{Chapter review}

Chapter one identified the research question and clearly stated the parameters of

the thesis. It provided a clear definition of the theory and the method of oral history interviewing as used in academia, with a particular focus on the life experience interview. It also noted that the likely beneficiary of such information is feature and/or investigative 
journalism, although it did not rule out applications to other genres of interviewing. Chapter one also emphasized that the thesis was not intended to be a guide to the interview—either journalistic or oral history—rather it was intended to provide a review of the generally accessible literature on both forms of interviewing, in order to determine what the assumptions and theories are behind both practices.

Chapter two deconstructed the journalistic interview, again, through an examination of available and common texts, both in written form and online. It placed the journalistic interview in an historical context, as a form of communication whose lineage runs parallel and often intersects with oral history. This review provided the foundation upon which to reveal a number of key points regarding what is known about the journalistic interview:

- While the literature on journalism is vast, there is very little formal instruction on the journalistic interview, both in journalism schools and in professional environments.

- While some journalists already employ a number of social scientific methods during their work, knowledge about the interview process specifically is largely limited to the mechanics of the interview: ensuring technological competency and identifying question types.

- There are no clear parameters by which to measure success in journalistic interviews.

- Even within the literature and the guides, there is some disagreement (to varying degrees) on many points including: ethics, preparation, question style and the relationship with the interviewee. 
Chapter three provided an introduction to the methodology of oral history and particularly life experience interviewing as it is used in the humanities and social sciences. It situated the oral history interview methodology as a qualitative research tool, identifying both strengths and weaknesses in the method. Chapter three followed with an extensive overview of some of the major themes that comprise the oral history interviewing process, concluding that:

- There is a vast and profound body of work that examines the oral history interview methodology in a number of fields in the humanities and social sciences.

- There is a massive amount of research into the value and reliability of oral evidence during the interview process, and specifically the oral history interview method.

- Much of the methodology is based on knowledge about memory and how human beings remember during the interview process.

- The relationship with the interviewee or "narrator" is paramount to both the theory and practice of oral history interviewing.

- The ethical requirements of oral history interviewing are stringent and extensive, often striving to meet both the standards of a university's ethics committee as well as the guidelines as set out by the Oral History Association. These are aimed at ensuring the highest possible level of academic and professional reliability and validity.

- A fundamental purpose of the oral history interview is to seek meaning from the interviewee's words and experiences. 
Chapter four synthesized chapters two and three and identified areas in which the academic exploration of the interview process could inform journalistic interviewing. Similarities, as well as clear differences, were highlighted, with a view to finding potential applications from scholarly oral history interviewing to journalistic interviewing. Chapter four presented these findings through an analysis of the literature drawn from books, journals, media, and online material, as well as from the views of experienced journalists. The chapter concluded that there are many ideas from oral history methodology that can indeed be applied to the practice of journalistic interviewing. It also identified areas in which a journalists' work would be hindered or compromised. Finally, chapter four briefly explored some of the future challenges and implications in terms of sharing the knowledge through journalism education programs.

In the conclusion, chapter five, the results of the thesis will be laid out. The findings conclude that there are numerous ways in which the journalistic interview could be enhanced by knowledge from academic oral history interview methodology. It approaches the results through the understanding that journalists need to balance their responsibility to inform the citizenry with a number of factors, including deadlines and financial constraints. In light of these pressures, the research also points to some areas of oral history interview methodology that would hinder the work of a journalist. What follows are recommendations based on the results of this thesis, demonstrating how oral history interview methodology, as it is used in the humanities and social sciences, can inform the journalistic interview. 


\subsection{Recommendations}

The following seven recommendations highlight the ways in which oral history methodology could enhance journalism; they also include perceived limits to any application.

\section{Journalists could benefit from oral history knowledge about memory and the way humans remember during the interview process.}

A significant finding from the research is the prominence of the focus on human memory by academics who conduct oral history interviews. There is an ever-growing and multi-disciplinary volume of literature on the matter of memory in university libraries, on store bookshelves and on the Internet. The research demonstrates that oral history and journalism interviewers value knowledge and skills while preparing to do interviews. Given that memory is central to the reliability of oral evidence, journalists stand to gain from this vast and profound body of work. A more thorough understanding about how people remember-such as how age affects memory, what effect trauma has on memory, concepts such as personal and collective memory, and how all these ideas relate to the interview process-can clearly contribute to the journalist who conducts interviews. The material is readily available. Academics who use oral history interviewing in their research have already tapped into this knowledge; so too, should journalists.

\section{Journalists could enhance the quality of their interviews by applying some of the concepts from the oral history academic approach to the relationship between interviewer and interviewee.}

Oral history academics who conduct life experience interviews give enormous consideration to issues far beyond basic manners and respect toward interviewees. Some 
of the ideas the research shows could be applied to journalism include: knowledge about the impact of factors such as gender, race and age differences in interviews; power differentials; sharing more information about the purpose and uses of the interview with the interviewee prior to recording; planning repeat visits with the interviewee in order to establish more trust and rapport; in edited pieces, including the interviewer's questions more frequently in order to illustrate the context and to be more transparent; taking the potential impact the interview might have on the interviewee more seriously; and even considering a more collaborative approach to the storytelling process, where appropriate.

A full-scale application of the extensive ethics requirements regarding the relationship between interviewer and interviewee from oral history methodology, however, would hinder a journalists' work. The administrative procedures (letters, consent forms, etc.) would amplify the journalists' existing time constraints. Also, the nature of the relationship as recommended in oral history interviewing would be unrealistic for most journalists as they carry out their day to day work.

\section{Journalists could augment their skills by borrowing techniques from oral history} methodology that involve shared ownership (or "shared authority, as it's called in oral history studies) of the story they're covering.

The commonly used term "narrator" to denote what journalists call "interviewee," represents the way in which oral history interviewers view the source of the story; it signifies that the individual is central to the life experience interview process. While the literature demonstrates a direct connection between the academic's ethical responsibility to research subjects and the respect with which they are treated, it also speaks to the value attached to the mutual experience of oral history interviewing. The research, based on the 
experiences of those who conduct oral history interviews in the social sciences and humanities, shows that this relationship results in more engagement, better rapport and more trust, and therefore more informative material deriving from the narrator. Journalists could adapt the collaborative approach from the oral history interview methodology to their journalistic interviews, when appropriate, in an effort to offer the interviewees a greater stake in the narrative, and to obtain more meaningful interviews.

This approach clearly has limits within the context of journalism. In oral history interviews, the weight attributed to the narrator's version of events is elemental, whereas in journalism the concept of balance would prevail in many cases. Also, a journalist's independence from influence, as well as their ability to present the story in a fair and impartial manner, would need to be considered before partaking in any form of shared ownership. In controversial stories, or in situations that involve reluctant interviewees, this concept would not apply.

4. While the literature shows that journalists are more advanced in terms of question types and technical skills during the recorded interview procedure, there are practices within the life experience genre of oral history interviewing that could enhance the way journalists do interviews.

Oral history interview methodology, and in particular the life review approach, focuses on placing intrinsic value on the contributions of the narrator/interviewee, and striving to allow that person to raise topics that he or she deems significant. One of the ways in which this is achieved is through an open interview format that allows the interviewee to talk about anything, often leading the interview into unchartered, unexpected and illuminating territory that tightly focused journalism-type questions 
would likely not achieve. The research shows that some journalists already subscribe to this method, but the vast majority of the journalism interview guides do not recommend any form of unfocused interviewing (with the exception of the "mop-up" question). There are other points from oral history interview methodology that could inform journalistic interviewing, including allowing more time for the interview component of the storygathering process, combining the nonspecific with the focused questions, and opting for more gentle coaxing of interviewees as opposed to confrontation, when the situation allows. All these ideas hold the promise of more memorable story-telling in journalism.

5. As journalists process material to be consumed and understood by the public, they can take valuable lessons from oral history interviewing methodology in how to treat people's recorded experiences during the editing process.

The recording of the interview is a central component of oral history methodology. It not only allows the researcher to examine in minute detail the words, phrases, grammar, and style of the interview, but it also enables the researcher to assess, interpret and, if appropriate, place in some greater societal context, after the interview. There are many factors academic oral history interviewers take into account during this process, including: ensuring that context is not lost while editing; balancing the pros and cons of removing or changing words, such as slang, dialects, grammatical errors or misspoken words; and taking into consideration the effect all editing will have on both interviewees and the message of the overall piece. The literature highlights two points: First, there is a more comprehensive level of discourse on the post-interview process in the oral history realm than in the journalism guides; and second, on all the above issues, 
the academic interviewer is much more careful to minimize any negative impact the use of material may have on the interviewee.

It's important to note that these topics are not foreign to journalists; indeed, journalists are more skilled than academics in editing and creating material that will resonate with a public audience. Keeping in mind their divergent purposes (the academic-to the interviewee, the journalist-to the public), the enhancement of journalism practice on this point could have some subtle but significant practical impact.

\section{The underlying emphasis of oral history methodology on the search for meaning} during interviews could inform the way in which journalists seek evidence as they cover in-depth feature or investigative stories.

The search for meaning, as opposed to simply facts or information, is a fundamental goal of oral history interview methodology. Internal and external corroboration are not new concepts for journalists, but by adding the practice of what some call "listening in stereo"-listening for words, opinions and feelings while constantly checking them mentally against the interviewer's words for internal reliability and against the context of societal realities-journalists could vastly enhance the understanding of an interview. This more methodological approach to listening can awaken the interviewer to insight and meaning that could prove to be significant to the journalistic story.

\section{Journalists can draw lessons from oral history interview methodology as a model for transcribing and archiving material for future verification.}

The research for this thesis demonstrates the critical importance of making oral history interviews available in print and recorded form, in their full, unedited shape so 
that other academics and members of the public can access them as secondary data. The ability to review and verify the material and also to assess the researcher's methods is vital to the reliability and validity of oral evidence in academic oral history methodology. The data analysis reveals that journalistic organizations as well as individual journalists are voluntarily making more material available to the public on a regular basis. The trend towards posting un-cut interviews on the Internet points to recognition that it is in the public's interest to be able to view or listen to unedited interviews. The academic literature supports the adoption by journalists of social science approaches to retaining oral evidence, mainly through the use of transcripts, archives, and effective indexing. Also, given that oral history interview scholars are always searching for better transcription technology, journalists may end up taking lessons from the field on that front as well. By continuing to build on the foundation already begun as it pertains to retaining and making available original documentation, journalism can become more reliable, verifiable, and valid.

\subsection{Hypotheses for further study}

As this thesis at no point purports to be an all-inclusive review of every aspect of the journalistic interview, findings from the research identified a number of topics that are not addressed in the results, but are worthy of future study. The following five points comprise suggested recommendations for further scrutiny:

- Accepting the results that some oral history interview methods could enhance the journalistic interview, at what stage of a journalists' career would these techniques be best learned and best incorporated into their work?

- To what degree, if at all, would they apply to daily news journalists? 
- Who would be best to teach the knowledge and skills that would be included in a curriculum for journalists: social scientists or journalists?

- In what ways could journalists draw from the vast collections of oral history recordings that exist? $?^{40}$

- There are numerous data bases of journalistic oral history collections. To what extent, if at all, would it be worthwhile to assemble them all in one large data base for educational or professional purposes?

These questions are directly or indirectly related to the shared experiences of oral history and journalistic interviewing and should be considered in future discourse. In many ways, they represent the recurring intersections of the two fields as their joint and parallel history binds them together so frequently.

This thesis, through a critical examination of the journalistic interview and the exploration of the oral history interview methodology, demonstrates clearly where their differences and similarities lie. The thesis shows some of the assumptions about the journalistic interview, in particular as it pertains to feature and investigative interviews. It also provides a detailed look at significant themes of oral history interview methodology, as it is used in the humanities and social sciences. What emerges is an examination and assessment of their different methods, dictated largely by different motives. For the journalist, educating the citizenry is the primary responsibility. For the scholar, there is a balance between generating new areas of knowledge and meeting rigorous academic standards, ethical and otherwise. The thesis demonstrates that while the two fields do not

\footnotetext{
${ }^{40}$ As an example, CBC producer Bob Carty does not believe that most of the material would be useful for broadcast: First because the recording quality is often poor. Second, because he records segues and introductions during the interview that he then uses in documentaries.
} 
have identical purposes, they do share a fundamental objective, that is to seek truth and meaning in order to better understand the world in which we. Through the recording of personal experience in the interview process, they also share a common tool to achieve their goals. By clearly identifying the applicability of elements from oral history interview methodology to the journalistic interview process, and by offering recommendations on how some of the concepts developed in the field of oral history interviewing could be adapted to journalistic practice, this thesis aims to contribute to the discussion already started about how journalists could improve the journalistic interview by incorporating those ideas into their work. A stronger understanding of these concepts could help journalists as they strive to create relevant, truthful and compelling reports, and to increase our individual and collective understanding of significant events in the world. 


\section{WORKS CITED}

Adam, G. Stuart, and Poynter Institute for Media Studies. Notes Towards a Definition of Journalism; Understanding an Old Craft as an Art Form. St. Petersburg, Florida: Poynter Institute for Media Studies, 1993. Print.

Adams, Sally, and Wynford Hicks. Interviewing for Journalists. London ; New York : Routledge, 2001. Print.

Altheide, David. In Handbook of Interview Research: Context \& Method. Ed. Jaber F.

Gubrium and James A. Holstein. Thousand Oaks, Calif.: Sage Publications, 2002. Print.

Anderson, Katherine, and Dana Jack. "Learning to Listen: Interview Techniques and Analysis." The Oral History Reader. Ed. Robert Perks and Alistair Thomson. 2nd ed. New York: Routledge, 2006. Print.

Atkinson, Robert. The Life Story Interview. Thousand Oaks, California: Sage Publications, 1998. Print.

Banaszynski, Jacqui. "Stories Matter." Telling True Stories: A Nonfiction Writers' Guide from the Nieman Foundation at Harvard University. Ed.Mark Kramer and Wendy Call. New York; Toronto: Plume, 2007. Print.

Barone, Jeanne Tessier, and Jo Young Switzer. Interviewing: Art and Skill. Toronto, Ontario: Allyn and Bacon, 1995. Print.

Baylis, Paul, and Joseph Scanlon. "A Very Mixed Bag: What Introductory Reporting Texts Say about Interviewing." Conference paper from the Annual Meeting of the Association for Education in Journalism and Mass Communication. Montreal, Quebec: August 1992. Print. 
Biagi, Shirley. Interviews that Work: a Practical Guide for Journalists. 2nd ed. Belmont, Calif: Wadsworth Pub. Co., 1992. Print.

Borland, K. “'That's not what I said:' Interpretative conflict in Oral Narrative Research." The Oral History Reader. Ed. Robert Perks and Alistair Thomson. $2^{\text {nd }}$ ed. New York: Routledge, 2006. Print.

Canadian Association of Journalists. Statement of Principles and Ethics Guidelines Investigative Journalism. 2004. Web. 10 Jan. 2011. http://www.caj.ca/?p=155

Canadian Broadcasting Corporation. Journalistic Standards and Practices. 2010. Web. 28 Dec. 2010.

$<$ http://cbc.radio-canada.ca/docs/policies/journalistic/xml/policies.asp?pol=25_en.xml>

---. Radio Skills. English Radio Training Department. Toronto: 1990. Print.

---. with Cardinal, Susan. Tips for Poc Docs. Calgary, Alberta: January 1994. Print.

---. CBC Radio Style Guide. 1999, 2003. Learning and Development Publications. Print.

---. Canadian Oral History Association. Web. 6 Dec. 2010. < http://www.canoha.ca/ $>$.

Carty, Bob. Personal interview. Ottawa. 26 Feb. 2009.

Charlton, Thomas L., Lois E. Myers, and Rebecca Sharpless. History of Oral History: Foundations and Methodology. Lanham, MD: Rowman \& Littlefield, 2007. Print.

Clandinin, D. Jean. Handbook of Narrative Inquiry: Mapping a Methodology. Thousand Oaks, Calif: Sage Publications, 2007. Print.

Clayman, Steven, and John Heritage. The News Interview: Journalists and Public Figures on the Air. Cambridge: Cambridge University Press, 2002. Print. 
Coleman, Renita. "Oral and Life Histories: Giving Voice to the Voiceless." Qualitative Research in Journalism: Taking it to the Streets. Ed. Sharon Hartin Iorio. Mahwah, NJ: Lawrence Erlbaum Associates, 2004. (93-108). Print.

Couric, Katie. CBS Evening News with Katie Couric. Sep. 24, 2009. Web. 10 Dec, 2010. $<$ http://www.cbsnews.com/stories/2008/09/24/eveningnews/main4476173.shtml>.

Cribb, Robert M., Dean Jobb, David McKie, and Fred Vallance-Jones. Digging Deeper: A Canadian Reporter's Research Guide. Don Mills, Ont.: Oxford University Press, 2006. Print.

Crook, Tim. International Radio Journalism: History, Theory and Practice. London; New York: Routledge, 1998. Print.

Cruikshank, Julie. Life Lived Like a Story: Life Stories of Three Yukon Native Elders. Lincoln: University of Nebraska Press, 1990. Print.

DeWerth-Pallmeyer, Dwight. The Audience in the News. Mahwah, N.J.: Erlbaum, 1997. Print.

Dickerson, Debra. "Telling True Stories: A Nonfiction Writers' Guide from the Nieman Foundation at Harvard University Eds. Wendy Call and Mark Kramer. New York; Toronto: Plume, 2007. Print.

Dornan, Christopher, and Peter Johansen. "Journalism Education in Canada." Journalism Education in Europe and North America: An International Comparison. Cresskill, NJ: Hampton Press, c2003. Print.

Eddy, Colleen. "Learning from John Sawatsky: Interview Methods." 30 April, 2008. Web. 28 Dec. 2010. <http://www.poynter.org/how-tos/career-development/colleenon-careers/88589/learning-from-john-sawatsky-interviewing-methods/>. 
Enright, Michael. "America in the Aftermath of Tuscon." Interview with Stephen Hess. The Sunday Edition. Canadian Broadcasting Corporation, 16 Jan. 2011. Radio.

Feldstein, Mark. "Kissing Cousins: Journalism and Oral History." Oral History Review 31.1(2004):par.26.Web.23Oct.2010.

http://www.historycooperative.org/journals/ohr/31.1/feldstein.html

Folkenflik, David. "The Art of the Interview, ESPN-style." Npr.org. Aug 14 2006. Web. 23 Oct. $2010 .<$ http://www.npr.org/templates/story/story.php?storyId=5625218>.

Frèohlich, Romy, and Christina Holtz-Bacha. Journalism Education in Europe and North America : An International Comparison. Cresskill, NJ: Hampton Press, c2003. Print.

Friend, Cecilia, and Jane B. Singer. Online Journalism Ethics: Traditions and Transitions. Armonk, N.Y.: M.E. Sharpe, 2007. Print.

Frisch, Michael H. A Shared Authority: Essays on the Craft and Meaning of Oral and Public History. Albany: State University of New York Press, 1990. Print.

Gibb, Don. "How to get the Most from Your Interview." Educational Pamphlet. ND. 29 pages. Print.

Glass, Ira. "The Transom Review vol. 4, Issue 2. Ira Glass Manifesto." 1 June, 2004. Web. 24 Sept. 2010

$<$ http://www.transom.org/guests/review/200406.review.glass1.html $>$.

Grele, Ronald J. "Oral History as Evidence." History of Oral History: Foundations and Methodology. Eds. Thomas Charlton, Lois E. Myers, and Rebecca Sharpless. Lanham, MD: Rowman \& Littlefield, 2007. 33-91. Print.

Grele, Ronald J., and Studs Terkel. Envelopes of Sound: The Art of Oral History. 2nd ed. Chicago, Ill.: Precedent Pub.: Distributed by Transaction Books, 1985. Print. 
Gubrium, Jaber F., and James A. Holstein. Handbook of Interview Research: Context \& Method. Thousand Oaks, Calif.: Sage Publications, 2002. Print.

Gutnick, David. Personal interview. Ottawa-Calgary. 5 March, 2009.

Gzowski, Peter. The Private Voice: A Journal of Reflections. Toronto: McClelland and Stewart, 1988. Print.

Harrington, Walt. Intimate Journalism: The Art and Craft of Reporting Everyday Life. Thousand Oaks, Calif.: Sage Publications, 1997. Print.

Hesse, Jurgen. The Radio Documentary Handbook: Creating, Producing, and Selling for Broadcast. 1st ed. Vancouver: International Self-Counsel Press, 1987. Print.

Hesse-Biber, Sharlene Nagy, and Patricia Leavy. The Practice of Qualitative Research. Thousand Oaks: SAGE Publications, 2006. Print.

Hoyt, Mike, and John Palattella, and the staff of the Columbia journalism review, eds. Reporting Iraq: An Oral History of the War by the Journalists Who Covered it. Hoboken, N.J.: Melville House Publishing, 2007. Print.

International Centre for Journalists. "Ten Tips for a Better Interview." Concernedjournalists.org. 2 Oct. 2007. Web. 15 Sept. 2010.

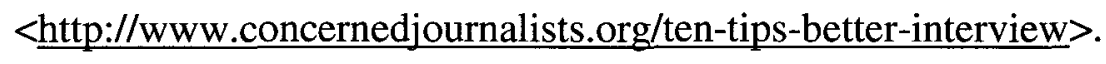

Iorio, Sharon Hartin, ed. Qualitative Research in Journalism: Taking it to the Streets. Mahwah, NJ: Lawrence Erlbaum Associates, 2004. Print.

Kines, Lindsay. "Should I share quotes with a source?" j-source.ca. Aug. 3, 2010. Web. 4 Sept. 2010. <http://www.j-source.ca/english new/detail.php?id=5437>. 
Klempner, Mark. "Navigating Life Review Interviews with Survivors of Trauma." The Oral History Reader. Ed. Robert Perks and Alistair Thomson. 2nd ed. London and New York: Routledge, 1998. Print.

Kovach, Bill, and Tom Rosenstiel. The Elements of Journalism: What Newspeople should Know and the Public should Expect. New York: Three Rivers Press, 2007. Print.

Kramer, Mark, and Wendy Call. Telling True Stories: A Nonfiction Writers' Guide from the Nieman Foundation at Harvard University. New York; Toronto: Plume, 2007. Print.

Lee, Edward, Ronald Chepesiuk, and Haney Howell. Raising Hell: Straight Talk with Investigative Journalists. Jefferson, N.C.: McFarland, 1997. Print.

Lummis, Trevor. Listening to History: The Authenticity of Oral Evidence. Totowa, N.J.: Barnes \& Noble Books, 1988, 1987. Print.

Maass, Peter. "The Toppling: How the media inflated a minor moment in a long war." The New Yorker. 10 Jan. 2011. Print.

McCombs, Maxwell E., Donald Lewis Shaw, and David L. Grey. Handbook of Reporting Methods. Boston: Houghton Mifflin, 1976.

McKie, David. "Interviewing the Interviewer: Getting to Know John Sawatksy." Media, 1993, 28-32. Print.

McKercher, Catherine, Allan Thompson, and Carman Cumming, eds. The Canadian Reporter: News Writing and Reporting. 3rd ed. Toronto: Nelson Education, 2011. Print.

McLaughlin, Paul. "The Art of an Effective Interview: Tips for Interviewing." Canadian Newspaper Association. ND. Web. 23 Jan. 2010. 
$<$ http://www.cane.ca/english/me res interviewingtipspaul.htm>.

---. Asking Questions: The Art of the Media Interview. 2nd ed. Vancouver: International Self-Counsel Press, 1990. Print.

McNair, Brian. The Sociology of Journalism. London; New York: Arnold; Co-published in the United States of America by Oxford University Press, 1998. Print.

Medsger, Betty. Winds of Change. Arlington; Virginia: The Freedom Forum, 1996. Print.

Merritt "Buzz", Davis. Public Journalism and Public Life: Why Telling the News is Not enough. 2nd ed. Mahwah, N.J.: Erlbaum, 1998. Print.

Metzler, Ken. Creative Interviewing: The Writer's Guide to Gathering Information by Asking Questions. 3rd ed. Boston: Allyn and Bacon, 1997. Print.

Miller, Dick. Personal interview. Ottawa-Halifax. 12 March 2010.

Nalder, Eric. "Loosening Lips: The Art of the Interview." pbs.org. ND. Web. 28 Jan. 2010. <http://www.pbs.org/wnet/expose/expose 2007/etools/loosenlips2.html>.

"Oral Tradition and Origin Myth." Allsands.com. ND. Web. 26 Oct. 2010. $<$ http://www.allsands.com/history/oraltraditionc wpw gn.htm $>$.

Osler, Andrew M. (Andrew Martin). News: The Evolution of Journalism in Canada. Toronto: Copp Clark Pitman, 1993. Print.

Hill, Dan, as told to Brittany Mahaney. "I feel a lot stronger at 56 than I did at 36." Ottawa Citizen 10 Jan. 2011, sec. D1. Print.

Paterno, Susan. “The Question Man.” ajr.org Oct. 2000, Web. 15 Jan. 2010.

Patterson, Kevin, and E. Jane Warren. Outside the Wire: The War in Afghanistan in the Words of its Participants. Toronto: Random House Canada, 2007. Print. 
Perks, Robert, and Alistair Thomson. The Oral History Reader. 2nd ed. London; New York: Routledge, 2006. Print.

Portelli, Alessandro. The Order has been Carried Out: History, Memory, and Meaning of a Nazi Massacre in Rome. New York, NY: Palgrave Macmillan, 2003. Print.

Quinlan, Mary Kay. Rev. of Reporting Iraq: An oral history of the war by the journalists who covered it. Oral History Review 37: 2. Summer/Fall 2010: 304-306. Print.

Radio Diaries. "Interview Tips." Radiodiaries.org. ND. Web. 28 Oct. 2010. $<$ http://www.radiodiaries.org/handbook4.html $>$.

Reid, Tim. "Caroline Kennedy." Ottawa Citizen. 30 Dec. 2008. 5. Print.

Ritchie, Donald A, ed. The Oxford Handbook of Oral History. New York, NY: Oxford University Press, 2011. Print.

---. Doing Oral History: A Practical Guide. 2nd ed. Oxford; New York: Oxford University Press, 2003. Print.

---. "Principles and Best Practices." Oral History Association. Oct. 2009. Web. 15 Dec. 2010. $<$ http://www.oralhistory.org/do-oral-history/general-principles-for-oral-historyand-best-practices-for-oral-history/>.

Rosen, Jay. What are Journalists For? New Haven: Yale University Press: 1999. Print.

---. Foreward. Qualitative Research in Journalism: Taking it to the Streets. Ed. Sharon Hartin Iorio. Mahwah, NJ: Lawrence Erlbaum Associates, 2004. Print.

Saul, Michael. "Caroline Kennedy: No Whiz with Words." Dailynews.com 29 Dec. 2008. Web. 10 Dec. 2010. <http://www.nydailynews.com/news/politics/2008/12/29/200812-29 caroline kennedy no whiz with words-1.html\#ixzz0UmYEh9Qr>. 
Sawatsky, John. "Interviewing: The Need for a Methodology." Paper presented at The Art of Journalism Conference. Carleton University, Ottawa, Ontario. 1993. Print.

---. "Revelations from the Rocket on 60 Minutes? Not likely." Espn.go.com. 4 Jan. 2008. Web. 20 Sept. 2010. <http://sports.espn.go.com/mlb/columns/story?id=3181572>.

---. Personal interview. Ottawa-Connecticut. 6 Feb. 2010.

Scanlon, Joe. "The Interview - Part II.” Lecture notes, ND. Carleton University, School of Journalism and Communication. Print.

Schudson, Michael. Discovering the News: A Social History of American Newspapers. New York: Basic Books, 1978. Print.

Shopes, Linda. "What is Oral History?" historymatters.com. ND. Web. 16 Sept. 2010. $<$ http://historymatters.gmu.edu/mse/oral/what.html $>$.

Society of Professional Journalists. "Ethics." Spj.org. ND. Web. 18 Sept. 2010. $<$ http://www.spj.org/ethicsfaq.asp $>$.

Stein, M. L. (Meyer L.), Susan Paterno, and R. Christopher Burnett. Newswriter's Handbook: An Introduction to Journalism. 2nd ed., Ames, Iowa: Blackwell Pub., 2006. Print.

Stein, M. L. (Meyer L.), and Susan Paterno. Talk Straight, Listen Carefully: The Art of Interviewing. 1st ed., Ames, Iowa: State University Press, 2001. Print.

Stephens, Mitchell. A History of News. 3rd ed., New York: Oxford University Press, 2007. Print.

Tait, Dave. "Storytelling." Journalism 2001. 12 pages. Print.

Terkel, Studs, "Interviewing an Interviewer," The Oral History Reader. Ed. R. Perks and A. Thomson. 2nd ed. Routledge, London and New York: 1998. Print. 
Thompson, Paul. The Voice of the Past: Oral Hisotry. $3^{\text {rd }}$ ed., New York: Oxford University Press, 2000. Print.

Weinberg, Steve. The Reporter's Handbook: An Investigator's Guide to Documents and Techniques. 3rd ed., New York: St. Martin's Press, 1996. Print.

Wilson-Smith, Anthony. "The Conflicts of Journalists: Journalism is Not a Profession." Macleans Magazine. 3 Aug. 1998. 11. Print.

Yow, Valerie Raleigh. Recording Oral History: A Guide for the Humanities and Social Sciences. 2nd ed. Walnut Creek, Calif.; Toronto: AltaMira Press, 2005. Print. 